\title{
Empirical Impact Evaluation of the Energy Savings Resulting from BPA's Stage II Irrigation System Retrofit Program
}
J. W. Tawil
E. S. Edin
A. J. Lyke
B. M. Bailey
L. A. Nieves
B. J. Harrer, Project Manager

July 1987

Prepared for

the Bonneville Power Administration

under a Related Services Agreement with

the U.S. Department of Energy

Contract DE-AC06-76RLO 1830

Pacific Northwest Laboratory Operated for the U.S. Department of Energy by Battelle Memorial Institute 


\section{DISCLAIMER}

This report was prepared as an account of work sponsored by an agency of the United States Government. Neither the United States Government nor any agency thereof, nor Battelle Memorial Institute, nor any of their employees, makes any warranty, expressed or implied, or assumes any legal liability or responsibility for the accuracy, completeness, or usefulness of any information, apparatus, product, or process disclosed, or represents that its use would not infringe privately owned rights. Reference herein to any specific commercial product, process, or service by trade name, trademark, manufacturer, or otherwise, does not necessarily constitute or imply its endorsement, recommendation, or favoring by the United States Government of any agency thereof, or Battelle Memorial Institute. The views and opinions of authors expressed herein do not necessarly state or reflect those of the United States Government or any agency thereof, or Battelle Memorial Institute.

\section{PACIFIC NORTHWEST LABORATORY operated by \\ BATTELLE MEMORIAL INSTITUTE for the \\ UNITED STATES DEPARTMENT OF ENERGY \\ under Contract DE-AC06-76RLO 1830}

\begin{tabular}{|c|c|}
\hline \multicolumn{2}{|c|}{ Printed in the United States of America } \\
\hline \multicolumn{2}{|c|}{$\begin{array}{l}\text { Available from } \\
\text { National Technical Information Service }\end{array}$} \\
\hline \multicolumn{2}{|c|}{ National Technical Information Service } \\
\hline \multirow{2}{*}{\multicolumn{2}{|c|}{$\begin{array}{c}\text { United States Department of Commerce } \\
5285 \text { Port Royal Road } \\
\text { Springfield, Virginia } 22161\end{array}$}} \\
\hline & \\
\hline \multirow{2}{*}{\multicolumn{2}{|c|}{$\begin{array}{l}\text { NTIS Price Codes } \\
\text { Microfiche A01 }\end{array}$}} \\
\hline & \\
\hline \multicolumn{2}{|c|}{ Printed Copy } \\
\hline & Price \\
\hline Pages & Codes \\
\hline $001-025$ & $\mathrm{~A} 02$ \\
\hline 026-050 & $\mathrm{A03}$ \\
\hline $051-075$ & $\mathrm{AO4}$ \\
\hline $076-100$ & A05 \\
\hline $101-125$ & A06 \\
\hline $126-150$ & A07 \\
\hline $151-175$ & $\mathrm{~A} 08$ \\
\hline $176-200$ & A09 \\
\hline $201-225$ & A010 \\
\hline $226-250$ & A011 \\
\hline $251-275$ & A012 \\
\hline $276-300$ & $\mathrm{~A} 013$ \\
\hline
\end{tabular}


PNL -6160

UC $-95 \mathrm{C}$

EMPIRICAL IMPACT EVALUATION OF THE ENERGY

SAVINGS RESULTING FROM BPA'S STAGE II IRRIGATION SYSTEM RETROFIT PROGRAM

FINAL REPORT

B. J. Harrer, Project Manager

J. W. Tawil

A. J. Lyke

L. A. Nieves

E. S. Edin

B. M. Bailey

July 1987

Prepared for

the Bonneville Power Administration dnder a Related Services Agreement with

the U.S. Department of Energy

Contract DE-AC06-76RLO 1830

Pacifis Northwest Laboratory

Richland, Washington 99352 



\section{ABSTRACT}

This report documents the results of an evaluation of the impacts on irrigation system energy consumption of conservation measures installed under the Bonneville Power Administration's Stage II retrofit program. Historical billing data and other farm records provided the basis for this evaluation. A number of different statistical techniques were used to estimate the actual energy savings resulting from the Stage II conservation measures. The results of the study reveal that the methodology used in predicting energy savings resulting from the Stage II program is accurate. The basis for energy savings predictions in the Stage II program are changes in brake horsepower, and, in this study, a $1 \%$ change in brake horsepower was found to result in slightly more than a $1 \%$ change in energy consumption. Overall, Stage II program conservation measures were found to reduce irrigation system energy use by an average of 34\%. The average costs of obtaining these savings were $6 \mathrm{mills}$ (.6 cents) per kwh saved. 


\section{EXECUTIVE SUMMARY}

This report presents the results of an evaluation of the electrical energy savings from conservation measures installed on irrigation systems as part of BPA's Stage II irrigation sector conservation program. Work conducted in this study was separated into three major tasks:

- Task 1 - Estimation of the energy savings resulting from the installation of conservation measures on irrigation systems using percentage differences between average pre-installation and post-installation electricity consumption values;

- Task 2 - Analysis of the factors influencing irrigation system electricity consumption (i.e. pump horsepower, crop types, acres planted, precipitation, etc.) using statistical regression techniques;

- Task 3 - Evaluation of the energy savings prediction methods of the Stage II program and estimation of the costs per kWh saved for Stage II program conservation measure installations.

The analysis conducted in Task 1 revealed that the installation of conservation measures under the Stage II program had unambiguously resulted in energy savings for participating systems. The mean values for the Task 1 savings estimates were $16 \%$ on an unadjusted basis and $23.1 \%$ on a weatheradjusted basis. However, the variances of the Task 1 savings estimates were so high and the corresponding confidence intervals so wide that these estimates provided little information for predicting and evaluating the levels of the energy savings resulting from the Stage II program.

Use of weather adjustment factors, stratification of estimates by utility, and other techniques generally were unsuccessful in reducing the variances of the Task 1 savings estimates. Comparison of the unadjusted Task 1 savings estimates to percentage savings estimates predicted on irrigation system audits conducted in association with the Stage II program revealed that predicted savings were higher than the Task 1 savings estimates. In addition, the difference was statistically significant. However, the data and methodology used in developing the Task 1 results are not sufficiently rigorous to support 
a conclusion that the Stage II program is achieving lower actual energy savings than were predicted in the audits.

Additional comparisons of matched control and retrofit irrigation accounts $^{(a)}$ for selected Stage II program participants were performed in Task 1. These comparisons revealed that conservation measures installed on irrigation systems under the Stage II program had reduced energy consumption on the retrofit accounts by $24 \%$ between the pre-retrofit and post-retrofit periods while consumption on control accounts operating under similar conditions increased by $45 \%$ over the same time periods. The difference in consumption was statistically significant at a $90 \%$ level of confidence.

Analysis performed in Task 2 revealed that BPA's methodology for forecasting the energy savings resulting from conservation measure installation on irrigation systems based on brake horsepower changes is sound. In the Stage II program, a $1 \%$ brake horsepower change is assumed to provide a $1 \%$ percent change in electrical energy consumption. In our analysis, a $1 \%$ change in brake horsepower calculated in pump test of irrigation systems involved in the Stage II program was found to lead to a 1.14\% change in billing record energy consumption. The statistical equation used to estimate this relationship had strong predictive power and was highly significant.

Statistical analyses performed using control account data indicate that the results of the relationship between brake horsepower and energy consumption for the retrofit accounts are generalizable to other accounts. A $1 \%$ change in the brake horsepower of control account irrigation systems produced a $1.17 \%$ change in billing record energy consumption (i.e., an elasticity of 1.17). The statistical equation used to estimate this relationship was also highly significant and had strong predictive power.

OIfferences between the percentage changes in brake horsepower measured in pump tests and the slightly higher percentage changes in billed energy consumption found in our analysis are believed to be primarily caused by methods of incorporating electric motor efficiency in the pump test calculations.

(a) A control account is an irrigation system operated by a stage II program participant on which no conservation measures were installed. A retrofit account is an irrigation system on which conservation measures were installed under the Stage II program. 
Using the elasticity estimates developed in this study, the energy consumption of irrigation systems involved in the Stage II program were reduced by an average of approximately $34 \%$ through the installation of conservation measures under the program.

Task 2 results also revealed that changes in irrigation system total dynamic head are good predictors of changes in brake horsepower. These two measurements were found to be almost perfectly correlated, implying that either measure can be used for estimating irrigation system energy use and potential savings.

A number of different types of statistical equations were developed in Task 2 to estimate the electrical energy use of irrigation systems using such variables as weather, acres planted, crop type and brake horsepower. The addition of these varlables did not produce any statistical relationship with as high a level of predictive power as the bivariate relationship between measured brake horsepower and irrigation system energy consumption. other variables found to be significant in influencing irrigation system energy use included number of acres planted, crop type, temperature, precipitation, month and year. Brake horsepower remained the most significant explanatory variable for irrigation system energy use in all of the alternative specifications, but its elasticity dropped to approximately .4, because its effects were correlated with those of other included variables.

Analysis performed in Task 3 of the study revealed that brake horsepower changes predicted in BPA's pre-retrofit irrigation system audits frequently differ from the brake horsepower changes measured in the Stage II post-retrofit pump tests, and that the audits are about as likely to under-predict measured horsepower changes as to over-predict these changes. Although the analysis revealed no statistically significant positive or negative bias in terms of the brake horsepower changes predicted in the audits compared to those measured in the post-retrofit pump tests, continuation of the pump tests is recommended as a means of insuring fairness and accuracy in the energy savings estimation procedure on an individual system basis.

Analysis of the costs per kwh of energy saved by the Stage II program indicates that these costs are relatively low. Using the results of the best predictive statistical relationship estimated in Task 2 and BPA's accepted 
methodology for computing annual levelized costs, the total costs for conservation measure purchase and installation under the Stage II program were found to average approximately 6 mills $(.6$ cents) per kWh saved. Total BPA costs per kWh saved were found to average 4.5 mills (.45 cents) per kWh saved. 
CONTENTS

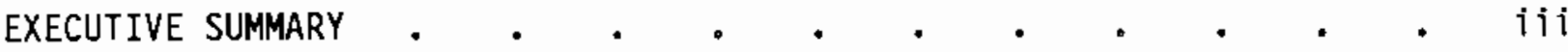

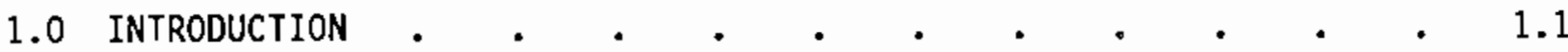

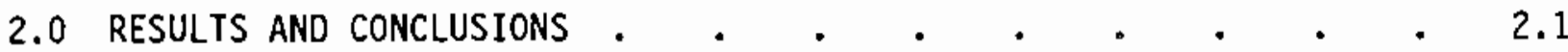

2.1 Conclusions . . . . . . . . . . . . 2.4

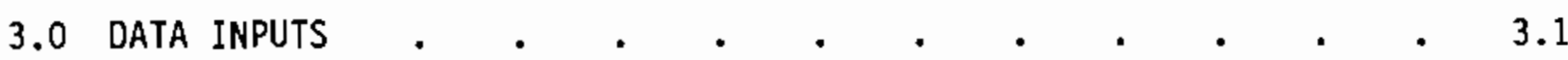

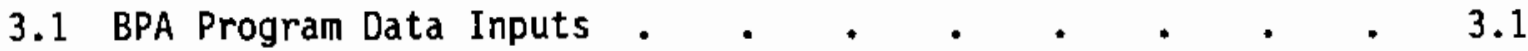

3.1.1 Stage II Participant Identification . . . . 3.1

3.1 .2 Inspection Form Data . . . . • . . 3.2

3.1.3 Incentive Claim Data . . . . . . . 3.4

3.2 Billing Record Data Inputs . . . . . . . . . 3.5

3.3 Weather Input Data . . . . . . . . . . 3.6

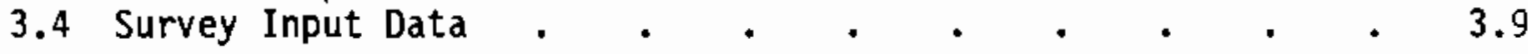

3.4.1 Telephone Survey Data . . . . . . . 3.11

3.4.2 Mail Survey Data . . . . . . . . . 3.13

3.4.3 Matching Process . . . . . . . . . . . $\quad . \quad 3.13$

3.5 Final Data Set(s) Used in Savings Analysis . . . . $\quad 3.15$

3.5.1 Final Data Set Used in Estimating Savings

Based on Mean Consumption (Task 1) . . . . 3.15

3.5.2 Final Data Set Used in Estimated Savings Based
on Statistical Regression Techniques (Task 2) . . $\quad 3.16$

4.0 TASK ONE ENERGY SAVINGS ESTIMATION METHODOLOGY AND RESULTS • $\quad$ • 4.1

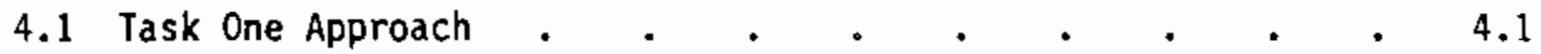

4.1.1 Unadjusted Energy Savings Methodology . . . . 4.1

4.1.2 Weather-Adjusted Estimation Methodology . . . 4.2

4.2 Task One Energy Savings Estimation Results . . . . 4.4

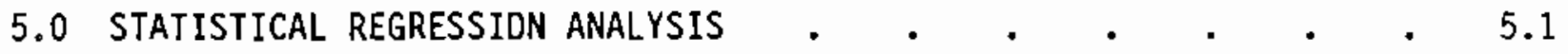

5.1 Task 2 Approach.$\quad$. $\quad . \quad$. $\quad . \quad$. $\quad . \quad$. 5.1

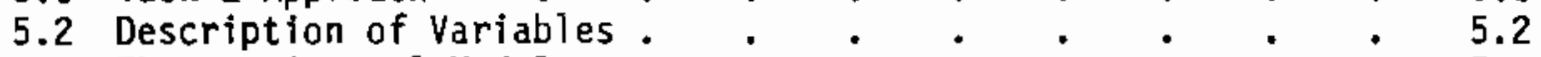

5.3 The Statistical Models . . . . . . . . . . 5.10

5.4 Control Account Results . . . . . . . . . . . 5.11 
5.5 Retrofit Account Results . . . . . . . . . . 5.13

6.0 OVERALL ASSESSMENT OF STAGE II

6.1 Evaluation of Differences in Estimated Energy Savings . $\quad 6.1$

6.2 Cost Estimates for Stage II Progran.$\quad$. . . . . . . 6.6

REFERENCES

\section{TABLES}

\subsection{Summary of Cost Estimates for}

Stage II Program Participants . . . . . . . $\quad$. 2.5

3.1 Participants in the Stage II Irrigation

System Retrofit Program 1982-1985 . . . . . . 3.3

3.2 Billing Records Data Set for

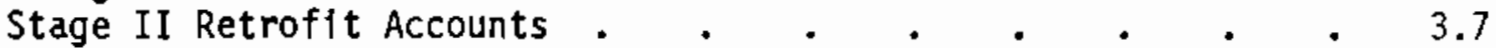

3.3 Weather Stations for Which PNL Obtained

Data and which Are in Close Proximity

to Utilities Having Stage II Participants . . . . . 3.8

3.4 Available Weather Data Elements for Stations Matched

with Stage II Participants' Utilities: 1981-1985 • • • 3.10

3.5 Number of Accounts Used for Task 1 Analysis of

Energy Savings from BPA's Stage II Retrofit Program • • • 3.18

3.6 Retrofit Account Data Summary for

Accounts Used in Task 1 Analysis . . . . . . . 3.19

3.7 Number of Accounts Used for Task 2 Analysis of

Energy Savings from BPA's Stage II Retrofit Program . • • 3.21

3.8 Retrofit Account Data Summary for

Account Used in Task 2 Analysis . . . . . . . . . 3.22

4.1 Summary of Results for Task I Energy Savings

Estimation on Data Set of Retrofit Accounts

with Known Outliers Eliminated . . . . . . . . 4.5

4.2 Mean Weather-Adfusted and Unadjusted Task I Energy
Savings Estimates by UtiTity/Weather Station . . . . 4.5

4.3 Mean Weather - Adjusted and Unadjusted Task 1

Energy Savings Estimate by List Category . . . . . 4.8 
4.4 Summary of Results for Task 1 Energy Savings Estimation on Data Set of Retrofit Accounts for Which Projected Savings Were Available . . . . . 4.8

4.5 Summary of Task 1 Unadjusted Energy Savings Estimation Results for a Group of 18

Matched Retrofit and Control Accounts . . . . . . 4.10

5.1 Utility Irrigation Rate Schedules Study Period * . • • • 5.5

6.1 Comparison of Stage 1 Inspection Brake Horsepower Changes to Stage II PostRetrofit Measured Brake Horsepower Changes . . . . . 6.2

6.2 Statistical Evaluation of Differences Between Brake Horsepower Changes Predicted in Stage I Inspections and Stage II Post-Retrofit Pump Tests . . 6.4

6.3 Cost Estimates for BPA Stage II Program Participants for Which Complete Program Data Was Available . . . . 6.10

6.4 Summary of Cost Estimates for Stage II Program Participants . . . . . . . . 6.11 
. 


\subsection{INTRODUCTION}

The Bonneville Power Administration (BPA) sponsors a program for energy conservation in the irrigated agricultural sector. The program is conducted in two stages. The first stage (Stage I) consists of on-farm inspections of irrigation equipment with a written evaluation of current equipment efficiencies, suggestions for improvements, and estimates of energy savings if BPA recommendations are followed. The second stage (Stage II) offers financial incentives for carrying out the BPA recommendations generated in Stage I in the form of partial cost retmbursement for eligible conservation measures that an irrigator chooses to install.

Two major types of evaluation issues were identified by BPA staff as being important in relation to the Stage I and II programs:

- program design and participation issues

- program impact issues

Program design and participation issues were analyzed in a previous study for BPA. In addition, Pacific Northwest Laboratory (PNL), operated for the U.S. Department of Energy by Battelle Memorial Institute, is planning further analyses of issues associated with the charac-teristics of Stage I and II program participants versus non-participants using data from an in-person survey of irrigators. However, the focus of the PNL study described in this report is an evaluation of the impacts of the installa-tion of conservation measures installed as part of the Stage II program on the energy consumption of program participants' irrigation systems.

In the Stage II program, energy savings are predicted based on changes in brake pump horsepower. Calculated correctly, these estimates should be accurate, provided no other changes in irrigation practices (such as longer hours of operation, new rotation patterns or cultivation of more water-intensive crops) occur. The purpose of PNL's study is to estimate the energy savings occurring for the irrigation systems included in the Stage II program based on changes in the energy consumption levels recorded on the billing records of the affected systems and incorporating information on cropping practices, 
irrigation system characteristics, changes in irrigation scheduling methods, weather and other types of factors that may affect these levels.

PNL's study is divided into three tasks. The study's first task culminated in estimates of energy savings from the Stage II retrofit program based on differences in average annual irrigation system energy consumption before and after conservation measure installation. Adjustments for weather variation between the before and after periods were calculated and applied to the data, but no other adjustments for changes in cropping patterns or other factors were incorporated in this task of the analysis.

The first segment of the study also involved identification of Stage II participants, acquisition of releases for billing records, collection and analysis of Stage I inspection forms, collection of billing record and weather data, selection of a method to correct for weather, and programming of an algorithm to adjust for weather and estimate savings. Assessments of the statistical reliability of the energy savings estimates were also developed.

The second task of PNL's study involved the development of estimates of the energy savings resulting from the installation of conservation measures under the Stage II program using statistical regression techniques. Data on billing record energy consumption, weather and irrigation system characteristics collected during the first part of the study were again utilized in developing these savings estimates. In addition, primary data on cropping patterns, irrigation scheduling methods, and other relevant information were collected from Stage II program participants using a combined mail and telephone survey. Incorporation of this data into the energy savings estimation process allowed for a more complete description of the factors that were expected to influence the levels of energy consumption of an irrigation system and, thus, more accurate estimates of the specific effects of conservation measure installation on consumption should have resulted.

The third task in the study provided an overall assessment of the methods used in predicting energy savings in the Stage I and II programs. Differences between the energy savings predicted in the Stage I irrigation system audits, the energy savings predicted in Stage II post-retrofit pump tests and savings estimated from Stage II program participant billing records are examined. 
The costs per kwh of electricity saved by Stage II program participants are estimated using results from the statistical regression analyses conducted in this study.

This report describes work performed in all three tasks of the study. The report is organized into six chapters. The second chapter describes the major findings of the study. Chapter 3.0 reports the types of data used in the study and the procedures that were used in collecting and formatting this data. In Chapter 4.0, the analytical procedures and results of estimating the energy savings based on mean energy consumption before and after conservation measure installation are described. The fifth chapter of the report presents a similar description for estimation of energy savings based on statistical regression techniques. The report concludes with an overall assessment of the Stage II program's energy savings and costs. 


\subsection{RESULTS AND CONCLUSIONS}

Analysis of the energy savings from BPA's Stage II program in Task 1 of this analysis produced the following results:

- The installation of conservation measures under the Stage II program has unambiguously resulted in energy savings when the average annual billed electrical consumption for periods before and after measure installation are compared. The mean values for these savings for all accounts for which billing record data were obtained were $16 \%$ on an unadjusted basis and $23.1 \%$ on a weather-adjusted basis.

- The variances of the Task 1 savings estimates were high and were higher for the weather-adjusted estimates than for the unadjusted estimates. These variances resulted in $90 \%$ confidence intervals of 8.8 to $23.2 \%$ for the unadjusted mean savings and 13.4 to $32.8 \%$ for the weather adjusted mean savings. The calculated $95 \%$ confidence intervals were 7.4 to $24.6 \%$ for the unadjusted mean savings and 11.5 to $34.7 \%$ for the weather adjusted mean savings.

- Attempts to reduce the variance and standard errors of the Task 1 savings estimates through stratification of the estimates into utility/weather station areas and lift zones were generally unsuccessful, and it was decided that the total sample estimates provided the best basis for comparison to predicted savings.

- Comparisons of arithmetic mean predicted savings on the Stage I audits to both unadjusted and adjusted mean savings estimates developed in Task 1 revealed that predicted savings were higher than both of the savings estimates and that the differences were statistically significant at a 95\% level of confidence. However, the nature of the predicted savings estimates used in this comparison and the method of calculating energy savings based on before and after average consumption values imply that little importance should be attached to this result.

- Installation of conservation measures under the Stage II proyram also resulted in significant energy savings for retrofit irrigation accounts for which matched control accounts were obtained. These control accounts, 
which were not involved in the Stage II program but are operated by Stage II program participants, demonstrated a mean increase in energy consumption of $44.8 \%$ from pre-retrofit to post-retrofit periods. The matched retrofit accounts involved in the Stage II program had a mean decrease in consumption of $24.2 \%$ for the same periods. The difference in the change in energy consumption was statistically significant at a $90 \%$ level of confidence and reveals that the Stage II program measures produced energy savings on participants' farms compared to systems operating under similar conditions.

The major findings of the Task 2 analysis include the following:

- The best predictor of the energy consumption of an irrigation system is the brake horsepower of the system. Use of a simple bivariate regression of billed irrigation account energy consumption on pump brake horsepower resulted in $\mathrm{R}^{2} \mathrm{~s}$ of .93 for the control account data and .74 for the retrofit account data. These predictive values were the highest of the numerous model specifications attempted.

- The coefficient values for the brake horsepower regressions imply that a $1 \%$ change in brake horsepower will lead to a $1.17 \%$ change in energy consumption for the control accounts and a $1.14 \%$ change in energy consumption for the retrofit accounts. The $95 \%$ confidence intervals around these percentage estimates are $1.09 \%$ to $1.25 \%$ for the control accounts and $1.05 \%$ to $1.23 \%$ for the retrofit accounts.

- Applicaticn of the $1.14 \%$ elasticity estimate developed in this study to average brake horsepower changes indicates that the energy consumption of irrigation systems participating in the Stage II program were reduced by an average of $34 \%$.

- Changes in the total dynamic heads of irrigation systems are almost perfectly correlaced with changes in brake horsepower.

- Other variarles found to be statistically significant in predicting the energy consumption of irrigation systems include the number of acres planted, crop type, temperature, precipitation, month and year. However, the statistical results for the equations incorporating these variables were inconsistent and none of them produced higher predictive power than 
the simple bivariate regression on brake horsepower. Thus, although these results are useful for explaining the various factors that influence the energy use of irrigation systems, they are not as appropriate for predicting the changes in energy consumption occurring as a result of the Stage II program as is the simple bivariate equation.

- Brake horsepower remained the most statistically significant variable in all of the regression equations estimated. However, the elasticity of electrical energy consumption with respect to a $1 \%$ change in brake horsepower decreased to approximately .4\% in equations involving the full set of variables, as a result of the correlation between brake horsepower and these other variables.

The major results of Task 3 of the study include the following:

- Predictions of brake horsepower changes in the Stage I audit frequently differ from the changes measured in the Stage II post-retrofit pump tests, and the Stage I predictions are about as likely to under-predict measured brake horsepower changes as to over-predict these changes.

- The mean difference between the percentage brake horsepower changes predicted on the Stage I audits and the percentage changes predicted on the Stage II post-retrofit pump test was found to be 3.4 percentage points. However, this difference was not statistically significant at even a $70 \%$ level of confidence. In addition, a statistical regression of the changes in Stage II measure brake horsepower on the Stage I audit predicted changes in brake horsepower produced an $R^{2}$ of .73 and a coefficient of .91 , indicating that for every one unit increase in Stage I predicted brake horsepower change, Stage II measured brake horsepower change will increase by .91 units.

- The costs per kwh saved for conservation measures purchased and installed under the Stage II program were estimated to average $5.9 \mathrm{mills}$ (.59 cents). BPA's costs were estimated to average 4.5 mills (.45 cents). These estimates were developed using the best predictive statistical relationship derived in Chapter 5 to estimate annual kwh savings as a function of measured brake horsepower changes. The annual levelized costs of measure purchase and installation were then estimated using BPA's standard assump- 
tions of a $3 \%$ real financing rate and a 20-year measure life. Estimates of costs per kwh saved were obtained simply by dividing estimated annual levelized costs by annual energy savings estimated using the statistical equations developed in this study.

\subsection{CONCLUSIONS}

One of the conclusions that can be drawn from the results of this analysis is that BPA's Stage II program has resulted in energy savings for participating accounts. However, the variances in the savings levels, as measured in Task 1 by average billed energy consumption, are large.

A second major conclusion that can be drawn is that BPA's method of predicting energy savings from irrigation system conservation measure installation based directly on changes in brake horsepower is valid. The introduction of other variables into the regression equations, while often producing statistical significance, resulted in a reduction in predictive power compared to using only brake horsepower.

The one to one correspondence between percentage brake horsepower reductions and percentage energy savings used by BPA in predicting energy savings was found to have empirical validity in the analysis of billing record data. The estimate of the change in billed energy consumption resulting from a $1 \%$ change in brake horsepower was found to be very close to $1 \%$ or slightly exceeding $1 \%$ in the best predictive estimation equation developed in this analysis.

Although this result somewhat conflicts with the results of comparisons of percentage changes in average billed electrical consumption before and after conservation measure installation to predicted percentage changes, the relationships developed in the statistical regressions are believed to be the best evaluators of the BPA energy savings prediction methods. These relationships indicate that, over the long term, the percentage energy savings that will occur as a result of frrigation system conservation measures will be very close to the percentage reductions in brake horsepower measured in pump tests after measure installation.

On average, the changes in brake horsepower predicted in the Stage I audits were found to slightly over-predict the actual measured changes in 
brake horsepower occurring in the Stage II post-retrofit pump tests. However, the difference was not found to be great enough to be of concern. For individual systems, however, differences between Stage I predicted horsepower changes and Stage II measured changes are frequent, and continuation of the Stage II post-retrofit pump tests is recommended as a means of insuring fairness and accuracy in the Stage II process for individual systems.

A final conclusion resulting from this study is that investments made to date in conservation measures in the irrigation sector have been relatively low cost in terms of costs per kwh saved. An average cost of less than 5 mills per kwh saved would appear to be extremely low relative to other types of conservation investments. Additional information summarizing the costs and energy savings associated with the Stage iI program are shown in Table 2.1.

Table 2.1. Summary of Cost Estimates for Stage II Program Participants

\begin{tabular}{|c|c|c|c|c|}
\hline & $\begin{array}{l}\text { A } \\
\text { oc. }\end{array}$ & $\begin{array}{l}\text { stimated } \\
\text { nnual } \\
\text { hh } \\
\text { avings (b) }\end{array}$ & $\begin{array}{l}\text { Estimated } \\
\text { Total Cost } \\
\text { Per kwh } \\
\text { Saved(Mills) }\end{array}$ & ed \\
\hline
\end{tabular}
Mean
7,853
4,970
131,862
5.9
4.5

(a) Source: BPA Stage II program incentive claims.

(b) Derived using Equation 5.9 of this study. 
$\therefore$

. 


\subsection{DATA INPUTS}

Estimation of the energy savings of conservation measures implemented as part of the Stage II program required the collection and formatting of a number of different types of data, including:

- BPA progran data

- utility billing data

- weather data

- data on cropping patterns, water management practices, and other information available only from the Stage II participants themselves.

Each type of data collected and used in the analysis is described in this chapter.

\subsection{BPA PROGRAM DATA INPUTS}

Data obtained from BPA program information associated with this analysis included the following:

- a listing of Stage II program participants and their location

- Stage I inspection forms for Stage II program participants containing information on their irrigation system characteristics and the energy savings predicted during their stage I inspection

- Stage II incentfve claim forms that report the changes in horsepower measured in the Stage II post-retrofit pump tests and the costs of the conservation measures installed under the Stage II program.

\subsubsection{Stage II Participant Identification}

Eighty-one irrigation accounts were affected by retrofits of conservation measures equipment that took place from 1982 through 1985 with incentives 
from BPA's Stage II Irrigation Retrofit Program. (a) Fifty-three irrigators from eight utilities participated in the program during these years. Some of the program participants had more than one retrofit account associated with the program.

Table 3.1 shows the initial distribution of irrigators and retrofit accounts among the eight utilities who had participants. For purposes of PNL's analysis, the totals shown in Table 3.1 represent the maximum number of retrofit accounts that might provide empirical data for estimating energy savings from the Stage II program. More accounts are tallied in Table 3.1 than could be used for PNL's analysis because of data availability and other problems. A final listing of the accounts used in this analysis is presented later in this chapter.

\subsubsection{Inspection Form Data}

The Stage I irrigation system inspection forms for Stage II program participants contain a substantial amount of data useful to this analysis. These data include the pumping $11 \mathrm{fts}$ and total dynamic heads of the systems, the horsepower of the pumps used in the systems, the efficiency of these pumps, the predicted changes in total brake horsepower and dynamic head, and the predicted percentage energy savings for implementing the recommended conservation measures.

In most cases, irrigation system inspection forms for stage II participants were available directly from program records. However, in some cases it was necessary to request copies of the inspection forms from the utilities of the participants. It was not possible to locate Stage I inspection forms for all of the identified Stage II systems, and forms for some of the systems did not contain all of the relevant data. However, a full set of data on pumping lifts, total dynamic heads and projected energy savings was located for most (85\%) of the identified stage II program participants.

(a) The actual number of Stage II retrofits through 1985 may be somewhat greater due to 1) uncounted Fall 1985 retroftts, and 2) accounts that meter more than one retrofitted sprinkler system. 
Table 3.1. Participants in the Stage (IS Irrigation System

\begin{tabular}{lcc} 
Utility & $\begin{array}{c}\text { Number of } \\
\text { Irrigators }\end{array}$ & $\begin{array}{c}\text { Number of } \\
\text { Stage II Accounts }\end{array}$ \\
\hline Benton REA & 1 & 1 \\
Big Bend Electric Cooperative & 16 & 23 (b) \\
Central Electric & 3 & 3 \\
Franklin PUD & 4 & 9 \\
Lincoln Electric & 3 & 7 \\
Mid-State Electric & 8 & 16 \\
Raft River Electric & 2 & 3 \\
Umatilla Electric & $\underline{16}$ & $\underline{19}$ \\
Total & 53 & 81
\end{tabular}

Source: Data collected from individual utilities.

(a) Some Fall 1985 retrofits are unaccounted for in these totals.

(b) More than one retrofit sprinkler system is metered by some of the Big Bend Electric Cooperative accounts. 
It should be noted that the predicted energy savings used in this analysis were usually obtained from the irrigation system inspection forms. The predicted savings on the inspection forms represent the savings levels if all of the measures recommended in the irrigation system inspections are implemented. Thus, if a Stage II program participant elected to only install part of the recommended measures, his predicted savings on the form will overestimate his actual savings without consideration of the accuracy of the prediction methodology. Savings estimates filed in association with the Stage II incentive claims were used whenever possible to represent predicted savings, but such estimates were not available in many cases.

\subsubsection{Incentive Claim Oata}

Incentive claim forms are filed in association with BPA's Stage II program as documentation for reimbursement for costs associated with conservation measure installation. These forms report the costs of measure installation, the claimed reimbursement level (i.e., BPA's costs), the measured changes in brake horsepower resulting from conservation measure installation (in either absolute or percentage terms), and other information.

In the early years of the Stage II program, the changes in horsepower resulting from the Stage II program were reported on the incentive claim only in percentage terms. In these cases, estimates of the ending horsepower resulting from conservation measure installation were derived by the following equation:

$$
E H P=B H P \times(1-P C H P) \quad \text { Equation } 3.1
$$

where

$$
\begin{aligned}
E H P= & \text { Ending horsepower after conservation measure installation as } \\
& \text { part of the Stage II program. } \\
\text { BHP = } & \text { Beginning brake horsepower reported on the Stage I irrigation } \\
& \text { system inspection form. } \\
\text { PCHP = } & \text { Percentage reduction in horsepower reported on the Stage II } \\
& \text { Incentive claim form. }
\end{aligned}
$$


All brake horsepower numbers reported on the incentive claims are derived from the results of field pump tests performed after conservation measures are installed as part of the Stage II program.

\subsection{BILLING RECORD DATA INPUTS}

A large amount of the data necessary to perform this analysis were available only from the utilities of the Stage II participants. Such data included kwh consumption records, price schedules, conservation measures installed as part of the Stage II program, dates of measure installation, and changes in brake horsepower as a result of measure installation.

Customer billing records are normally considered proprietary, which imposes a constraint on their use by those outside a utility. PNL dealt with this constraint in two ways: 1) where the utility desired, PNL obtained waivers from irrigators allowing the utility to release their records for purposes of this study, and 2) in this report, Stage II participants' identities are masked. The following utilities required waivers for release of billing records data for Stage II participants: Big Bend Electric Cooperative, Lincoln Electric, Mid-State Electric, Raft River Electric, Umatilla Electric and Lincoln Electric. Thus, waivers were required in order to obtain billing data for 45 of the 53 irrigators who participated in the Stage II program, or 68 of the 81 accounts.

PNL succeeded in obtaining waivers and billing records for all but four irrigators, each responsible for one retrofit account. Irrigators who did not return waivers included one who began with a big gun system and changed his water source after conversion to low pressure sprinklers, one who farms only 14 acres, one who considers the information proprietary and one who failed to return a waiver within PNL's time constraints. Thus, the use of waivers eliminated only four irrigation accounts, two of which were outliers, from the data set.

PNL collected billing records for 77 of the 81 irrigation accounts affected by Stage II retrofits. PNL also collected billing records for a control group of 20 accounts. Accounts in the control group are operated by Stage II program participants. However, they represent the consumption levels of separate irrigation systems and were not affected by the retrofits of conservation 
measures made under the Stage II program. The 20 control accounts collected from the utilities were the maximum number that could be collected given constraints on time and staffing at the utilities and a lack of non-retrofit accounts for many of the Stage II participants. Billing records were collected for both retrofit and control group accounts every season since 1981 at the highest possible resolution (i.e., the shortest time intervals billed).

A summary of the billing record data collected from the utilities, including the frequency of billing, is presented in Table 3.2. Samples of the waiver and data collection forms used in this process are presented in Appendix A.

\subsection{WEATHER INPUT DATA}

In recognition of the large influence weather conditions may have on crop watering requirements and hence irrigation energy consumption, PNL collected a significant amount of weather data for areas impacted by the Stage II program. Data for weather stations located near Stage II irrigators were purchased from the National Climatic Data Center in Asheville, North Carolina.

Weather stations were selected for inclusion in the data set based on their location within a participating utility's service area. Comparisons between maps of utility service areas and maps of weather station locations aided the selection. One Stage II retrofit pump is immediately adjacent to one of the selected weather stations. In general, however, although the weather stations were located in the appropriate utility service areas, their proximity to specific farms was not known.

PNL obtained datly weather data for the 14 weather stations listed in Table 3.3 back to 1981 . Daily rather than monthly resolution was selected to allow for accurate correlation with billing cycles which sometimes begin or end in the middle of a month.

A subset of seven of the 14 weather stations was chosen for actual use in this analysis based on an evaluation of the quality and completeness of data received from the National Climatic Data Center for each weather station. 

Table 3.2. $\begin{aligned} & \text { Billing Records Data Set for Stage II } \\ & \text { Retrofit Accounts }\end{aligned}$

\begin{tabular}{lcccc} 
Utility & $\begin{array}{l}\text { Number of } \\
\text { Cycles in } \\
\text { Irrigation } \\
\text { Season }\end{array}$ & $\begin{array}{l}\text { Retrofit Accounts } \\
\text { Billing Records }\end{array}$ & $\begin{array}{l}\text { Retrofit Accounts } \\
\text { with Control Account } \\
\text { Billing Records }\end{array}$ \\
\cline { 2 - 2 } Benton REA & 2 & 1 & 1 \\
Big Bend Electric & 1 & 22 & 12 \\
Central Electric & 1 & 3 & 0 \\
Franklin PUD & 5 & 9 & 0 \\
Lincoln Electric & 1 & 7 & 0 \\
Mid-State Electric & 3 & 16 & 6 \\
Raft River Electric & 6 & 3 & 0 \\
Umatilla Electric & 8 & 16 & 1 \\
Total & & 77 & 20
\end{tabular}

(a) Irrigation season defined as March to October for purposes of this study.

(b) Billing records are for every season, 1981-1985, except in two cases where early year information was missing.

(c) Control accounts were net retrofit, but are operated by irrigators who operate at least one account that was retrofit with incentives from the Stage II Irrigation Retrofit Program. 
Table 3.3. Weather Stations for Which PNL Obtained Data and Which Are In Close Proximity to Utilities Having Stage II Participants

Utility Name

Big Bend

Franklin PUD

Lincoln Electric

Benton REA

Umatilla Electric

Mid-State Electric

Central Electric

Raft River Electric
Weather Stations

Lind, Washington

Odessa, Washington

Elthopia, Washington

Kennewick, Washington

Wilbur, Washington

Odessa, Washington

Kennewick, Washington

Hermiston, Oregon

Chemult, Oregon

Fremont, Oregon

Wickiup Dam, Oregon

Redmond, Oregon

Malta, Idaho

Burley, Idaho 
Daily temperature, precipitation and several other daily surface weather characteristics were available for all the weather stations listed in Table 3.3. However, many of these weather stations are very small and were lacking data for several elements of surface weather characteristics. An important data element that was often missing from the data for these stations were daily temperature/precipitation normals and deviations from normals. PNL acquired monthly weather normals where they were avajlable and pro-rated by day when daily resolution was required.

The final weather stations used by PNL are shown in Table 3.4. One weather station corresponds to each utility service area with the exception of the Kennewick station, which corresponds to both Benton REA and Franklin PUD. Table 3.4 al so shows the weather characteristics that were available for each of these weather stations as well as their resolution (daily or monthiy). As shown in Table 3.4, the only relevant weather data consistently available overall stations were dally precipitation and temperature, and monthly normals.

\subsection{SURVEY INPUT DATA}

To refine PNL's estimate of energy savings from the BPA Stage II Retrofit program and reduce the variance of the estimate, account specific data only available by interview and/or survey of the participant were gathered. The objective here was to separate changes in electrical energy usage that had taken place as a result of the installation of conservation measures under the BPA Stage II program from other external factors. Such factors include:

- crop types and acreage levels for crops grown during the study period,

- additional conservation measures installed,

- changes in ownership of acreage included in the retrofit program,

- leasing of acreage involve in the study, and

- water and electricity prices. 
Table 3.4. Arailable Neather Data Elenents for Stations Matched

With Stago II Participants' Utilities: 1981-1985

\begin{tabular}{|c|c|c|c|c|c|c|c|c|c|c|}
\hline $\begin{array}{l}- \\
\text { Utility }\end{array}$ & $\begin{array}{l}\text { Weather } \\
\text { Station }\end{array}$ & EVAP $^{(a)}$ & PRECIP & SNOT & $\begin{array}{l}\text { SNOY } \\
\text { DEPTH }\end{array}$ & $\begin{array}{l}\text { wh } \\
\text { TEMP }\end{array}$ & $\begin{array}{l}\text { UIN } \\
\text { TEYP }\end{array}$ & $\begin{array}{l}\text { TEAP AT } \\
\text { OBSEFNTION }\end{array}$ & $\begin{array}{l}\text { IND(a) } \\
\text { LOVENGTT }\end{array}$ & $\begin{array}{l}\text { MONTHLY } \\
\text { NORWLLS (b) }\end{array}$ \\
\hline Benton REA & Kennevick, Wh & & $x$ & $x$ & $x$ & $x$ & $x$ & $x$ & & $x$ \\
\hline Big Bend & Odessz, $\mathrm{TA}$ & & $x$ & & & $\mathbf{x}$ & $\mathbf{x}$ & $x$ & & $x$ \\
\hline Contral Electric & Rednond, OR & & $x$ & $\mathbf{x}$ & $x$ & $x$ & $x$ & & & $x$ \\
\hline Franklin PuD & Kennovick, Ith & & $x$ & $x$ & $x$ & $x$ & $x$ & $x$ & & $x$ \\
\hline Lincoln Eloctric & Filbur, WA & & $x$ & $x$ & $x$ & $x$ & $x$ & $x$ & & $x$ \\
\hline Vid-State & Vickiup Das, OR & & $x$ & $x$ & $x$ & $x$ & $x$ & $x$ & $x$ & $x$ \\
\hline Raft River & Burley, ID & & $x$ & & $x$ & $x$ & $x$ & & & $x$ \\
\hline Unatilla Electric & Hera iston, OR & $x$ & $x$ & $x$ & $x$ & $x$ & $x$ & $\mathbf{x}$ & $x$ & $x$ \\
\hline
\end{tabular}

(a) Evzporation and wind movenent are not reported in all nonths.

(b) Wonthly nornals include aaxieun, wininum and mean tenperature normals, procipitation nornals, heating degree dayo and cooling degroe days. Wonthly data has been pro-rated for purposes of analysis. 
Two data collection methods were used. First, a phone survey directed at specific farm characteristics ( $t$.e., ownership status of acreage, acreage per retrofit pump, additional conservation measures implemented outside the BPA Stage II program, etc.) was administered. Upon its completion, a mail survey was distributed for the purpose of gathering crop specific data by pump/account number. Both surveys are discussed, in turn, below.

\subsubsection{Telephone Survey Data}

The telephone questionnaire was designed by PNL's staff, and coded and administered by Market Trends of Bellevue, Washington. It included five main areas of interest. It served to:

1) clarify previously collected data,

2) check for changes in ownership made during the study period,

3) determine if acreage was leased to or from other farmers,

4) collect water price data, and

5) check for conservation measures installed and other operational changes, in addition to measures installed under the BPA Stage II program during the study period.

A copy of the questionnaire used in the telephone survey is shown in Appendix B.

Clarification of data served two purposes. It allowed PNL to check the consistency of data across all collection methods (i.e., mail survey, billing records, inspection forms), and refreshed the respondents memory as to which pump/account belonged to which system. This was necessary in order to assure correct results to pump specific questions on the questionnaire.

Data collected regarding the ownership status of acres irrigated by the pumps involved in the BPA Stage II Retrofit program determined if changes in ownership had occurred during the study period. Where changes were noted, respondents were asked if they had any information on crop acres for the period before the change occurred (i.e., before respondent took ownership). If no information was avallable, PNL tried to obtain a source (a past owner) for these records from the respondent. If previous ownership differed from the 
current respondent, records collected would only include information since the last ownership change.

The possibility of electricity consumption, as collected by utility billing records, varying from actual consumption arose because irrigators may lease land to or from other farmers. Here, the questions of who pays for the electricity on the leased land may be of concern because of its impact on energy consuming behavior. Several questions in the survey addressed this point.

It is belfeved that water prices could potentially affect a Stage II program participant's energy use if such water was priced on a unit basis, where total charges for water would vary directly with amounts consumed. Thus, a question regarding the irrigation water district supplying the Stage II participant was asked on the telephone survey. The irrigation districts cited by survey respondents were subsequently called by PNL staff to determine the nature of their water charges. This investigation revealed that water charges are normally levied on a per-acre basis and total charges do not vary with consumption. Thus, water prices were dropped as an explanatory variable for energy consumption in subsequent analyses.

If additional changes beyond the conservation measures installed as part of the BPA Stage II program were made at any time during the study period to the pumps involved in the retrofit program, energy savings for the pump/account involved could vary from expected savings. Examples of factors that PNL needed to control for was the possibility of changes in irrigation scheduling methods, pump efficiency improvements, and abnormal system downtime. This information was collected during the telephone survey so that estimated energy savings could be estimated more precisely from measures installed under the BPA program.

In general, the telephone questionnaire served to sharpen the energy savings results determined in the initial stage of analysis by looking at additional factors of variation. Upon completion of the telephone survey, respondents were sent a mail questionnaire requesting information about their individual crops grown during the study period. 


\subsubsection{Mail Survey Data}

An external factor that could have a significant impact on the energy consumption of the irrigation systems involved in the Stage II program is the types and acreage levels of crops grown during the study period. A crop requiring less water, requires less electricity. Planting/harvesting dates and crop yields, can also influence irrigation system water requirements and energy use.

To collect the required data on crop types, acreage levels, plant/harvest dates and yields, a mail survey was administered to Stage II program participants. The mail survey requested data for a 1981-1985 time period and was administered by mail to provide respondents with enough time to access their cropping records. A copy of the mall survey questionnaire is also presented in Appendix B.

To assure accurate results, a letter associating each participant's account number with a specified pump number was included. This letter was aimed at simplifying the survey for the respondent and at obtaining a correct match between a pump and the crops irrigated with that specific pump. For example, if PNL had billing records for an irrigator with two utility account numbers, PNL identified each of them with a unique pump number of Pump \#1, and Pump \#2. Throughout the survey whenever a respondent needed to refer to a certain account number, he could simply refer to it as \#1 or \#2. Because of differences in billing record formats and irrigation system designs, this method did not always work as planned. Thus, additional matching of pump accounts and cropping data was necessary. The process used in matching survey responses to pump accounts is described in the next section.

\subsubsection{Matching Process}

The collection of additional data by PNL required a significant matching process to assure consistency and accuracy. A few problems that needed to be overcome in :his process included:

- incomplete mail questionnaires,

- inconsistencies between telephone surveys, mail questionnaires, billing records, and inspection forms, 
- matching appropriate cropping data to corresponding billing record accounts,

- combining accounts with two or more pumps feeding into one main line, and

- collection of additional billing records for those respondents providing data on pump/accounts that were not initially requested.

With the help of Market Trends, several callbacks were made to individual study participants. This was necessary to finish incomplete questionnaires, where possible, and to check the accuracy of data provided. Data from each collection method was checked against all other methods. Initially, all pump/account data were examined to determine if certain variables made logical sense. For instance, different responses to the same question asked on the telephone and matl surveys occurred. When large discrepancies were noted, PNL had to determine which data were accurate. This often led to callbacks to individual farmers.

One situation that frequently arose was cropping data not labeled with the appropriate pump/account number. By looking at billing records and comparing consumption for each account owned by one respondent to horsepower and cropping data provided in the mail survey, it was determined which sets of data (one set of cropping to one pump/account number) belonged together. Irrigation system maps provided on the Stage I audit forms and by mail survey respondents were also used in the matching process. If each pump/account owned by the respondent had a unique horsepower then HP provided by cropping data was simply matched to HP provided on billing records. If a precise matching of irrigation accounts and cropping records could not be obtained by reviewing available data, callbacks to Stage II program participants were made to clarify the matching of the data.

In a few instances, one set of billing records was received correspondi.ig to more than one set of cropping data. Here it was determined that the individual pumps used to irrigate acreage were feeding into one main line. The billing records provided represented consumption for this main line. To remain consistent with these billing records the cropping data for individual pumps were grouped together. 
In several other instances, survey respondents were unable to break their cropping records down by individual pump accounts. Rather than eliminate these participants from the estimation data base, their pumping account consumption records were summed and matched to the aggregate cropping record data.

Finally, though not all accounts of a respondent were included in the survey, some farmers provided additional cropping data. To make use of this added data, all efforts were made to collect corresponding billing records from the appropriate utilities.

\subsection{FINAL DATA SET(S) USED IN SAVINGS ANALYSIS}

As discussed previously this analysis of the energy savings resulting from conservation measures installed under the Stage II retrofit program is being conducted in two tasks. The first task involved estimation of the energy savings resulting from the Stage II program based on the difference in mean energy consumption before and after conservation measure installation. The second task uses the survey data described in the previous section and other data to estimate the energy savings using statistical regression techniques. The different approaches used in the two tasks of the study required that slightly different data sets be utilized for estimation purposes. These data sets are described in this section.

\subsubsection{Final Data Set Used In Estimating Savings Based On Mean Consumption Task 1)}

After data on the time of conservation measure installation were collected, it was discovered that billing records had been obtained for some accounts with retrofit dates in the middle to the end of the 1985 irrigation season. These accounts did not yet have billing data for the period after conservation measure installation, and thus, could not be used in estimating a mean energy consumption value for this period. Nine of the 77 accounts listed previously in Table 3.2 were eliminated from the analysis due to a retrofit date of mid-season 1985 or later. 
Four of the remaining accounts came to PNL's attention as outliers. Two of these were out of operation one or more years preceding the retrofit including the year imuediately preceding the retrofit. One account changed owners two years before the retrofit and had only one third of its acreage in crops the year before the retrofit. After the retrofjt, the system was used to irrigate a full crop acreage, leading to an enomous increase in energy use. A fourth outlier account was elliminated because a partial gravity system was installed in the same year as the retrofit, leading to far higher savings than should be attributed to the retrofit alone. Table 3.5 summarizes the distribution by utjlity of accounts remaining in the task one analysis.

Table 3.6 summarizes data for retrofit and control accounts used in task one of PNL's empirical analysis of energy savings from BPA's Stage II Irrigation Retrofit program. Dates of retrofits, projected savings, pumping lifts and measures taken are tabulated.

Note again that PNL obtained as many of the Stage I energy savings projections as possible for the retrofit accounts included in this study and that projections were obtained for 52 of the 64 retrofit accounts in the study. Eight of the data points are missing because the inspections took place in 1982 when savings were not consistently calculated. Four accounts that were covered by one inspection form had to be eliminated from the portions of the analysis requiring projected energy savings. Pumping lifts were also not available for several of the accounts and the lifts that were available were highly skewed towards extremes of very low or very high pumping lifts. It was necessary to eliminate accounts, from selected analyses involving stratification of data, where projected savings and/or pumping lifts were not available.

\subsubsection{Final Data Set Used In Estimating Savings Based On Statistical Regression Techniques (Task 2)}

The response rate for the mafl/telephone survey was high, with approximately 40 of the 53 original identified Stage II participants returning mail surveys. Many of these irrigators had more than one billing record account. Consolidation of selected accounts and other actions described previously in Section 3.4.3 provided the final data set of 70 accounts listed in Table 3.7. 
For most accounts, cropping record and other data were obtained for all five years from 1981 to 1985 . Thus, at least 300 observations were available for savings estimation performed on an annual basis, and a significantly greater number of observations were available when estimation was performed on a billing period basis. A summary of selected characteristics of the retrofit accounts impacted by conservation measures installed under the Stage II program and used in Task 2 of this study is presented in Table 3.8.

The estimated energy savings figures shown in Table 3.8 are based on the percentage changes in brake horsepower measured in the Stage II post-retrofit pump tests. The data used in computing these figures were obtained from either the Stage II incentive claim forms provided by BPA or from billing record information supplied by utilities with Stage II program participants. 
Table 3.5. Number of Accounts Used for Task 1 Analysis of Energy Savings from BPA's Stage II Retrofit Program

\begin{tabular}{lcc} 
Utility & Retrofit Accounts & Control Accounts \\
\cline { 2 - 3 } Benton REA & 1 & 1 \\
Big Bend Electric & 21 & 12 \\
Central Electric & 2 & 0 \\
Franklin PUD & 9 & 0 \\
Lincoln Electric & 6 & 0 \\
Mid-State Electric & 9 & 5 \\
Raft River Electric & 3 & 0 \\
Umatilla Electric & 13 & 1 \\
\multicolumn{1}{c}{ Total } & 64 retrofit & 19 control \\
& & accounts
\end{tabular}

(a) Control accounts were not retrofit under the BPA program, but are operated by irrigators who operate at least one account that was retrofit with incentives from the Stage II Irrigation Retrofit program. 
Table 3.6. Retrofit Account Data Summary For

Accounts Used in Task 1 Analysis

\begin{tabular}{|c|c|c|c|c|c|c|c|c|c|}
\hline Utflity & $\begin{array}{l}\text { Farm } \\
\text { ID } \\
\end{array}$ & $\begin{array}{l}\text { Account } \\
\text { ID } \\
\end{array}$ & $\begin{array}{l}\text { Date } \\
\text { Measures } \\
\text { Installed } \\
\end{array}$ & $\begin{array}{l}\text { Projected } \\
\text { Energy } \\
\text { Savings (\%) }\end{array}$ & $\begin{array}{l}\text { Pump } \\
\text { Lift } \\
\text { (Feet) }\end{array}$ & $\begin{array}{l}\text { Cons } \\
\text { Meas } \\
\mathrm{LP} \\
\end{array}$ & $\begin{array}{l}\text { erva } \\
\text { ures } \\
M L \\
\end{array}$ & $\begin{array}{l}\text { ion } \\
\text { Inst } \\
\text { PPR }\end{array}$ & $\begin{array}{l}\text { a) } \\
\frac{\text { alled }}{\text { FR }} \\
\end{array}$ \\
\hline BENTON REA & 001 & $R-1$ & $5 / 84$ & 38 & 3 & $Y$ & $\mathbf{N}$ & $Y$ & $Y$ \\
\hline BIG BEND & 001 & $R-1$ & $4 / 9 / 85$ & 48 & 3 & $Y$ & $\mathrm{~N}$ & N & Y \\
\hline BIG BEND & 001 & $R-2$ & $4 / 9 / 86$ & 48 & -4 & $Y$ & N & $\mathrm{N}$ & $Y$ \\
\hline BIG BEND & 002 & $R-1$ & $5 / 14 / 85$ & 40 & 6.8 & $Y$ & N & $\mathrm{N}$ & $Y$ \\
\hline BIG BEND & 003 & $R-1$ & SUMMER 84 & 76 & 3 & $Y$ & $\mathrm{~N}$ & $\dot{Y}$ & Y \\
\hline BIG BEND & 003 & $R-2$ & SUMMER 84 & 45 & 3 & $Y$ & $\mathbb{N}$ & $y$ & Y \\
\hline BIG BEND & 004 & $R-1$ & $6 / 21 / 83$ & NA & $5 B 5$ & 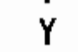 & 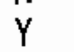 & N & Y \\
\hline BIG BEND & 004 & $\mathrm{R}-2$ & $6 / 21 / 83$ & NA & 710 & $Y$ & $y$ & $\mathrm{~N}$ & Y \\
\hline BIG BEND & 005 & $R-1$ & $5 / 1 / 84$ & 62 & 0 & Y & N & $\ddot{Y}$ & $\mathrm{~N}$ \\
\hline 8IG BEND & 005 & $R-2$ & $5 / 1 / 84$ & 53 & 0 & $Y$ & $\mathrm{~N}$ & $Y$ & N \\
\hline BIG BEND & 006 & $R-1$ & $3 / 85$ & NA & NA & $Y$ & N & $\mathrm{N}$ & $\mathrm{N}$ \\
\hline BIG BEND & 006 & $R-2$ & $3 / 85$ & NA & NA & Y & N & $\mathrm{N}$ & $\mathrm{N}$ \\
\hline BIG BEND & 007 & $R-1$ & $6 / 28 / 83$ & NA & NA & Y & $\mathrm{N}$ & $\dot{y}$ & $\mathrm{~N}$ \\
\hline BIG BEND & 008 & $R-1$ & $6 / 10 / 83$ & NA & 5 & $Y$ & $y$ & N & $\mathrm{y}$ \\
\hline BIG BEND & 009 & $R-1$ & $1 / 85$ & 47 & 5 & $Y$ & $\mathrm{~N}$ & $\mathrm{~N}$ & $\mathrm{~N}$ \\
\hline BIG BEND & 009 & $R-2$ & $1 / 85$ & 35 & 4 & $Y$ & $N$ & $\mathrm{~N}$ & $\mathrm{~N}$ \\
\hline BIG BEND & 009 & $R-3$ & $1 / 85$ & 27 & 4 & Y & $\mathrm{N}$ & $\mathrm{N}$ & $\mathrm{N}$ \\
\hline BIG BEND & 010 & $R-1$ & $12 / 20 / 84$ & 62 & 5 & Y & $\mathrm{N}$ & $\mathrm{N}$ & $\mathrm{N}$ \\
\hline BIG BEND & 011 & $R-1$ & $5 / 4 / 84$ & 67 & 3 & Y & $\mathrm{N}$ & $\ddot{y}$ & $\mathrm{~N}$ \\
\hline BIG BEND & 012 & $R-1$ & $5 / 17 / 84$ & 13 & 201 & $Y$ & $\mathrm{Y}$ & N & $\mathrm{N}$ \\
\hline BIG BEND & 013 & $R-1$ & $4 / 84$ & 39 & 3.3 & Y & Y & $\mathrm{Y}$ & $\mathrm{N}$ \\
\hline BIG BEND & 013 & $\mathrm{R}-2$ & 4/B4 & NA & 3.0 & Y & y & Y & $\mathrm{N}$ \\
\hline BIG BEND & 014 & $\mathrm{R}-1$ & $8 / 19 / 83$ & NA & -3.5 & Y & $\dot{y}$ & Y & Y \\
\hline CENTRAL ELECTRIC & 001 & $R-1$ & $12 / B 3$ & 15 & 3 & y & Y & $Y$ & $\mathrm{~N}$ \\
\hline CENTRAL ELECTRIC & 002 & $R-1$ & $1 / 83$ & 34 & NA & Y & Y & $\mathrm{N}$ & $\mathrm{N}$ \\
\hline FRANKLIN PUD & 001 & $R-1$ & $2 / 84$ & 41 & 111 & Y & Y & $y$ & $\mathrm{~N}$ \\
\hline FRANKLIN PUD & 002 & $R=1$ & $12 / 83$ & 78 & 66 & y & Y & Y & y \\
\hline FRANKLIN PUD & 002 & $R-2$ & $12 / 83$ & 78 & & & & & \\
\hline FRANKLIN PUD & 003 & $R-1$ & $12 / 83$ & 32 & NA & Y & $\mathrm{N}$ & $\mathbf{N}$ & $\mathrm{N}$ \\
\hline FRANKLIN PUD & 003 & $R-2$ & $12 / 83$ & 41 & 67.3 & $\dot{y}$ & $\mathrm{~N}$ & $\mathrm{~N}$ & $\mathrm{~N}$ \\
\hline FRANKLIN PUD & 003 & $R-3$ & $12 / 83$ & 29 & 52.4 & Y & $\mathrm{N}$ & $\mathrm{N}$ & $\mathrm{N}$ \\
\hline FRANKLIN PUD & 003 & $R-4$ & $12 / 83$ & 51 & $\mathrm{NA}$ & $y$ & N & $\mathrm{N}$ & N \\
\hline FRANKLIN PUD & 004 & $R=1$ & $12 / 83$ & 41 & NA & y & $\mathrm{N}$ & $\mathrm{N}$ & $\mathrm{N}$ \\
\hline FRANKLIN PUD & 004 & $R-2$ & $12 / 83$ & 8 & NA & $Y$ & $\ddot{y}$ & $\mathrm{~N}$ & $\mathrm{~N}$ \\
\hline LINCOLN ELECTRIC & 001 & $R-1$ & $3 / 84$ & NA & 340 & Y & $y$ & $\mathrm{~N}$ & $\mathrm{~N}$ \\
\hline LINCOLN ELECTRIC & 002 & $R-1$ & $3 / 84$ & NA & 360 & y & $Y$ & $\mathrm{y}$ & $\mathrm{Y}$ \\
\hline LINCOLN ELECTRIC & 003 & $R-1$ & $3 / 84$ & NA & 325 & Y & $y$ & $\mathrm{~N}$ & $\mathrm{~N}$ \\
\hline LINCOLN ELECTRIC & 004 & R-1 & $3 / B 4$ & NA & 432 & Y & y & $\mathrm{N}$ & $\mathrm{N}$ \\
\hline LINCOLN ELECTRIC & 006 & $R-1$ & $11 / 84$ & NA & NA & Y & $\mathrm{N}$ & $\mathrm{N}$ & $\mathrm{N}$ \\
\hline LINCOLN ELECTRIC & 007 & R-1 & $3 / 85$ & 12 & 461 & Y & $\mathrm{N}$ & $\mathrm{N}$ & $\mathrm{N}$ \\
\hline MID-STATE & 001 & $R-1$ & $7 / 2 / 85$ & 15 & 61.5 & Y & $\mathrm{N}$ & N & $y$ \\
\hline MID-STATE & 002 & $R-1$ & $10 / 30 / 84$ & 31 & 30 & Y & N & N & N \\
\hline MID-STATE & 003 & $R=1$ & $5 / 15 / 85$ & 28 & 27 & Y & $\hat{N}$ & $\mathrm{~N}$ & $\mathrm{~N}$ \\
\hline
\end{tabular}


$\underline{\text { Utility }}$

MID-STATE

MID-STATE

MID-STATE

MID-STATE

MID-STATE

MID-STATE

RAFT RIVER

RAFT RIVER

RAFT RIVER

UMATILLA

UMATILLA

UMATILLA

UMATILLA

UMATILLA

UMATILLA

UMATILLA

UMATILLA

UMATILLA

UMATILLA

UMATILLA

UMATILLA

UMATILLA
Table 3.6. Retrofit Account Data Summary For
Accounts Used in Task 1 Analysis (cont)

Table 3.6. Retrofit Account Data Summary For
Accounts Used in Task 1 Analysis (cont)

\begin{tabular}{|c|c|c|c|c|c|}
\hline & & & Pro & & Conservation ${ }^{(a)}$ \\
\hline ID & ID & $\begin{array}{l}\text { Measures } \\
\text { Installed }\end{array}$ & $\begin{array}{l}\text { Energy } \\
\text { Savings (\%) }\end{array}$ & $\begin{array}{l}\text { Lift } \\
\text { (Feet) }\end{array}$ & $\begin{array}{l}\text { Measures Installed } \\
L P M L \quad P P R \quad F R\end{array}$ \\
\hline
\end{tabular}

$\begin{array}{lll}004 & R-1 & 5 / 10 / 83 \\ 005 & R-1 & 6 / 30 / 85 \\ 005 & R-2 & 5 / 26 / 85 \\ 006 & R-1 & 5 / 30 / 84 \\ 007 & R-1 & 10 / 11 / 83 \\ 008 & R-1 & 5 / 30 / 84 \\ 001 & R-1 & 5 / 1 / 84 \\ 001 & R-2 & 7 / 19 / 83 \\ 002 & R-1 & \text { NA } \\ 001 & R-1 & \text { SPRING } 83 \\ 002 & R-1 & \text { SPRING } 83 \\ 002 & R-2 & \text { SPRING } 85 \\ 003 & R-1 & \text { FALL } 83 \\ 004 & R-1 & \text { FALL 83 } \\ 004 & R-2 & \text { FALL 83 } \\ 005 & R-1 & \text { SPRING } 85 \\ 006 & R-1 & \text { SPRING } 83 \\ 007 & R-1 & \text { SPRING 85 } \\ 008 & R-1 & \text { FALL 83 } \\ 009 & R-1 & \text { SPRING } 84 \\ 010 & R-1 & \text { SPRING 83 } \\ 011 & R-1 & \text { SPRING } 84\end{array}$

$\begin{array}{ll}27 & 37 \\ 38 & 26 \\ 48 & 53 \\ 61 & 32 \\ 20.8 & 31 \\ 30.9 & 11 \\ 38.9 & 127 \\ 9.76 & 104 \\ 13.2 & 131 \\ 27.0 & 255 \\ 40.0 & 3 \\ 33.3 & 4.5 \\ 42.9 & \text { NA } \\ 42.2 & 3 \\ 50.7 & 0 \\ 26 & \text { NA } \\ 35.0 & \text { NA } \\ 34.7 & 4 \\ 38.5 & 4 \\ \text { NA } & 92 \\ 54.5 & 2 \\ 53.6 & 1\end{array}$

(a) Conservation Measures: $L P=L$ ow Pressure conversion, $M L=M a i n l i n e$ Modification, $P P R=P u m p i n g$ Plant Replacement, FR=Fittings Redesign. 
Table 3.7. Number of Accounts Used for Task 2 Analys is of Energy Savings from BPA's Stage II Retrofit Program

$\begin{array}{lcc}\text { Utility } & \text { Retrofit Accounts } & \text { Control Accounts } \\ \text { Benton REA } & 1 & 1 \\ \text { Big Bend Electric } & 16 & 6 \\ \text { Central Electric } & 1 & 0 \\ \text { Franklin PUD } & 2 & 1 \\ \text { Mid-State Electric } & 12 & 11 \\ \text { Raft River } & 3 & 0 \\ \text { Umatilla } & \underline{15} & 11 \\ \quad \text { Total } & 50 \text { retrofit } & 20 \text { control } \\ & \text { accounts } & \text { accounts }\end{array}$

(a) Control accounts were not retrofit under the BPA program, but are operated by irrigators who operate at least one account that was retrofit with incentives from the Stage II Irrigation Retrofit program. 
Table 3.8. Retrofit Account Data Summary for

Accounts Used in Task 2 Analysis

\begin{tabular}{|c|c|c|c|c|c|c|c|c|c|}
\hline Utility & $\begin{array}{l}\text { Farm } \\
\text { ID } \\
\end{array}$ & $\begin{array}{l}\text { Account } \\
\text { ID } \\
\end{array}$ & $\begin{array}{l}\text { Date } \\
\text { Measures } \\
\text { Installed } \\
\end{array}$ & $\begin{array}{l}\text { Estimated } \\
\text { Energy } \\
\text { Savings (\%) }\end{array}$ & $\begin{array}{l}\text { Pump } \\
\text { Lift } \\
\text { (Feet) }\end{array}$ & $\begin{array}{l}\text { Cons } \\
\text { Meas } \\
\mathrm{LP} \\
\end{array}$ & $\begin{array}{l}\text { erva } \\
\text { ures } \\
\text { ML }\end{array}$ & $\begin{array}{l}\text { tion } \\
\text { Inst } \\
\text { PPR } \\
\end{array}$ & $\begin{array}{l}\text { a) } \\
\text { a] led } \\
\text { FR }\end{array}$ \\
\hline$\overline{8}$ enton REA & 001 & $\mathrm{R}-1$ & $5 / 84$ & 40 & 3 & $Y$ & $\mathbf{N}$ & $Y$ & $y$ \\
\hline Big Bend & 001 & $\mathrm{R}-1$ & $4 / 9 / 85$ & 37 & -.6 & $Y$ & $\mathbf{N}$ & N & $Y$ \\
\hline Big Bend & 004 & $\mathrm{R}-1$ & $6 / 21 / 83$ & 4 & 585 & $Y$ & $Y$ & $\mathrm{~N}$ & y \\
\hline Big Bend & 005 & $R-1$ & $5 / 1 / 84$ & 43 & 0 & $Y$ & $y$ & N & y \\
\hline $8 \mathrm{ig}$ Bend & 005 & $R-2$ & $5 / 1 / 84$ & 41 & 0 & $\gamma$ & $\mathbf{N}$ & Y & N \\
\hline Big Bend & 004 & $\mathrm{R}-2$ & $6 / 21 / 83$ & 10 & 710 & $\dot{\gamma}$ & $Y$ & $\mathrm{~N}$ & $Y$ \\
\hline Big Bend & 012 & $\mathrm{R}-1$ & $5 / 17 / 84$ & 30 & 201 & $y$ & $\dot{y}$ & N & $\mathrm{N}$ \\
\hline Big Bend & 008 & $\mathrm{R}-1$ & $6 / 10 / 83$ & 32 & 5 & $Y$ & $y$ & $\mathrm{~N}$ & $y$ \\
\hline Big Bend & 008 & $R-2$ & $6 / 10 / 83$ & 53 & 5 & & & & \\
\hline 8 ig 8end & 008 & $\mathrm{R}-3$ & $6 / 10 / 83$ & 18 & 5 & & & & \\
\hline Big Bend & 007 & $R-1$ & $6 / 28 / 83$ & 46 & 335 & $y$ & $\mathbf{N}$ & $Y$ & $\mathrm{~N}$ \\
\hline Big Bend & 014 & $\mathrm{R}-1$ & $8 / 19 / 83$ & 50 & 3.5 & $\gamma$ & N & y & $\hat{N}$ \\
\hline Big Bend & 011 & $\mathrm{R}-1$ & $5 / 4 / 84$ & 41 & 3 & y & $\mathrm{N}$ & Y & $\mathrm{N}$ \\
\hline Big Bend & 006 & $R-3$ & $3 / 85$ & 8 & 280 & Y & $\mathbf{N}$ & N & y \\
\hline Big Bend & 009 & $R-1$ & $1 / 85$ & 25 & 4.3 & $y$ & $\mathrm{~N}$ & $\mathrm{~N}$ & N \\
\hline Big Bend & 010 & $R-1$ & $12 / 20 / 84$ & 11 & 10 & Y & $N$ & $\widehat{N}$ & $\mathrm{~N}$ \\
\hline Franklin PUD & 002 & $\mathrm{R}-1$ & $12 / 83$ & 40 & 66 & $y$ & $\mathrm{~N}$ & $Y$ & y \\
\hline Franklin PUD & 001 & $\mathrm{R}-1$ & $2 / 84$ & 44 & 111 & $y$ & $\mathrm{~N}$ & $y$ & $\mathrm{~N}$ \\
\hline Central Electric & 001 & $\mathrm{R}-1$ & $12 / 83$ & 43 & 3 & $y$ & Y & Y & $\mathrm{N}$ \\
\hline Mid-State & 007 & $\mathrm{R}-1$ & $10 / 11 / 83$ & 30 & 31 & $\dot{Y}$ & $\mathbf{N}$ & N & N \\
\hline Mid-State & 001 & $\mathrm{R}-1$ & $7 / 2 / 85$ & 14 & 61.5 & $Y$ & $\mathbf{N}$ & $N$ & $N$ \\
\hline Mid-State & 004 & $\mathrm{R}-1$ & $5 / 10 / 83$ & 23 & 37 & Y & $\mathbf{N}$ & $\mathrm{N}$ & N \\
\hline Mid-State & 006 & $\mathrm{R}-1$ & $5 / 30 / 84$ & 35 & 32 & $\mathrm{Y}$ & $\mathbf{N}$ & N & N \\
\hline Mid-State & 006 & $\mathrm{R}-2$ & $5 / 2 / 85$ & 24 & 70 & $Y$ & $\mathbf{N}$ & $\mathrm{N}$ & N \\
\hline Mid-State & 006 & $R-4$ & $5 / 3 / 85$ & 38 & 52 & $Y$ & $\mathbf{N}$ & $N$ & $N$ \\
\hline Mid-State & 003 & $\mathrm{R}-1$ & $5 / 15 / 85$ & 40 & 27 & $Y$ & $\mathrm{~N}$ & $\mathrm{~N}$ & N \\
\hline Mid-State & 008 & $R-1$ & $5 / 30 / 84$ & 10 & 11 & $Y$ & $y$ & $\mathbf{N}$ & $N$ \\
\hline Mid-State & 005 & $\mathrm{R}-1$ & $6 / 30 / 85$ & 30 & 26 & $\dot{y}$ & $\mathbf{N}$ & $\mathrm{N}$ & $N$ \\
\hline Mid-State & 005 & $R-2$ & $5 / 26 / 85$ & 59 & 53 & $Y$ & $\mathbf{N}$ & $\mathrm{N}$ & N \\
\hline Mid-State & 002 & $R-1$ & $10 / 30 / 84$ & 25 & 30 & $\mathbf{N}$ & $\mathbf{N}$ & N & N \\
\hline Raft River & 002 & R-1 & NA & 10 & 131 & $N$ & $\mathbf{N}$ & N & $Y$ \\
\hline Raft River & 001 & $R-2$ & $7 / 19 / 83$ & 12 & 109 & $\mathbf{N}$ & $\mathbf{N}$ & N & $\mathbf{N}$ \\
\hline Umatilia & 011 & $R-1$ & SPRING 84 & 43 & .5 & $Y$ & $\mathbf{N}$ & Y & $y$ \\
\hline Umatilla & 009 & $R-1$ & SPRING 84 & 5 & 92 & $Y$ & $\mathbf{N}$ & N & $N$ \\
\hline Umatilla & 013 & R-1 & FALL 85 & 35 & 5 & Y & $\mathbf{N}$ & & $\mathbf{N}$ \\
\hline Umatilla & 003 & $R-1$ & FALL 83 & 22 & NA & $Y$ & $Y$ & $\mathrm{~N}$ & $y$ \\
\hline Umatilla & 002 & R-1 & SPRING 85 & 34 & 4.5 & Y & $\mathbf{N}$ & N & $\mathbf{N}$ \\
\hline Umatilla & 002 & $\mathrm{R}-2$ & SPRING 85 & 22 & 3 & $\dot{Y}$ & $\mathbf{N}$ & N & $\mathrm{N}$ \\
\hline Umatilla & 002 & $R-3$ & SPRING 85 & 29 & 4.5 & $Y$ & $\mathbf{N}$ & $\mathrm{N}$ & $N$ \\
\hline Umati1la & 007 & R-1 & SPRING 85 & 35 & 4 & Y & $\mathbf{N}$ & $N$ & N \\
\hline Umatilla & 010 & R-1 & SPRING 83 & 61 & 2 & $Y$ & $N$ & $N$ & $N$ \\
\hline
\end{tabular}


Table 3.8. Retrofit Account Data Summary for

Utility

Ümatilla

Umatilla

Umatilla

Umatilla
Accounts Used in Task 2 Analysis (cont)

\begin{tabular}{|c|c|c|c|c|c|c|c|c|}
\hline $\begin{array}{c}\text { Farm } \\
\text { ID }\end{array}$ & $\begin{array}{l}\text { Account } \\
\text { ID } \\
\end{array}$ & $\begin{array}{l}\text { Date } \\
\text { Measures } \\
\text { Installed } \\
\end{array}$ & $\begin{array}{l}\text { Estimated } \\
\text { Energy } \\
\text { Savings (\%) }\end{array}$ & $\begin{array}{l}\text { Pump } \\
\text { Lift } \\
\text { (Feet) }\end{array}$ & $\begin{array}{l}\text { Cons } \\
\text { Meas } \\
\text { LP } \\
\end{array}$ & $\begin{array}{l}\text { erva } \\
\text { ures } \\
\text { ML }\end{array}$ & $\begin{array}{l}\text { ion } \\
\text { Inst } \\
\text { PPR }\end{array}$ & $\begin{array}{l}\text { (a) } \\
\frac{\text { talled }}{F R}\end{array}$ \\
\hline $\begin{array}{l}004 \\
004 \\
008 \\
006\end{array}$ & $\begin{array}{l}R-1 \\
R-2 \\
R-1 \\
R-1\end{array}$ & $\begin{array}{l}\text { FALL } 83 \\
\text { FALL } 83 \\
\text { FALL } 83 \\
\text { SPRING } 83\end{array}$ & $\begin{array}{l}54 \\
55 \\
45 \\
35\end{array}$ & $\begin{array}{l}3 \\
0 \\
4 \\
\text { NA }\end{array}$ & $\begin{array}{l}Y \\
Y \\
Y \\
Y\end{array}$ & $\begin{array}{l}\mathbf{N} \\
\mathbf{N} \\
\mathbf{N} \\
\mathbf{N}\end{array}$ & $\begin{array}{l}N \\
N \\
Y \\
N\end{array}$ & $\begin{array}{l}Y \\
Y \\
N \\
N\end{array}$ \\
\hline
\end{tabular}

\footnotetext{
(a) Conservation Measures: LP=Low Pressure conversion, ML=Mainline Modification, $P P R=P l a n t$ Replacement, FR=Fittings Redesign.
} 
.

. 


\subsection{TASK ONE ENERGY SAVINGS ESTIMATION METHODOLOGY AND RESULTS}

The methodology and results for estimating irrigation system conservation measure energy savings in Task One are described in this chapter.

\subsection{TASK ONE METHODOLOGY}

PNL calculated energy savings from the billing records of Stage II retrofit accounts in Task One by two different methods. In one method, weather variations between seasons are taken into account. Energy consumption in warmer, drier years is adjusted downward, and energy consumption in cooler, wetter years is adjusted upward, in order to normalize the data. The other method uses unadjusted data. In both methods, post-retrofit energy consumption is compared with pre-retrofit energy consumption.

\subsubsection{Unadjusted Energy Savings Methodology}

Billing records and retrofit dates were the only data inputs for the unadjusted energy savings calculation. Unadjusted energy savings were calculated by Equation 4.1. Equation 4.1 subtracts average energy consumption over the growing season (March 1 to October 31) before conservation measure installation, from average growing season energy consumption after conservation measure installation. It then divides that difference by average consumption before measure installation and multiplies by 100 .

$$
\begin{aligned}
& \left.P E S_{k}=\left[\stackrel{n-1}{(\Sigma} u_{j k} / N\right)-\left(\Sigma U_{j k} / M\right)\right] /\left(\Sigma u_{j k} / N\right) \times 100 \\
& \mathrm{~J}=1981 \quad \mathrm{~J}=\mathrm{n} \quad \mathrm{J}=1981 \\
& \text { (Equation 4.1) } \\
& \text { where } \quad \mathrm{PES}_{\mathbf{k}}=\text { percent change in } \mathbf{k w h} \text { consumption for participant } \\
& \text { account } k \text {; } \\
& \mathrm{n}=\text { the year the retrofit measure is installed, if it is } \\
& \text { installed in the spring; the year after the retrofit } \\
& \text { measure is installed, if it is installed in the fall; } \\
& \mathrm{U}_{\mathbf{j k}}=\text { the total unadjusted } \mathrm{kwh} \text { consumption for March to } \\
& \text { october irrigation season } \mathrm{J} \text { for participant account } \\
& \text { k; }
\end{aligned}
$$


$\mathbf{N}=$ the number of years of pre-retrofit energy consumption occurring 1981 or later;

$M \quad=\quad$ the number of years of post-retrofit energy consumption occurring up to and including 1985.

\subsubsection{Weather-Adjusted Estimation Methodology}

PNL investigated methods of adjusting the energy consumption records to normalize for weather variations. The goal was to avoid measuring decreases in energy consumption that might have occurred because of lower irrigation requirements due to unusually cool, wet weather, and likewise to avoid measuring increases in energy consumption that might have occurred because of higher irrigation requirements due to unusually hot, dry weather.

Theoretically, weather-normalized energy savings estimates should reflect long-run expected savjngs from the retrofits more accurately than unadjusted energy savings. In practice, however, the process by which irrigators adjust their water applications in response to weather changes is not well understood. A number of methods for estimating these adjustments are avallable, but the degree to which these methods actually reflect irrigators' behavior is not known. Thus, the indexing methods described here should be regarded as rough approximations. Later work conducted in Task 2 attempts to derive empirical estimates of the impacts of weather variations on irrigation energy consumption through statistical regression methods.

After reviewing available adjustment methods and analyzing the available data, a modified Blaney-Criddle equation was chosen for use in adjusting for weather impacts. The Blaney-Criddle is one of the few estimating methods that requires little weather data beyond temperature and daylight hours, both of which were available. The Blaney-criddle equation estimates consumptive water use, which theoretically determicies the amount of water applied through irrigation.

PNL adopted the Soll Conservation Service (SCS) Modified Blaney-Criddle (Hill, Johns and Frevert 1983) to allow calculation of consumptive use at billing interval time increments: 
$u_{m}=k_{m} \sum_{i=1}^{n} t_{i} p_{i} / 100$

(Equation 4.2)

where $U_{m}=$ consumptive crop water use in inches in billing period $m$;

$k_{m}=$ empirical coefficient (Hill, Johns and Frevert 1983)

$\mathrm{k}_{\mathrm{m}}=0.0173 \mathrm{t}_{\mathrm{m}}-0.314$ if $\mathrm{t}>35.43 \mathrm{~F}$

$t_{m}=$ mean temperature in billing period $m$

$t_{j}=$ mean temperature, daily:

$p_{f}=$ percentage of daylight hours of the year occurring during a particular day (James, et. al. 1982)

$n=$ number of days in billing period $m$

Consumptive use estimates from the Blaney-Criddle equation were incorporated in developing a weather adjustment index in the following steps:

1) A daily actual consumptive use factor was estimated for each day in each billing cycle, and consumptive use was estimated over the billing cycle $\left(U_{a}\right)$ using Equation 4.2;

2) Normal consumptive use $\left(U_{n}\right)$ was estimated for the same period, using monthly weather normals data pro-rated on a daily basis;

3) A weather adjustment numerator was calculated as normal consumptive use, over the billing period, minus normal precipitation over the billing period; $U_{n}-P_{n}$ i where $U_{n}=$ normal use and $P_{n}=$ normal precipitation.

4) A weather adjustment denominator was calculated as actual consumptive use, over the billing period, minus actual precipitation over the billing period; $U_{a}-P_{a}$; where $U_{a}=$ actual use and $P_{a}=$ actual precipitation

5) The weather index was calculated:

$$
W_{i j}=\frac{U_{n i j}-P_{n i j}}{U_{a i j}-P_{a i j}} ;
$$


where $W_{i j}=$ the weather index for each weather station $i$ and billing interval $j$;

6) The adjusted energy consumption was calculated:

$$
A_{k j}=E_{k j} * W_{i j}
$$

where

$$
\begin{aligned}
A_{k j}= & \text { the adjusted energy consumption for participating } \\
& \text { account } k \text { for billing interval } j ; \\
E_{k j}= & \text { the measured kwh consumption for participating account } \\
& k \text { for billing interval } j ; \\
W_{j j}= & \text { as defined previously. }
\end{aligned}
$$

Weather-adjusted energy savings were calculated using adjusted energy consumption $\left(A_{j k}\right)$ in Equation 4.1. In the same manner as unadjusted consumption

\subsection{TASK ONE ENERGY SAVINGS ESTIMATION RESULTS}

The results of the unadjusted and weather-adjusted energy savings calculations for the entire Stage I retrofit data set are presented in Table 4.1. Both the unadjusted and the adjusted savings estimates shown in Table 4.1 indicate that the introduction of conservation measures under the Stage II program reduced irrigation system energy consumption. The mean reduction in average energy consumption between the pre-retrofit and post-retrofit periods is 16 percent for the unadjusted measure and 23.1 percent for the adjusted measure.

Although the estimation results unambiguously indicate that the Stage II program produced energy savings, the estimates are not very precise. The variance of both the unadjusted and the adjusted energy savings measures are high, and result in a confidence intervals that are likely too large for evaluating the accuracy of projected savings for the Stage II retrofits. Within a $95 \%$ confidence interval, the mean unadjusted savings may vary from $7.4 \%$ to $24.6 \%$ and the adjusted savings may vary from $11.5 \%$ to $34.7 \%$. Within a $90 \%$ confidence interval, mean unadjusted savings fall between $\varepsilon .8 \%$ and $23.2 \%$, and adjusted savings fall between $13.2 \%$ and $32.8 \%$. 
Table 4.1. Summary of Results for Task I Energy Savings Estimation on Data Set of Retrofit Accounts with Known Outliters Eliminated

Mean of $\%$ Change

Variance of $\%$ Change

Std. Deviation of $\%$ Change

Std. Error of Mean \% Change

90\% Confidence Interval

$95 \%$ Confidence Interval

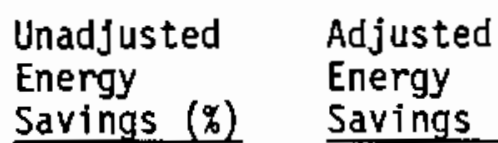

Savings (\%) Savings

$\begin{array}{cc}16.0 & 23.1 \\ 1165.6 & 2138.9 \\ 34.1 & 46.2 \\ 4.3 & 5.8 \\ 8.8-23.2 & 13.4-32.8 \\ 7.4-24.6 & 11.5-34.7\end{array}$

Table 4.2. Mean Weather-Adjusted and Unadjusted Task I Energy Savings Estimates by Utility/Weather Station

\begin{tabular}{|c|c|c|c|c|c|c|c|}
\hline \multirow{2}{*}{$\begin{array}{l}\text { Utility/ } \\
\text { Weather } \\
\text { Station }\end{array}$} & \multirow[b]{2}{*}{$\begin{array}{c}\# \\
\text { Cases }\end{array}$} & \multicolumn{3}{|c|}{ Unadjusted savings } & \multicolumn{3}{|c|}{ Adjusted Savings } \\
\hline & & $\begin{array}{l}\text { Mean } \\
(\%)\end{array}$ & $\begin{array}{l}\text { Std. } \\
\text { Dev. }\end{array}$ & $\begin{array}{l}\text { Std. } \\
\text { Error } \\
\text { of Mean }\end{array}$ & $\begin{array}{l}\text { Mean } \\
(\%)\end{array}$ & $\begin{array}{l}\text { Std. } \\
\text { Dev. }\end{array}$ & $\begin{array}{l}\text { Std. } \\
\text { Error } \\
\text { of Mean }\end{array}$ \\
\hline $\begin{array}{l}\text { Franklin PUD, } \\
\text { Kennewick, WA }\end{array}$ & 9 & 3.1 & 41.4 & 13.8 & 7.88 & 39.39 & 13.3 \\
\hline $\begin{array}{l}\text { Lincoln Electric, } \\
\text { Wilbur, WA }\end{array}$ & 6 & 6.2 & 45.3 & 18.5 & 20.57 & 90.99 & 37.1 \\
\hline $\begin{array}{l}\text { Central Electric, } \\
\text { Redmond, OR }\end{array}$ & 2 & 24.9 & 22.0 & 15.6 & 32.23 & 19.55 & 13.9 \\
\hline $\begin{array}{l}\text { Benton REA, } \\
\text { Kennewick, WA }\end{array}$ & 1 & 31.2 & $N / A$ & $N / A$ & 31.24 & N/A & N/A \\
\hline $\begin{array}{l}\text { Big Bend, } \\
\text { Odessa, WA }\end{array}$ & 21 & 11.7 & 36.8 & 8.0 & 15.56 & 46.85 & 10.2 \\
\hline $\begin{array}{l}\text { Mid-State, } \\
\text { Wickíup Dam, OR }\end{array}$ & 9 & 9.8 & 31.7 & 10.6 & 52.94 & 20.38 & 6.8 \\
\hline $\begin{array}{l}\text { Raft River, } \\
\text { Burley, ID }\end{array}$ & 3 & 44.0 & 16.0 & 9.2 & 35.85 & 27.35 & 15.8 \\
\hline $\begin{array}{l}\text { Umatilla Electric } \\
\text { Hermiston, OR }\end{array}$ & 13 & 31.7 & 19.0 & 5.4 & 40.66 & 19.18 & 5.3 \\
\hline
\end{tabular}


The higher variance and standard error for the adjusted savings compared to the unadjusted savings indicates that the method of adjusting for weather conditions used in Task 1 was not successful in reflecting irrigators' responses to changing weather conditions. The purpose of the weather adjustment was to reduce the variance in energy consumption caused by changing weather conditions and the adjustment used was not successful in this purpose. The relative lack of success of the weather adjustment is likely related to two causes:

1) The weather adjustment procedure and/or the weather data available for use in the procedure were not precise enough to accurately adjust for changing weather conditions, even though the procedure is based on a proven and well-known method.

2) Irrigators do not directly adjust their energy consumption behavior in response to changing weather conditions as assumed in the weather adjustment procedure.

In an attempt to reduce the variance of the mean savings estimates, the estimates were first stratified by utility/weather station. These two stratification variables are equivalent in this study because each utility was assigned its own weather station. The results of this process are shown in Table 4.2.

Note from Table 4.2 that stratification by utility/weather station was generally not successful in producing better estimates of the energy savings occurring as part of the Stage II program when compared to the total sample. The standard deviations of the unadjusted savings for three of the utilities were higher than for the total sample and the standard errors of the means were higher for every utility. Improvements in the precision of the adjusted savings were also generally not noted, al though the standard error of the mean for Umatilla Electric was reduced compared to the total sample mean standard error. In general, the larger standard deviations and standard errors associated with the smaller sample sizes of the individual utilities indicate that a calculated confidence interval around the mean savings for individual utilities would be wider than for the total sample. 
Another attempt to reduce the variance of the savings estimates was implemented through stratification by pumping lift. The results of this stratification procedure are shown in Table 4.3 . It can be seen from these results that stratification by lift was also generally unsuccessfut in reducing the standard error of the mean savings estimates, and that confidence intervals about the mean will generally be higher within the lift categories than for the total sample.

The two primary purposes of this study are: 1) to estimate the energy savings resulting from the Stage II program, and 2) to compare these estimates to those that were projected as part of the system audits and/or the postretrofit pump tests. Based on the results presented in Tables 4.1, 4.2 and 4.3, it was decided that the results for the total sample could provide the most meaningful results for comparison of savings estimated from billing records to projected savings. The results of Task 1 comparisons of projected savings to billing record savings are shown in Table 4.4. Note that the means of both the unadjusted and the adjusted energy savings are 21.1 and 11.7 percent less than the mean of the projected savings. Both of these differences are statistically significant at a $95 \%$ level of confidence. In addition, the confidence intervals for the projected savings are significantly narrower than those calculated for the bllling record savings.

The results shown in Table 4.4 appear to indicate that the Stage II program audits are projecting higher savings than are actualiy occurring. However, these results should be used with caution. One likely reason for the significantly higher projected savings is that the projected savings avallable to PNL for the Task I analysis were generally taken directly from the Stage I audit form and these estimates are based on the sum of the savings for all recommended conservation measures. If an irrigator chose not to undertake a recommended action, his billing records savings would be less than the total savings the audit projected, even if the audit projections were accurate.

Another likely reason for the significant difference in projected versus billing record savings is the rough nature of the Stage I estimation procedure, which did not account for pumping lifts, crop acres and other variables which likely impact upon the energy consumption of irrigation systems. Further 
Table 4.3. Mean Weather - Adjusted and Unadjusted Task I Energy Savings Estimate by Lift Category

\begin{tabular}{|c|c|c|c|}
\hline $\begin{array}{l}\text { Unadjusted } \\
\text { Savings ( }) \\
\text { for Lifts } \\
\leq 10 \text { feet } \\
\end{array}$ & $\begin{array}{l}\text { Unadjusted } \\
\text { Savings (\%) } \\
\text { for Lifts } \\
\sum 10 \text { feet }\end{array}$ & $\begin{array}{l}\text { Adjusted } \\
\text { Savings }(\%) \\
\text { for Lifts } \\
\leq 10 \text { feet }\end{array}$ & $\begin{array}{l}\text { Adjusted } \\
\text { Savings ( }) \\
\text { for Lifts } \\
\sum 10 \text { feet }\end{array}$ \\
\hline $\begin{array}{r}21.8 \\
987.5 \\
31.4 \\
6.4 \\
25.0\end{array}$ & $\begin{array}{r}15.4 \\
798.6 \\
28.3 \\
6.2 \\
25.0\end{array}$ & $\begin{array}{r}31.6 \\
715.8 \\
26.8 \\
5.5 \\
22.0\end{array}$ & $\begin{array}{r}35.4 \\
865.3 \\
29.4 \\
6.4 \\
22.0\end{array}$ \\
\hline
\end{tabular}

Table 4.4. Summary of Results for Task I Energy Savings Estimation on Data Set of Retrofit Accounts

for Which Projected Savings Were Available

Mean of $\%$ Change

Variance of $\%$ change

Std. Deviation of $\%$ Change

Std. Error of Mean \% Change

Number of Cases

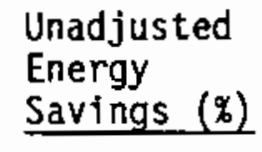

Mean of $\%$ Change

Variance of $\%$ Change

Std. Error of Mean

$90 \%$ Confiderce Interval

95\% Confidence Interval

Difference, in Means

(Projected-Billing Record)

$t$-test for

Difference Significance

Probability of $t$
$8.6-23.8$

$7.3-25.3$

$-21.1$

4.2

0

.2

Std. Deviation of $\%$ Change

(two-talled test $\%$ )
Adjusted

Energy

Savings (\%)

25.7

1791.4

42.3

5.7

$16.2-35.2$

14.3-37.1

$-11.7$

2.0

4

2.0

Projected

Savings (\%)
N/A

N/A 
analysis reported in Chapter 5.0 refines both the data and procedures used in evaluating the accuracy of the projected energy savings.

A final analysis was performed as part of Task 1 using both the control accounts and the retrofit accounts. Changes in billing record consumption between pre-retrofit and post-retrofit periods were estimated for pairs of matched farm irrigation accounts. PNL had access to 18 such matched accounts where billing records were obtained for both control and retrofit accounts operated by the same farmer.

The results of the estimation of unadjusted savings for matched control and retrofit accounts are shown in Table 4.5. Note that while energy consumption increased between the pre-retrofit and post-retrofit periods for the control accounts, it decreased for the matched retrofit accounts. The difference of $69 \%$ in the changes in energy consumption between the control and retrofit groups was significant at a $90 \%$ level of confidence. In addition, the installation of conservation measures in the retrofit accounts significantly reduced the variance in the billed energy consumption of these accounts compared to the control accounts. Thus, for accounts operating in similar geographic areas, under similar climatic conditions and for similar farmers, conservation measures installed under the Stage II program produced statistically significant levels of energy savings. 
Table 4.5. Summary of Task I Unadjusted Energy Savings Estimation Results for a Group of 18 Matched Retrofit and Control Accounts ${ }^{\text {a) }}$

\begin{tabular}{l} 
Control Account \\
Unadjusted Energy \\
Savings (\%) \\
\hline
\end{tabular}

Mean of $\%$ Change

variance of $\%$ Change

Std. Deviation of $\%$ Change

Std. Error of Mean $\%$ Change

Difference in Means

t-Statistic for Difference

Probability of $t$

(two-tailed test $\%$ )

-44.8
25817.7
160.7
39.0
69.0
1.8
7.0

1.0

7.0
Retrofit Account Unadjusted Energy

Savings (\%)

24.2

802.1

28.3

6.5

(a) Weather adjustment not needed for matched accounts because both sets of systems experienced the same weather conditions. 


\subsection{STATISTICAL REGRESSION ANALYSIS}

In this section, the statistical regression analysis conducted in Task 2 using the survey and supplemental data is described. The discussion first addresses the approach that was taken in developing the statistical estimates. This is followed by a description of the variables that were used in the analyses and any special measures taken to create these variables. Thirdly, we describe the models that were evaluated and the statistical techniques applied. Lastly, the results from the statistical analysis are reported.

\subsection{TASK 2 APPROACH}

As described earlier, the data base consists of a sample of 20 control accounts and 50 retrofit accounts. Each retrofit account consists of a set of data for an irrigation pump that has been retrofitted with one or more energy-conserving measures under the BPA Stage II program. The control accounts relate to irrigation pumps not retrofit with conservation measures under the State II program, but operated by farmers with other pumps under the program.

The avallability of the control accounts facilitated taking an approach that is seldom found in econometric analysis, but has clear advantages. To perform valid statistical tests on a body of data, it is necessary to perform the tests on a random sample. However, once a sample has been used and a test applied, the data comprising that sample can no longer be considered random. This means that hypotheses based on alternative model specifications or transformations of the same data can not be evaluated statistically. While $t$ values or $F$ values typically reported with regression packages can be useful in suggesting alternative specifications for hypothesis testing, a new random sample is required to test each specification.

In view of the foregoing, the control account data were used to develop the model specification to be tested with the retrofit accounts. The analysis therefore proceeded in two phases. In the first phase, regression techniques were applied to the control accounts using various model specifications. After a specification had been decided upon, it was statistically tested in the second phase using the retrofit account data. 


\subsection{DESCRIPTION OF VARIABLES}

Each variable used in the regression analysis is described below. The description generally consists of three underlined items, followed by a discussion. The first item gives the name of the variable as used in the regression equation; the second item is a descriptor of the variable; and the units of the variable are given as the third item. The discussion following these items includes information pertinent to the creation of the variable and the expectations regarding the sign of the estimated coefficient. In some cases, the expected magnitude of the coefficient is also discussed.

ELEC - Electricity Consumption - For regressions based on billing period data, the dependent variable was the average daily consumption of electricity in each billing period. In those regressions using annual data rather than billing period data, the dependent variable was total kwh consumed during the year, with the year consisting of 244 days from March 1 to October 31 for all accounts. For regressions based on billing periods, if electricity consumption during the billing period was zero, the observation was excluded from the sample except where noted.

BHP - Brake Horsepower - As reported in Chapter 3, data on brake horsepower from the Stage II irrigator incentive claims or data supplied by utility irrigation conservation program personnel were used as input data for the retrofit accounts. Because these data were not reported for the control accounts, a proxy was developed from the retrofit data. Specifically, we used the retrofit account data to determine an average value of BHP for each farm. This average was felt to be a good proxy for the unknown BHP value, since variation of BHP within a farm was found to be sma11. The coefficient of BHP is expected to have a positive sign, since more powerful pumps should consume more electricity.

CR1,...,CR4 - Crops Planted (Dummy Variable) - As explained in Chapter 3, survey respondents reported on the crops that they had planted, including the planting and harvesting dates. Since over 30 different crops were reported in the survey, we divided the crops into five categories, basad on their relative water requirements. The crops were divided into the following categories: 


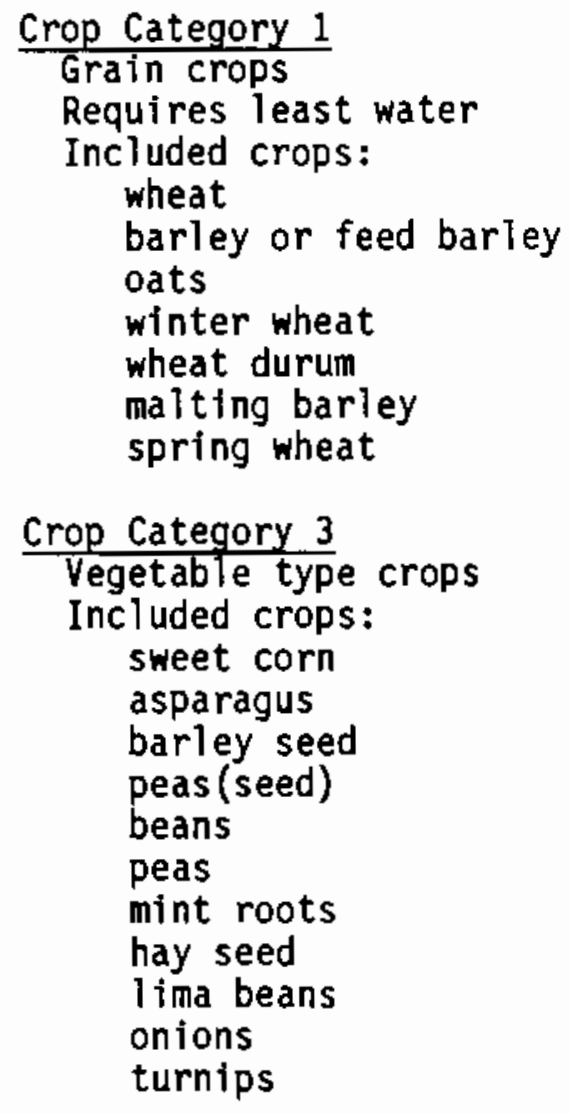

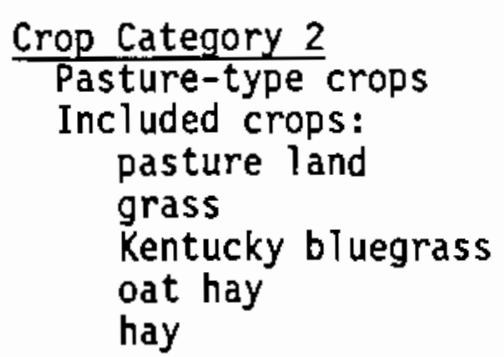

Crop Category 4 Heavily irrigated crops Included crops: potatoes alfalfa corn/field corn peppermint sugar beets corn silage

Crop Category 5 consists of mixed crops. In cases where crops from two or more of the above categories are irrigated by a single pump within a calendar year, a crop category of 5 is assigned, unless:

1) more than $2 / 3$ of the acreage was in a single crop category, in which case that crop category was assigned.

2) the mix was in Categories 3 and 4 only, in which case the category with the larger acreage was assigned.

3) the mix was in Categories 1 and 2 only, in which case the category with the larger acreage was assigned.

A small amount of the crop data was not usatle. For example, for the following conditions, the affected observations were excluded: (1) the crops were unknown (coded 98 or 99); (2) the acreage was in the payment-In -Kind (PIK) program; (3) the number of acres was unknown; or (4) the crop was miscoded as a " 0 ".

Dumny variables were used to indicate the relevant crop category. For example, if a crop in Category 2 was in the ground in the billing 
period year, then CR1 was given a value of 1 and all other crop variables assumed zero values. If a Category 3 crop was in the ground during the billing period year, CR2 was given a value of 1 and all other crop variables assumed zero values. Similar assignments were given to all other crop dumny vartables. Based on relative water demands, the following relationship is expected between the crop coefficients: CR1 < CR2 < CR3. The coefficient on CR4, the mixed crop category, is expected to lie between CR1 and CR3.

ACRES - Acreage in Crops - This variable contains the number of acres being irrigated by the pump. Acreage in the PIK program is excluded. The coefficient on acreage should clearly be positive.

PRICE - Incremental Price of Electricity in Billing Period (cents/kwh) The pricing schedule for each utility was obtained so that we could determine the appropriate price for irrigation electricity. Under some pricing schedules, payment of an initlal fee entitles the purchaser to a fixed number of electrical units without additional charge. All of the utility districts impose a fixed charge on either a monthly or annual basis. The fixed charge may be a $\mathrm{kw}$ demand charge, or it may be based on the horsepower of the pumping unit. In addition to the fixed charge, there is an energy charge for each unit of electricity purchased during the billing period. A further complexity to these schedules is that incentive rates are sometimes offered during the early months of the planting season, when irrigation needs tend to be light.

Table 5.1 summarizes the irrigation schedule in effect for each utility district during each period from 1981 though 1985 . It is ciear from Table 5.1 that, during the period of the program, energy prices have increased. While the effect of price on irrigation practices may be an important one, our preliminary feeling was that the use of irrigation water would be relatively insensitive to the range of prices shown in the table. We felt this would be particularly true in the early years of price increases, since farmers could conceivably take several years to become fully adjusted to the higher price levels. 
Table 5.1. Utility Irrigation Rate Schedules

Study Period

\begin{tabular}{llll} 
UTILITY & DATE & $\begin{array}{c}\text { ENERGY CHARGE } \\
\text { (CENTS PER kwh) }\end{array}$ & FIXED CHARGE \\
\cline { 2 - 3 } Midstate & & & \\
& $1 / 80$ & $2.00 \mathrm{first} 400 \mathrm{kwh} / \mathrm{HP}$ & $\$ 12 / \mathrm{HP}$ Annually \\
& - & 1.25 over $400 \mathrm{kwh} / \mathrm{HP}$ & $\$ 12 / \mathrm{HP}$ Annually \\
& $7 / 81$ & 1.8 & $\$ 12 / \mathrm{HP}$ Annually \\
& $10 / 82$ & 2.79 & $\$ 12 / \mathrm{HP}$ Annually \\
& $12 / 1 / 82$ & 2.89 & $\$ 12 / \mathrm{HP}$ Annually \\
& $1 / 1 / 83$ & 2.98 & $\$ 12 /$ HP Annually \\
& $9 / 1 / 83$ & 3.60 & $\$ 12 /$ HP Annually \\
& & & \\
Benton REA & 81 & 1.0 & $\$ 15 /$ HP Annually \\
& 82 & 1.0 & $\$ 15 /$ HP Annually \\
& 83 & 1.6 & $\$ 24 /$ HP Annually \\
& 84 & 1.7 & $\$ 26 /$ HP Annually \\
& 85 & 1.33 & $\$ 26 /$ HP Annually
\end{tabular}

Big Bend

$\begin{array}{lll}2 / 20 / 81 & 0.8 \text { first } 200 \mathrm{kwh} / \mathrm{HP} & \$ 14 / \mathrm{HP} \text { Annually } \\ 10 / 20 / 82 & 0.0 \text { f5/HP Annually } \\ - & 1.5 \text { over } 200 \mathrm{kwh} / \mathrm{HP} & \\ 3 / 7 / 83 & 0.0 \text { first } 200 \mathrm{kwh} / \mathrm{HP} & \$ 25 / \mathrm{HP} \text { Annually } \\ \overline{1} & 1.5 \text { over } 200 \mathrm{kwh} / \mathrm{HP} & \\ 3 / 31 / 84 & 0.0 \text { first } 200 \mathrm{kwh} / \mathrm{HP} & \$ 25 / \mathrm{HP} \text { Annually } \\ 5 / 84-10 / 84 & 0.35 & \$ 25 / \mathrm{HP} \text { Annually } \\ - & 0.0 \text { first } 200 \mathrm{kwh} / \mathrm{HP} & \$ 25 / \mathrm{HP} \text { Annually } \\ 4 / 85-8 / 85 & 1.6 \text { over } 200 \mathrm{kwh} / \mathrm{HP} & \\ - & 0.0 \text { first } 200 \mathrm{kwh} / \mathrm{HP} & \$ 25 / \mathrm{HP} \text { Annually } \\ 9 / 85 & 1.4 \text { over } 200 \mathrm{kwh} / \mathrm{HP} & \$ 25 / \mathrm{HP} \text { Annually } \\ - & 0.0 \text { first } 200 \mathrm{kwh} / \mathrm{HP} & \$ 25 / \mathrm{HP} \text { Annually } \\ & 1.7 \text { over } 200 \mathrm{kwh} / \mathrm{HP} & \end{array}$

Central Electric

81

1.45 first $200 \mathrm{kwh} / \mathrm{kwD}$

$\$ 2.80 / \mathrm{kwD}$ Mon.

- $\quad 0.85$ over $200 \mathrm{kwh} / \mathrm{kwD}$

$2 / 10 / 82 \quad 1.70$

$3 / 1 / 83 \quad 1.97$

$9 / 20 / 83 \quad 1.97$

$3 / 1 / 84 \quad 0.98$

$4 / 16 / 84 \quad 1.20$

$5 / 16 / 84 \quad 1.97$

$4 / 15 / 85 \quad 1.38$

$5 / 16 / 85 \quad 1.97$

$\$ 3.75 / \mathrm{kwD}$ Mon.

$\$ 4.35 / \mathrm{kwD}$ Mon.

$\$ 5.35 / \mathrm{HP}$ Mon.

$\$ 2.67 / \mathrm{kwD}$ Mon.

$\$ 3.21 / \mathrm{kwD}$ Mon.

$\$ 5.35 / \mathrm{kwD}$ Mon.

$\$ 3.75 / \mathrm{kwD}$ Mon.

$\$ 5.35 / \mathrm{kwD}$ Mon. 
Frank 7 in County

$\begin{array}{ll}5 / 1 / 81 & 0 \text { first } 150 \mathrm{kwh} / \mathrm{HP} \\ - & 0.80 \text { over } 150 \mathrm{kwh} / \mathrm{HP} \\ 11 / 1 / 82 & 0 \text { first } 150 \mathrm{kwh} / \mathrm{HP} \\ - & 1.51 \text { over } 150 \mathrm{kwh} / \mathrm{HP} \\ 83 & 0 \text { first } 150 \mathrm{kwh} / \mathrm{HP} \\ - & 1.51 \text { over } 150 \mathrm{kwh} / \mathrm{HP} \\ 8 \overline{4} & 0 \text { first } 150 \mathrm{kwh} / \mathrm{HP} \\ - & 1.51 \text { over } 150 \mathrm{kwh} / \mathrm{HP} \\ 3 / 84,4 / 84 & 1.39 \\ 85 & 0 \text { first } 150 \mathrm{kwh} / \mathrm{HP} \\ - & 1.51 \text { over } 150 \mathrm{kwh} / \mathrm{HP}\end{array}$

$\$ 13.50 /$ HP Annually

$\$ 21.20 /$ HP Annuatly

$\$ 21.20 /$ HP Annually

$\$ 18.50 /$ HP Annually

$\$ 21.20 /$ HP Annually

Raft River REC

$\$ 10 / k w D$ Annually

$\begin{array}{ll}81 & 1.36 \\ 82 & 1.36 \\ 11 / 1 / 83 & 3.70 \text { first } 250 \mathrm{kwh} \\ & 1.65 \text { over } 250 \mathrm{kwh} \\ 12 / 1 / 84 & 3.70 \text { first } 250 \mathrm{kwh} \\ 1 / 23 / 85 & 1.65 \text { over } 250 \mathrm{kwh} \\ & 2.08\end{array}$

$\$ 1.50 / \mathrm{kwD}$ Mon.

$\$ 1.50 / \mathrm{kwD}$ Mon.

$\$ 10 / \mathrm{kwD}$ Annually

$\$ 10 / \mathrm{kwD}$ Annually

$\$ 10 / k w D$ Annually

$\$ 3 / \mathrm{kwD}$ Mon. $\$ 10 / \mathrm{kwD}$ Annually

Umatilla ECA

$$
\begin{array}{ll}
1 / 1 / 80 & 0.68 \\
7 / 1 / 81 & 0.90 \\
10 / 1 / 82 & 1.90 \\
11 / 83 & 1.70 \\
4 / 85 & 1.3871 \\
9 / 85 & 1.7571 \\
\text { Additional } & \text { Annual Charges: } \\
& \text { first } 0-50 \mathrm{HP} \\
& \text { next } 51-100 \mathrm{HP} \\
& \text { next } 101-200 \mathrm{HP} \\
& \text { next } 201-300 \mathrm{HP} \\
& \text { next } 301-400 \mathrm{HP} \\
& \text { All over } 400 \mathrm{HP}
\end{array}
$$

$\$ 2 / \mathrm{kwD}$ Mon.

$\$ 2.80 / \mathrm{kwD}$ Mon.

$\$ 2.91 / \mathrm{kwD}$ Mon.

$\$ 3.42 / \mathrm{kwD}$ Mon.

$\$ 3.492 / \mathrm{kwD}$ Mon.

$\$ 3.492 / \mathrm{kwD}$ Mon.

$\$ 7.00 /$ HP Annually

$\$ 6.00 /$ HP Annually

$\$ 5.00 /$ HP Annually

$\$ 4.00 /$ HP Annually

$\$ 3.00 /$ HP Annually

No Additional Charge

Lincoln ECI

$\begin{array}{ll}12 / 20 / 79 & 3.4 \text { first } 307 \mathrm{kwh} / \mathrm{HP} \\ - & 1.0 \text { over } 307 \mathrm{kwh} / \mathrm{HP} \\ 12 / 20 / 80 & 0.95 \\ 12 / 20 / 81 & 1.15 \\ 12 / 20 / 82 & 2.00 \\ 10 / 20 / 83 & 2.09 \mathrm{first} \\ & 222,000 \mathrm{kwh} / \mathrm{farm} \\ & 2.49 \text { over } \\ & 222,000 \mathrm{kwh} / \mathrm{farm}\end{array}$

$\$ 12 /$ HP Annually

$\$ 12 /$ HP Annual 1y

$\$ 12 /$ HP Annually

$\$ 8 /$ HP Annually

\$10/HP Annually

\$10/HP Annually 
We encountered several conceptual difficulties with respect to evaluating the effect of price on irrigation use. Most of these difficulties can be traced to the complexities of the pricing schedules that were noted above.

The price measure that should be included in the regression is the appropriate marginal cost of electricity at the time fundamental irrigation decisions are made. Unfortunately, for defining the price variable, the decisions are made at several points throughout the crop cycle and the relevant marginal cost is not a stable concept. First, there is the decision on which crop to plant, and both the fixed charge (annual or monthly) and the unit rate may influence this decision. There is the decision on how carefully to control the use of water during any month, and the incremental rate in effect during that month will be relevant to that decision. There is also the decision of whether to irrigate a crop at the beginning or end of the growing season, when the benefits from added irrigation may be relatively smal1. Both the fixed charge and the incremental rate can affect this decision. Finally, we note that announced price changes occurring within a season (after a crop has been planted) will likely have less effect on irrigation decisions than will announced price changes between crop seasons.

Our construction of the price variable responds only partially to the difficulties identified above. First of all, in cases where a fixed charge entitled the famer to a fixed number of electrical units at no additional cost, we assumed that the purchaser consumed electricity in excess of this allowance, so that the incremental price applied. To avoid the problems posed by more than a single rate during the irrigation season (e.g., incentive rates), we assumed that the relevant rate was the incremental rate in effect on July 15 th of that year. This decision was based on the presumption that this rate is known when all of the decisions relating to irrigation are made. This price also has the advantage of most likely being the incremental price paid for most of the electrical units purchased. 
In at least one instance, a utility lowered the incremental rate but increased the fixed charge between seasons. Thus, the incremental price does not capture what may have been a net increase in electricity costs for some farmers. A problem with including the fixed charge in the regression is that it is not defined in the same way for different utility districts; some districts base the fixed charge on pump horsepower, while others base it on $\mathrm{kW}$ demand. We do not possess the information to include the fixed charge in a consistent way.

YR1,...,YR4 - Billing Period Year (Dummy Variable) - The billing period year dummy variables are included to indicate the year in which the billing period falls. The purpose of these is to capture effects that may occur over time, but which are not explained by other variables in the regression. For example, these variables may capture the effect of the annual increases in the fixed charge for electricity that we have not been able to include explicitly in the regression.

The survey contained a number of questions pertaining to the introduction of energy-saving irrigation technologies and practices during the period of the program. Responses to these questions may not have included all of the energy-saving measures introduced on the farms. Thus, the introduction of energy-conserving practices not otherwise identified in the regression would be captured by the billing period year dummies.

This set of dummy variables was constructed as follows: if the billing period fell in 1982, YR1 was given a value of 1 and all other year variables assumed a value of zero. If the billing period fell in 1983, YR2 was given a value of 1 and all other year variables assumed a value of zero. Similar assignments were made for all other billing period year dummy variables. In cases where a billing period spanned two calendar years, the year containing the irrigating months was assigned.

Based on the foregoing discussion we expect the relationship among these variables to be as follows: $0>$ YR1 > YR2 > YR3 > YR4. In other words, for temporal effects not otherwise included in the regression, we expect that energy consumption will decline monotonically over time. 
M1,...,M8 - Billing Period Months (Dummy Variable) - The billing period month dummy variables are designed to capture systematic monthly effects of variables that are not explicitly included in the regression. For example, although temperature and precipitation variables are included in the regression, the effect of wind is not. If some months are windier than others and windy months are associated with high transpiration rates leading to increased irrigation requirements, then the monthly dummies would capture this effect. Another potentially more important type of effect relates to water requirements over the growth cycle of a particular crop. If a crop is planted in the spring and it requires relatively large amounts of water during this period, then the month dummies for the spring period could be expected to capture this effect. Another example is provided by wheat, which has substantially reduced water requirements prior to harvest in the months of July and August.

The billing period month dummies were constructed as follows: if the btlling period spanned more than half of the month of April, M1 was given a value of 1 and all other monthly variables assumed a value of zero. If it spanned more than half of the month of May, M2 was given a value of 1 and all other billing period monthly dummy variables assumed a zero value. Simflar assignments were made for all other monthly dumny variables. Note that unlike most other dummy variable applications, several of the dunny variables in this set may (simultaneously) assume values of 1 for any given observation.

Based on considerations discussed above, we conjecture that the dummy variables for May (M2) and June (M3) will be positive, the effect of wheat may make July (M4) and August (M5) negative and September (M6) positive, and the beginning and ending months--April (M1), October (M7) and November (M8)--will be negative.

HITEMP - Mean Daily High Temperature (degrees F) - This variable contains the mean of the high temperatures for all of the days within the billing period. Obviously, higher temperatures will increase water requirements, other things remaining equal. This variable should have a positive coefficient. 
HIVAR - Variance of Daily High Temperature (degrees F) - This variable is the sample variance of the daily high temperatures for all the days within the billing period. The idea behind this variable is that a higher variance for high temperatures means more days with extreme temperature values. In summer, extremes of high temperatures may necessitate additional irrigation. Lower high temperatures during the summer months seem less likely to result in changes in irrigation practices. PRECIP - Mean Daily Precipitation (in/day) - This variable contains the mean of the precipitation amounts for all the days within the billing period. Higher levels of precipitation should reduce irrigation requirements. Therefore, we expect the coefficient of PRECIP to be negative. Q20 - Changed Method of Measuring Soil Moisture - If a neutron probe, gypsum block or other instrument was used to measure soil moisture on a frequent basis, Q20 takes on the value 1; otherwise, it is zero. The expected sign for the variable is negative, because the use of these soil moisture measurement methods would be expected to reduce water applications and energy use.

\subsection{IHE STATISTICAL MODELS}

A statistical model of the form

$$
E L E C=a_{0}+a_{1} x_{1}+\ldots+a_{k} x_{k}+\epsilon
$$

was estimated, where ELEC is average daily electrical consumption, or total annual consumption as defined earlfer, the $x_{1}$ through $x_{k}$ are independent variables taken from the 1 ist above, $a_{0}$ through $a_{k}$ are parameters to be estimated, and $\epsilon$ is a stochastic disturbance term distributed $N:\left(0, \sigma^{2}\right)$, with zero covariances. It is noted that the sample consists of panel data; that is, we have for each of several billing accounts a time series of observations. The Ordinary Least Squares (OLS) regression technique is used to estimate Equation (5.1). This model assumes that there is no statistical dependence among observations, either across accounts or temporally.

Another model that we considered was an error components model. This type of model allows for some dependence in the error structure. In particular, it allows for correlation of the disturbance term over time; however, for 
tractability, it is assumed that the correlation between the errors in any two time periods is identical for all billing accounts.

The form of the error components model is

$$
E L E C=b_{0 t}+b_{1} x_{1 i t}+\ldots+b_{k} x_{k i t}+\epsilon_{i t}
$$

(Equation 5.2)

Here, the $b_{0 t}$ are independent random variables, with mean $\beta$ and variance $\sigma^{2} \beta^{\text {; }}$ the $b_{0 t}$ may assume different values for each account. The reader is referred to Judge (Judge 1982) for a description of this mode1, including details of the error structure.

In addition to evaluating the effects of including various subsets of the variables described earlier, we also considered alternative structural forms of the model. For the dependent/independent variables, these included untransformed/untransformed, untransformed/logarithmic and logarithmic/ logarithmic specifications. Which form to choose is often an empirical issue; in the absence of theoretical grounds to the contrary, it is generally resolved on the basis of statistical significance of the regressions. In the following sections, we evaluate the results of the statistical analysis.

\subsection{CONTROL ACCOUNT RESULTS}

After several experimentations with the inclusion and exclusion of the various variables in the OLS regression model, the following two specifications proved most satisfactory. As sometimes happens in statistical analysis, the simplest model turned out to be the best in terms of its predictive power. This model is:

$$
\begin{aligned}
& \text { ANNUAL ELEC }=-23792+1489 \text { BHP } \\
&(-2.6) \quad(27.5) \\
& F(2,55)=377.65 \quad \text { RBAR }^{2}=.931
\end{aligned}
$$

(Equation 5.3)

The regression uses untransformed variables based on a total of 57 annual observations spread over 20 individual accounts. The constant ierm and the coefficient on BHP are both highly significant, as is the regression model itself. The elasticity of billed electrical consumption with respect to BHP is 1.17 , measured at the means of the variables. This is interpreted to mean that a one percent decrease (increase) in BHP will lead to a 1.17 percent 
decrease (increase) in annual energy consumption. The standard error of the coefficient on BHP is $54(=1489 / 27.5)$, indicating a 95 percent chance that the confidence interval $1489+$ or -108 contains the true value of the coefficient. The corresponding $95 \%$ confidence interval for the elasticity is $1.17+$ or -.08 . This simple bivariate regression of the annual electrical consumption of an irrigation account as a function of brake horsepower provided the best fit of any specification tried.

While Equation (5.3) is particularly useful for predicting energy savings based on retrofits that affect brake horsepower, this relationship sheds no light on the effect of other variables on electricity consumption. In the control account analysis, we considered several specifications that included alternative subsets of independent variables. The most successful specification was

$$
\begin{aligned}
& \begin{array}{llll}
(-5.02)(11.41) & (1.13) \quad(0.294) & (3.50) & (3.34)
\end{array} \\
& +\underset{(5.68)}{8.65} \text { In HITEMP }-\underset{(-1.66)}{0.368} \text { in HIVAR }-\underset{0.525}{(-2.97)} \text { in PRECIP }+\underset{(6.52)}{0.863} \text { ACRES } \\
& -\underset{(-1.66)}{0.364} \text { YR1 }-\underset{(-4.83)}{1.55} \text { YR2 }-\underset{(-5.13)}{1.85} \mathrm{YR3}-\underset{(-6.11)}{2.11} \mathrm{YR4}+\frac{1.79}{(5.16)} \mathrm{ln} \text { PRICE } \\
& +0.687 \mathrm{M} 1+0.360 \mathrm{M} 2+0.136 \mathrm{M} 3-1.25 \mathrm{M} 4-0.886 \mathrm{M} 5+1.31 \mathrm{M} 6 \\
& \begin{array}{lllll}
(1.49) \quad(1.35) \quad(0.602) \quad(-4.69) & (-3.50) \quad(4.82)
\end{array} \\
& -0.560 \mathrm{M7}+0.564 \mathrm{MB}-0.645 \mathrm{Q20} \\
& \begin{array}{lll}
(-2.34) \quad(2.66) \quad(3.33)
\end{array} \\
& \text { (Equation 5.4) } \\
& F(23,69)=18.61 \quad \text { RBAR }^{2}=.823
\end{aligned}
$$

Descriptions of the variables contained in this equation were provided previously in Section 5.2. Regression Equation (5.4) is highly significant, as evidenced by the $\mathrm{F}$-statistic. In addition, most of the regression coefficients are statistically significant (or would be if our data were still a random sariple). The t-values, shown in parentheses below the coefficients, higher than 2.00 are significant at the $5 \%$ significance level, and t-values above 2.66 are significant at the $1 \%$ significance level. 
Regression coefficients with algebraic signs contrary to expectations are those for the variables HIVAR, PRICE, M1 and M8. HIVAR and MI are not, however, statistically significant and, therefore, their contrary signs are not a matter of large concern.

Unfortunately, the unexpected positive coefficient on price is highly significant. Prior expectations had led us to believe that the price coefficient would be negative, but would not be an important variable in explaining energy consumption used in irrigation because of the low incremental cost once the inftial fixed charge had been incurred. A reasonable explanation for this anomalous result may be found in our earlier discussion on the PRICE variable, with particular emphasis on the fact that low incentive rates are highly correlated with low usage periods.

The month dummy for November, M8, is highly significant and has a positive sign contrary to expectations. A reasonable explanation for this contrary result is not apparent. Except for the statistically insignificant coefficient on M1, all of the other month dummies had the expected sign, and the coefficients on July, August, September and October were all significant.

Our expectations regarding the coefficients on the year dummies were fulfilled. Furthermore, the coefficients on YR2 through YR4 are highly significant. The weather variables, HITEMP and PRECIP, both have the expected signs and are highly significant. The acres variable also has the expected positive sign and is highly significant.

The magnitudes of two of the crops dummies are not as expected. The coefficient on CR2 is less than the CR1 coefficient, although it is not significant, while the coefficient on CR4 is highly significant, but it is greater than CR3. Finally, variable $Q 20$ has the expected sign and is highly significant.

\subsection{RETROFIT ACCOUNT RESULTS}

The relationships selected for the control accounts were reestimated using the untested sample consisting of the retrofit accounts. While we recognize the shortcomings of the retrofit data as a random sample, we still 
consider the estimation of Equation (5.4) with the retrofit data as a usefut basis for hypothesis testing.

The results from applying OLS to a reestimation of Equation $(5.4)$ with the retrofit data are presented in Equation (5.5) below.

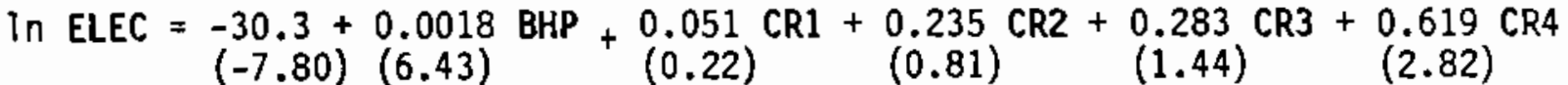

$$
\begin{aligned}
& +7.87 \text { in HITEMP }+0.405 \text { in HIVAR }+0.077 \text { in PRECIP + } 0.0002 \text { ACRES } \\
& \text { (8.62) (3.46) (1.96) (0.54) }
\end{aligned}
$$

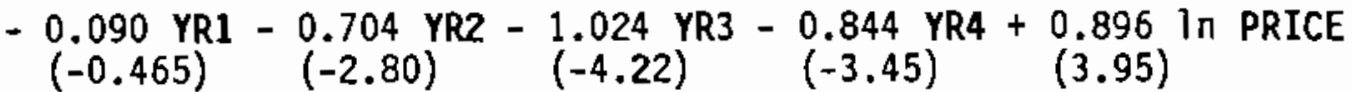

$$
\begin{aligned}
& -0.451 M 1+0.276 M 2-0.065 M 3-0.0003 \text { M4 }-0.170 M 5+0.428 M 6 \\
& \begin{array}{lllll}
(-2.08) \quad(1.79) & (-0.46) & (-0.002) & (-1.03) & (3.02)
\end{array} \\
& -0.061 \mathrm{M7}+0.383 \mathrm{MB}+0.688 \mathrm{Q20} \quad \text { (Equation 5.5) } \\
& (-0.33) \quad(1.81) \quad(5.24) \\
& F(24,551)=28.96 \quad \operatorname{RBAR}^{2}=.528
\end{aligned}
$$

Regression Equation (5.5) is more statistically significant than regression Equation (5.4), as evidenced by the F-statistic, but its predictive power is lower, as indicated by $i$ ts adjusted $R^{2}$. In addition, the $t$-values show that fewer of its regression coefficients are statistically significant. Only one of the crop dumnies is significant, acres is not significant, and only two of the month dummies are significant.

With respect to magnitudes, the caefficient of CR4 does not 1 ie between the coefficients of CR1 and CR3 as predicted, although neither of the latter two coefficients is statistically significant. The year dummies were generally monotonically decreasing, as expected, except that YR4 was slightly larger than YR3. All of the month dummies have the expected sign except M3 and M8, neither of which is statisticaliy significant. In addition, precipitation has the wrong sign and is just barely significant. Finally, Q20 is significant but now has the wrong sign. One notable improvement is that HIVAR retains its significance but now has the right sign.

The coefficient for BHP is about two-fifths as large as the corresponding coefficient in Equation 5.4. This is disturbing, since the standard errors 
of these coefficients are both extremely small. Because the mean value of BHP for the retrofits is nearly twice the mean value for the control accounts, the differences in the elasticity are less dramatic. For the control accounts, the elasticity is estimated at 0.53 as measured at the mean BHP value, while for the retrofit accounts it is estimated at 0.36 . The interpretation of the elasticity is that a one percent change in brake horsepower will lead to a 0.36 percent change in energy consumption, as determined from the retrofit accounts, or a 0.53 percent change as determined from the control accounts. It is noted that both of these estimates are significantly lower than the elasticity estimated from Equation (5.3).

Equation (5.5) reports results in which all instances of zero consumption and zero acres were removed from the sample. The reason we excluded these observations is that a large number of them can inflate the F-value and RBAR ${ }^{2}$ statistic without materially improving the goodness of fit. In Equation (5.6) we have included the observations with zero consumption. For these observations, ELEC is set equal to 1.0 (since $\ln 0$ is not defined), and BHP is set equal to zero.

$$
\begin{aligned}
& 1 n \text { ELEC }=-36.7+0.0015 \mathrm{BHP}+0.001 \mathrm{CR} 1+0.122 \mathrm{CR} 2+0.233 \mathrm{CR} 3+0.659 \text { CR4 } \\
& (-8.67)(4.86)+(0.004) \quad(0.37) \quad(1.05) \quad(2.67) \\
& +9.36 \text { In HITEMP }+0.416 \text { In HIVAR }+0.068 \text { In PRECIP + } 0.0001 \text { ACRES } \\
& \text { (9.37) (3.17) (1.54) (0.53) } \\
& \begin{array}{c}
-\underset{(-0.411)}{0.090} \text { YR1 } \\
(-0.485 \\
(-1.72)
\end{array} \\
& -\underset{(-1.39)}{0.334} \mathrm{M1}+\underset{(1.28)}{0.219} \mathrm{M2}+\underset{(0.13)}{0.020} \mathrm{M3}-\underset{(-0.72)}{0.131} \mathrm{M4}-\underset{(-1.38)}{0.253 \mathrm{ML}}+\underset{(3.88)}{0.612} \mathrm{M6} \\
& -0.181 \mathrm{M7}+0.620 \mathrm{MB}+0.704 \mathrm{Q20} \\
& (-0.92) \quad(2.64) \quad(4.78) \\
& F(24,563)=27.52 \quad \operatorname{RBAR}^{2}=.510
\end{aligned}
$$

The results in Equation (5.6) are not materially different from those reported in Equation (5.5).

A variation of Equation (5.5) is reported for annual data. The result, 
reported below as Equation (5.7), uses annual billing data for electrical consumption, and omits the month dummies, HITEMP and HIVAR.

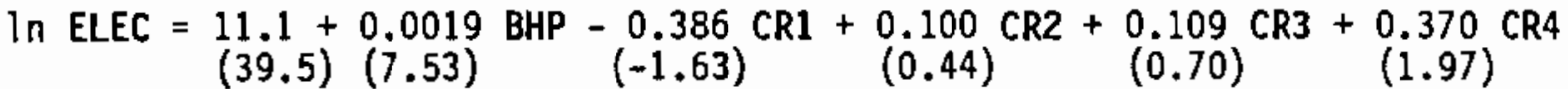

$$
\begin{aligned}
& +0.154 \text { In PRECIP + } 0.0006 \text { ACRES }-0.004 \text { YR1 + } 0.190 \text { YR2 - } 0.049 \text { YR3 } \\
& \begin{array}{lllll}
(0.78) & (2.02) & (-0.02) & (0.89) & (-0.21)
\end{array} \\
& +0.086 \text { YR4 }-0.419 \text { ln PRICE }+0.056 \text { Q20 }
\end{aligned}
$$

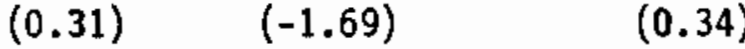

$$
\begin{aligned}
& \text { (Equation 5.7) } \\
& F(14,159)=26.46 \quad \operatorname{RBAR}^{2}=.657
\end{aligned}
$$

The results for Equation (5.7) are similar to those from Equation (5.6), but few of the coefficients are significant. Apart from the intercept term and the coefficient on BHP--which are extremely significant--only the coefficients of CR4 and ACRES are statistically significant.

The coefficient of CR4 does not lie between the coefficients of CR1 and CR3 as predicted, but this is not of concern since only CR4 is statistically significant. The year dummies did not reveal the expected monotonically decreasing characteristic, but, again, none of these dummies is significant. Also with the wrong sign but not significant is precipitation. Finally, ACRES has the expected sign and is significant.

We also ran a regression to evaluate the hypothesized close relationship between brake horsepower and total dynamic head. The specific hypothesis is that the ratio of beginning brake horsepower to beginning total dynamic head is directly proportional to the ratio of final brake horsepower to final total dynamic head. The results from estimating this model were

$$
\begin{gathered}
\text { (BEGBHP / BEGTDH) }=\frac{-0.027+1.029 \text { (ENDBHP / ENDTDH) }}{(-.646)} \quad \text { (Equation 5.8) } \\
F(2,55)=610.15 \quad \text { RBAR }^{2}=.967
\end{gathered}
$$

Equation (5.8) strongly supports the hypothesis of a proportional relationship between brake horsepower and total dynamic head. The intercept term is not significantly different from zero, and the coefficient on 
(ENDBHP/ ENDTDH) is highly significant and almost identical to 1.00. This result implies that one does not need both beginning and final brake horsepower and beginning and final total dynamic head to estimate energy savings from irrigation retro-fits; either pair will perform at about the same level of satisfaction.

Annualized data for the retrofit accounts were used to reestimate Equation (5.3), with the following result:

$$
\begin{aligned}
& \text { ANNUAL ELEC }=\frac{-40851}{(-1.31)}+\frac{1763 \mathrm{BHP}}{(22.0)} \quad \text { (Equation 5.9) } \\
& F(2,172)=482.92 \quad \text { RBAR }^{2}=.737
\end{aligned}
$$

Although not quite as good a fit as Equation (5.3), the results here are highly significant. The intercept term in Equation (5.9) is not significantly different from zero, as would be expected, and the coefficient on BHP is somewhat larger than the BHP coefficient in Equation (5.3). The elasticity of electrical consumption with respect to BHP is 1.14 , measured at the means of the variables. This is interpreted to mean that a one percent decrease (increase) in BHP will lead to a 1.14 percent decrease (increase) in annual energy consumption. The standard error of the coefficient on BHP is $83(=1763 / 22.0)$, indicating a 95 percent chance that the confidence interval $1763+158$ contains the true value of the coefficient. The corresponding $95 \%$ confidence interval for the elasticity is $1.14 \pm .09$.

One final specification of the regression was attempted using pooled data for both retrofit and control accounts. This specification allowed for the inclusion of a dumny variable (RETROFIT) that explicitly tested for the impacts of a retrofit performed as part of the Stage II program on the energy consumption of the irrigation systems. The results of this specification are shown in Equation 5.10. 


$$
\begin{aligned}
& \text { In ELEC }=-32.0+0.0052 \mathrm{BHP}+0.208 \mathrm{CR} 1+0.216 \text { CR2 }+0.375 \text { CR3 }+0.534 \text { CR4 } \\
& \begin{array}{llll}
(-4.74)(9.56) \quad(.91) \quad(1.04) \quad(2.55) \quad(2.73)
\end{array} \\
& +9.04 \text { In HITEMP }-0.407 \text { in HIVAR }-0.442 \text { in PRECIP + } 0.003 \text { ACRES } \\
& \begin{array}{lll}
(5.78) \quad(-1.91) & (-2.46)
\end{array} \\
& \text { - } 0.097 \text { YR1 - } 1.610 \text { YR2 - } 1.706 \text { YR3 - } 1.849 \text { YR4 + } 2.077 \text { In PRICE } \\
& \begin{array}{llll}
(-0.33) \quad(-4.20) \quad(-4.35) \quad(-4.60) \quad(5.10)
\end{array} \\
& +1.244 \mathrm{M1}+0.034 \mathrm{M2}+0.678 \mathrm{M3}-1.254 \mathrm{M4}-0.573 \mathrm{M5}+1.446 \mathrm{M6} \\
& \begin{array}{lllll}
(2.29) & (0.12) & (2.70) & (-4.46) & (-2.35)
\end{array} \\
& \text { - } 0.631 \mathrm{M7}-0.334 \mathrm{MB}-0.497 \text { Q20 - } 0.167 \text { RETROFIT (Equation 5.10) } \\
& \begin{array}{llll}
(-2.39) \quad(-1.42) & (-1.97) \quad(-1.19)
\end{array} \\
& F(24,151)=15.80 \quad \text { RBAR }^{2}=.702
\end{aligned}
$$

Regression Equation (5.10) provides a model that is highly significant (as indicated by the F-statistic) and has strong predictive power (as indicated by the RBAR $^{2}$ statistic). BHP is again the most statistically significant variable in the model and its coefficient is similar to that estimated for Equation (5.4). Two of the four crop variables are significant and they all have the expected sign. HITEMP, PRECIP and ACRES are all statistically significant and have the expected signs. HIVAR again has the wrong sign, but is not statistically significant at the $5 \%$ level. The month dummy variables generally have the expected signs, with June and September statistically significant and positive and July, August and October statistically significant and negative. The variable PRICE was again significant and positive. The problems associated with this variable have been described previously. Finally the variable Q20 had the expected sign and was significant at the $5 \%$ level.

The purpose of estimating Equation 5.10 was to explicitly test for the effect of the retrofits. However, the variable RETROFIT indicating the presense or absense of a retrofit in Equation (5.10) is not statistically significant, although it does have the correct sign. The hypothesis for this result is that this variable is likely highly correlated with the BHP variable which apparently captures most of its effects on energy consumption. A subsequent run of the model without the variable BHP confirmed this hypothesis and a statistically significant result for the variable RETROFIT was obtained. However, the statistical significance and predictive power of the model without 
BHP as an explanatory variable was much lower than that of Equation 5.10 and thus, was not believed to be appropriate for analytical purposes. 
. 


\subsection{OVERALL ASSESSMENT OF STAGE II PROGRAM ENERGY SAVINGS AND COSTS}

BPA's Stage II program incorporates two major components for estimating the potential energy savings available from installing conservation measures:

1) a Stage I irrigation system inspection and pump test, and 2) a Stage II post-retrofit pump test. Energy savings payments from BPA for conservation measure purchase and installation are based on the results of the Stage II pump tests. In this chapter, various aspects of the Stage I and II energy savings predictions are evaluated in the context of the results presented previously in this report. In particular, the report focuses on differences between: 1) energy savings levels predicted in the Stage I audits, 2) energy savings predicted by the post-retrofit pump tests, and 3) energy savings estimates derived from billing records. In addition, progran costs are evaluated using results from the statistical regression analysis described in Chapter 5.0 of this report.

\subsection{EVALUATION OF DIFFERENCES IN ESTIMATED ENERGY SAVINGS}

Estimates of the changes in brake horsepower resulting from conservation measure installation are used as the basis for predicting energy savings in both the Stage I system inspections and the Stage II post-retrofit pump tests.

Previous analysis presented in Chapter 5.0 demonstrated that measured changes in brake horsepower are relatively accurate predictors of the changes in energy consumption that are likely to occur on irrigation systems as a result of conservation measure implementation. However, information presented in Table 6.1 (a) indicates wide variations exist in terms of differences between the brake horsepower changes predicted in the Stage I Irrigation system inspections and the brake horsepower changes measured in the Stage II post-retrofit pump tests.

As illustrated in Table 6.1, large differences were found for some of the Stage II systems between the percentage brake horsepower changes predicted

(a) Comparisons in Table 6.1 are for Stage II systems where all Stage I inspection form and Stage II post-retrofit pump test data necessary for making comparisons were obtained. 
TABLE 6.1. Comparison of Stage I Inspection Brake Horsepower Changes To Stage II Post-Retrofit Measured Brake Horsepower Changes

\begin{tabular}{|c|c|c|c|}
\hline$===\mathbf{=}=$ & 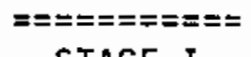 & $====ா=ニ==$ & $=\leq======\pi=0$ \\
\hline & $\begin{array}{l}\text { STAGE I } \\
\text { INSPECTION } \\
\% \text { CHANGE }\end{array}$ & $\begin{array}{l}\text { STAGE II } \\
\text { MEASURED } \\
\% \text { CHANGE }\end{array}$ & \\
\hline $\begin{array}{c}\mathrm{CODE} \\
======\end{array}$ & $\begin{array}{c}\text { IN BPH } \\
=========0\end{array}$ & $\begin{array}{l}\text { IN BHP } \\
=========\end{array}$ & $\begin{array}{l}\text { DIFFERENCE } \\
===========\end{array}$ \\
\hline 100111 & 38.00 & 40.00 & -2.00 \\
\hline 200111 & 37.40 & 24.30 & 13.10 \\
\hline 200411 & 4.30 & 4.30 & 0.00 \\
\hline 200412 & 2.80 & 9.50 & -6.70 \\
\hline 200511 & 62.00 & 43.20 & 18.80 \\
\hline 200512 & 48.90 & 41.00 & 7.90 \\
\hline 200613 & 18.00 & 10.30 & 7.70 \\
\hline 200911 & 36.90 & 24.50 & 12.40 \\
\hline 201011 & 61.60 & 10.90 & 50.70 \\
\hline 201111 & 66.90 & 40.50 & 26.40 \\
\hline 201211 & 12.80 & 30.50 & -17.70 \\
\hline 201411 & 53.80 & 49.50 & 4.30 \\
\hline 300111 & 41.00 & 44.40 & -3.40 \\
\hline 500111 & 15.00 & 14.00 & 1.00 \\
\hline 500211 & 30.70 & 25.30 & 5.40 \\
\hline 500311 & 27.80 & 39.90 & -12.10 \\
\hline 500411 & 27.00 & 23.10 & 3.90 \\
\hline 500511 & 38.00 & 30.40 & 7.60 \\
\hline 500512 & 48.00 & 58.60 & -10.60 \\
\hline 500612 & 27.70 & 23.70 & 4.00 \\
\hline 500614 & 19.70 & 38.30 & -18.60 \\
\hline 500711 & 20.80 & 29.60 & -8.80 \\
\hline 500811 & 30.90 & 10.00 & 20.90 \\
\hline 600211 & 40.00 & 33.50 & 6.50 \\
\hline 600212 & 11.00 & 21.60 & -10.60 \\
\hline 600213 & 33.30 & 28.70 & 4.60 \\
\hline 600311 & 42.90 & 42.90 & 0.00 \\
\hline 600411 & 54.00 & 40.80 & 13.20 \\
\hline 600412 & 55 & 45.60 & 9.40 \\
\hline 600611 & 20 & 28.10 & 14.10 \\
\hline 600711 & 25.50 & 42.40 & -16.90 \\
\hline 600811 & 38.50 & 44.90 & -6.40 \\
\hline 600911 & 12.30 & 5.10 & 7.20 \\
\hline 601011 & 54.50 & 61.20 & -6.70 \\
\hline 601111 & 53.60 & 43.00 & 10.60 \\
\hline 601211 & 44.40 & 44.40 & 0.00 \\
\hline 601311 & 30 & 34.60 & 1.70 \\
\hline 700112 & 10.10 & 11.80 & -1.70 \\
\hline 700211 & 7.90 & 9.60 & -1.70 \\
\hline
\end{tabular}


in the Stage I inspection and the percentage changes predicted in the Stage II post-retrofit pump test. However, for many systems, the calculated differences were relatively small. Negative differences, which indicated greater measured brake horsepower changes in the Stage II post-retrofit pump test than had been predicted in the Stage I audit, were found for about as many systems as positive differences.

A statistical evaluation of the $\mathrm{d} f$ fferences between percentage changes in brake horsepower predicted in the Stage I audit and those measured in the Stage II post-retrofit pump tests is shown in Table 6.2. The results shown in statistical Test 1 of Table 6.2 indicate that, on average, the percentage brake horsepower change predicted on the Stage I audits were 3.4 percentage points higher than the percentage brake horsepower changes measured in the Stage II post-retrofit pump tests. However, this difference was not statistically significant at even a 70 percent level of confidence.

Results shown in statistical Test 2 of Table 6.2 represent comparisons of differences between Stage I mean projected energy consumption changes and unadjusted billing record mean energy consumption changes for all accounts for which complete data were obtained. These results indicate a difference of 13.1 points between Stage I projected and unadjusted billing record energy consumption percentage changes and this difference is significant at a 98 percent level of confidence.

Results shown in statistical Test 3 of Table 6.2 represent comparisons of differences between Stage II mean projected energy consumption changes and unadjusted billing record mean energy consumption changes for all accounts for which complete data were obtained. The calculated difference of 9.9 percentage points between the two means is significant at a 95 percent level of confidence.

In addition to the results shown in Tables 6.1 and 6.2 , the brake horsepower changes measured in the Stage II post-retrofit pump tests were regressed on the brake horsepower changes predicted in the Stage I inspections. The results of this regression are shown in Equation 6.1 . 
Table 6.2. Statistical Evaluation of Differences Between Brake Horsepower Changes Predicted in Stage I Inspections and Stage II Post-Retrofit Pump Tests

\section{Stage I \\ Inspection \\ Form BPH \\ Change (\%)}

\section{Mean $\%$ Change}

Median $\%$ Change

Variance of $\%$ Change

Std. Deviation of $\%$ Change

Std. Error of Mean \% Change

$90 \%$ Confidence Interval

95\% Confidence Interval

Test 1

Difference in Means (Stage I-Stage II)

Std. Deviation of the

Difference in Means

t-statistic for Difference

Significance

Probability of $t$

(two-tailed test $x$ )

Test 2

Difference in Means

(Stage I-Billing Record)

Std. Deviation of the

Difference in Means

t-statistic for Difference

Significance

Probability of $t$

(two-tailed test $\mathrm{x}$ )

Test 3

Difference in Means

(Stage II-Billing Record)

Std. Deviation of the

Difference in Means

t-statistic for

Difference Significance

Probability of $t$

(two-tailed test $\%$ )

34.1

36.3

296.7

17.2

2.8

29.4-38.8

28.4-39.8

3.2

3.6

.9

40.0

13.1

4.9

2.7

2.0

NA

NA

NA

NA

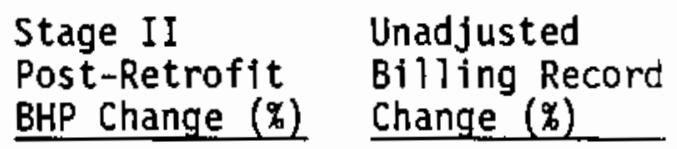

30.9

30.4

222.1

14.9

2.4

26. $9-34.9$

26. 1-35.7

21.0

NA

611.8

24.7

4.2

13. $9-28.1$

$12.4-29.6$

NA

NA

NA

NA

NA

NA

NA

NA

NA

NA

NA

NA

NA

NA

NA

NA

9.9

NA

4.7

NA

2.1

NA

5.0

NA 


$$
\begin{aligned}
& \text { ST2BHP }=\underset{(1.45)}{14.41}+\underset{(10.2)}{.91 \text { ST1BHP }} \\
& F(2,37)=104.69 \quad \text { RBAR }^{2}=.732
\end{aligned}
$$

where

$$
\begin{aligned}
\text { ST2BHP = } & \text { Change in brake horsepower measured } \\
& \text { in the stage II post-retrofit pump test. } \\
\text { ST1BHP = } & \text { Change in brake horsepower predicted } \\
& \text { in the Stage I inspection. }
\end{aligned}
$$

The results shown in Equation 6.1 indicate that Stage I project brake horsepower changes are relatively accurate predictors of Stage II measured brake horsepower changes. The coefficient for the equation indicates that for every one unit change in the level of Stage I projected horsepower, Stage II measured horsepower changes by approximately .9 units. The high RBAR ${ }^{2}$ and $F$ values for the equation indicate a high level of statistical confidence in the results.

The major implications of the results shown in Tables 6.1 and 6.2 and Equation 6.1 can be summarized as follows:

- differences between levels of brake horsepower changes predicted in the Stage I inspections and those measured in Stage II post-retrofit pump tests are frequent and these differences are about as likely to be negative (i.e., Stage I inspections under-predict) as positive (i.e., Stage I inspections over-predict).

- on average, differences between brake horsepower changes predicted in the Stage I inspections and those measured in the Stage II post-retrofit pump tests are not statistically significant.

- a one unit change in brake horsepower predicted in the Stage I audit results in approximately a .9 unit change in measured brake horsepower in the Stage II post-retrofit pump test.

- the mean differences of 13.1 and 9.9 points between the percentage brake horsepower changes of the Stage I audits and Stage II pump tests versus the percentage change in billing record electricity consumption are both statistically significant. 
The summarized results listed above imply that while Stage I inspections are generally accurate predictors of the measured brake horsepower changes in Stage II post-retrofit pump tests, differences between the two types of estimates for individual irrigation systems are frequent and differ in both magnitude and sign. Thus, it appears that the Stage II program's procedure of measuring brake horsepower changes after conservation measures are installed and basing incentive payments on these measurements is appropriate.

The finding that significant differences exist between the mean percentage changes of the Stage I audits and Stage II pump tests and the mean percentage change of billing record energy consumption appears to conflict with the finding of Equation 5.9. Equation 5.9 implies that changes in brake horsepower are an accurate predictor of changes in irrigation system energy consumption and that a one percent change in brake horsepower will result in at least a one percent change in system energy consumption. The conflict between these two findings is believed to be attributable to the different methodologies used to evaluate the Stage II energy savings.

In one methodology, the simple arithmetic means of the percentage differences between average billed energy consumption before conservation measure installation and average consumption after measure installation are used as the basis for comparison. In the other methodology, statistical relationships between brake horsepower levels and billed energy consumption are used as the basis for comparison. The statistical relationships developed in Chapter 5 are believed to be more reliable indicators of the validity of the Stage II program's energy estimation procedures because of: 1) the greater degrees of freedom present in the statistical regressions, 2) the equal weighting of small horsepower pumps with large horsepower pumps in calculating savings based on mean percentage changes in energy consumption, 3) more accurate estimation in the timing of the introduction of conservation measures in the regression equations, and 4) biases introduced by PIK program participation in calculating average billed pre-retrofit energy consumption.

\subsection{COST ESTIMATES FOR STAGE II PROGRAM}

The costs of the Stage II program were evaluated in this study through the following activities: 
1) Compilation of data on the total purchase and installation costs of conservation measures by Stage II program participants and on BPA's costs associated with these participants.

2) Estimation, using a three percent real discount rate and a 20-year measure life, of the annuat levelized costs of conservation measure purchase and installation by Stage II program participants and the annual levelized costs incurred by BPA.

3) Estimation of the $k$ wh energy savings resulting from the installation of conservation measures by Stage II program participants using post-retrofit pump test data on the brake horsepower changes resulting from measure installation and coefficient estimates from Equation 5.9.

4) Estimation of the costs per kwh saved for Stage II program partictpants by dividing estimated annual levelized costs by estimated annuat energy savings.

Cost data were compiled from available incentive claims filed with BPA by Stage II program participants and their utilities. These claim forms list total measure purchase and installation costs. They also list total BPA costs associated with conducting the Stage I audit, financing a portion of measure purchase and installation, and administering the Stage II post-retrofit pump test. Because the percentage of measure purchase and installation costs financed by BPA has varied over time, total BPA costs will also vary. In some cases, BPA costs may be greater than total measure purchase and installation costs as a result of the administrative costs associated with conducting the Stage I audits and the Stage II pump tests.

Estimation of annuai levelized costs was performed in accordance with current BPA methodologies for such estimation. Estimation of annual energy savings was performed using estimated changes in brake horsepower as explanatory variables in Equation 5.9. As a reminder, Equation 5.9 estimates the change in annual billing record energy consumption of an irrigation system for a one unit change in brake horsepower. Thus, all that is necessary to derive an estimate of actual kwh savings is to multiply the change in brake horsepower measured in each post-retrofit pump test by the coefficient from Equation 5.9 
of 1763. Estimates of the costs per kwh saved were obtained by dividing annua? estimated costs by annual estimated savings.

The results of the cost estimation procedures for all Stage II irrigation systems for which complete data were available are shown in Table 6.3. Note from Table 6.3 that estimated total costs per $k$ wh saved for conservation measure purchase and installation were generally less than 6 mills or .6 cents. BPA costs associated with the Stage II program were generally below 5 mills (.5 cents). The highest level of total cost per kwh saved was 19.2 mills (1.9 cents) and the highest level of BPA costs was 17.3 mills (1.7 cents).

A sumnary of statistical results pertaining to Stage II program costs and energy savings is shown in Table 6.4. This information provides the following major results:

- total conservation measure purchase and installation costs for Stage II program participants generally cost between 5 and 10 thousand dollars per system, with a mean of approximately $\$ 7,900$.

- total BPA costs associated with the Stage II systems generally ranged from 4 to 6 thousand dollars, with a mean of about $\$ 5,000$.

- annual energy savings for the Stage II program systems were found to range from approximately 67,000 to $199,000 \mathrm{kwh}$, with a mean of about $132,000 \mathrm{kwh}$.

- estimated costs per kwh saved for measure purchase and installation generally ranged from about 4.5 to $7.5 \mathrm{mi} 1 \mathrm{ls}$, with a mean of $5.9 \mathrm{mills}$.

- BPA's costs per kwh saved for the Stage II program were found to generally be from 3.3 to $5.7 \mathrm{mills}$, with a mean of $4.5 \mathrm{mills}$.

Because the total estimated measure purchase and installation costs per kwh saved for Stage II participants are much less than current average rates for power, they imply that conservation investments should be undertaken by irrigators without BPA assistance. In fact, it was found in an extensive telephone survey of irrigators (Harrer et.al. 1987) that many irrigators have undertaken such investments. It should also be remembered that few irrigators have access to a three percent real financing rate extended over 20 years. Using a more realistic six percent real financing rate and a 3-year investment time frame, the average cost per kwh saved for conservation measure purchase 
and installation in the Stage II program would be approximately 22 mills or 2.2 cents. 
Table 6.3. Cost Estimates for BPA Stage II Program Participants for Which Complete Program Data Was Available

\section{Code}

200111

200512

201011

201111

201211

300111

300211

400111

500111

500211

500311

500411

500511

500512

500611

500612

500614

500711

500811

600211

600212

600213

600311

600711

600811

600911

601011

601111

601311

\begin{tabular}{l} 
Total Measure \\
Purchase and \\
Instaljation \\
Cost \\
\hline
\end{tabular}

8,361

3,179

5,717

1,252

16,749

464

9,344

2,205

1,587

493

7,947

2,340

4,882

7,767

3, 313

2,735

2,316

5,761

3,573

14,528

30,391

12,754

22,363

839

17,796

10,807

2,560

2,552

2,343 \begin{tabular}{ll} 
Total BPA & Estimated \\
Cost Assoc. & Annual \\
with Stage (a) & $\begin{array}{l}\text { kwh } \\
\text { II Program (b) }\end{array}$ \\
\cline { 1 - 2 } & Savings (b) \\
\hline
\end{tabular}

4,132

2,893

4,923

1,352

13,749

721

7,476

2,114

1,144

745

4,323

2,222

2,791

6,563

2,006

1,718

1,508

2,762

3,209

7,614

15,546

6,727

18,241

770

14,587

8,996

1,630

2,148

1,521
93,439

47,425

25,564

36,670

151,442

58,355

132,519

38,433

19,393

37,723

112,303

26,445

63,292

111,598

42,312

27,679

41,783

27,150

12,517

701,498

830,373

545,296

246,820

21,685

164,664

44,075

87,727

20,803

55,006
Estimated

Total Cost

Per kwh

Saved(Mills)

6.0

4.5

15.0

2.3

7.4

0.5

4.7

3.8

5.5

.9

4.8

5.9

5.2

4.7

5.3

6.6

2.8

14.3

19.2

1.4

2.5

1.6

6.1

2.6

7.3

16.5

2.0

8.3

2.9
Estimated

BPA Cost

Per kwh

Saved(Mills)

3.0

4.1

12.9

2.5

6.1

0.8

3.8

3.7

4.1

1.3

2.6

5.6

2.9

4.0

3.2

4.2

2.4

6.9

17.3

.7

1.3

.8

5.0

2.4

6.0

13.7

1.3

6.9

1.9

(a) Source: BPA Stage II program incentive claims.

(b) Derived using Equation 5.9 of this study. 
Table 6.4. Summary of Cost Estimates for

Stage II Program Participants

$\begin{array}{lllll}\text { Total Measure } & \text { Total BPA } & \text { Estimated } & \text { Estimated } & \text { Estimated } \\ \text { Purchase and } & \text { Cost Assoc. } & \text { Annual } & \text { Total Cost } & \text { BPA Cost } \\ \text { Instaljation } & \text { with Stage (a) kwh } & \text { kwh (b) Per kwh } & \text { Per kwh } \\ \text { Cost } & \text { II Program } & \text { Savings } & \text { Saved(Mills) } & \text { Saved(Mills) } \\ & & \end{array}$

Mean

Std. Deviation

7,853

4,970

7,800

Std. Error of Mean

1,474

4,892

131,862

204,543

5.9

37,983

4.7

925

$90 \%$ Confidence

$5,346-10,360$

$3,397-6,542$

$67,253-199,115 \quad 4.4-7.4$

4.5

Interval

$95 \%$ Confidence

$4,834-10,872$

$3,076-6,864$

$54,073-209,651 \quad 4.1-7.7$

4.0

.7

3.3-5.7

Interva 1

(a) Source: BPA Stage II progran incentive claims.

(b) Derived using Equation 5.9 of this study. 
. 


\section{REFERENCES}

Hi11, R. W., Johns, E. L. and Frevert, D. K. 1983. Comparison of Equations Used for Estimating Agricultural Crop Evapotranspiration with Field Research. Utah State University and Bureau of Reclamation, E\&R Center, Denver, Colorado

Judge, G. C., et al. 1982. Introduction to the Theory and Practice of Econometrics. John Wiley \& Sons Publishing, New York, New York.

Harrer, B. J., et al. 1987. Irrigation Customer Survey Procedures and Results. PNL-6181. Prepared for the Bonneville Power Administration by Pacific Northwest Laboratory, Richland, Washington. 


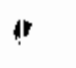

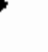

. 
APPENDIX A

EXAMPLES OF BILLING RECORD WAIVER AND DATA COLLECTION FORMS 
I hereby give Big Bend Electric Cooperative, Inc. permission to release information to Pacific Northwest Laboratories on the quantity and price of electricity used by my irrigation equipment, from 1981 to 1985 . This information witl be used in connection with their study of the Stage II Irrigation Retrofit Program for the Bonneville Power Administration. In accordance with Federal law, my name will never be published as a participant in this study and I will never be contacted for advertising or promotional purposes.

This agreement does not bind my further participation in this or any future project.

I have read and understood the above statements and agree to their provisions.

Date:

Signature:

$\begin{array}{ll}\text { PLEASE } & \text { Silling Name: } \\ \text { PRINT } & \text { City: } \\ & \text { Telephone: }()\end{array}$

Please maif this agreement in the attached seif-addressed envelope that we tave enclosed. 
Date:

Participant Name:

Account Number of Retrofitted System:

Inspection Number, If Available:

PART A: Measure ${ }^{(a)}$

Date Measure Installed

PART B: KWH Consurmtion Records ${ }^{(b)}$

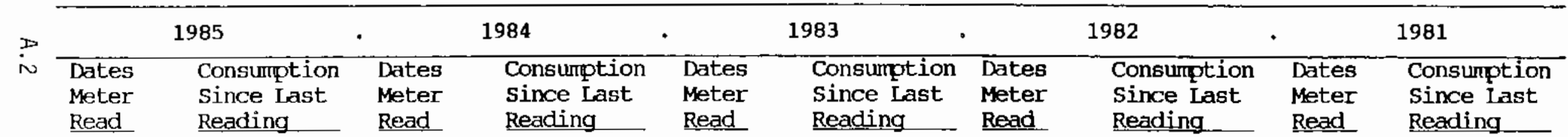

(a) Low-Pressure (LP), Pumping Plant Modification (PPM), Mainline (ML), Fittings (F).

(b) Monthly or at the most frequent interval available. 
APPENDIX B

EXAMPLES OF STAGE II PARTICIPANT

SURVEY QUESTIONNAIRES 


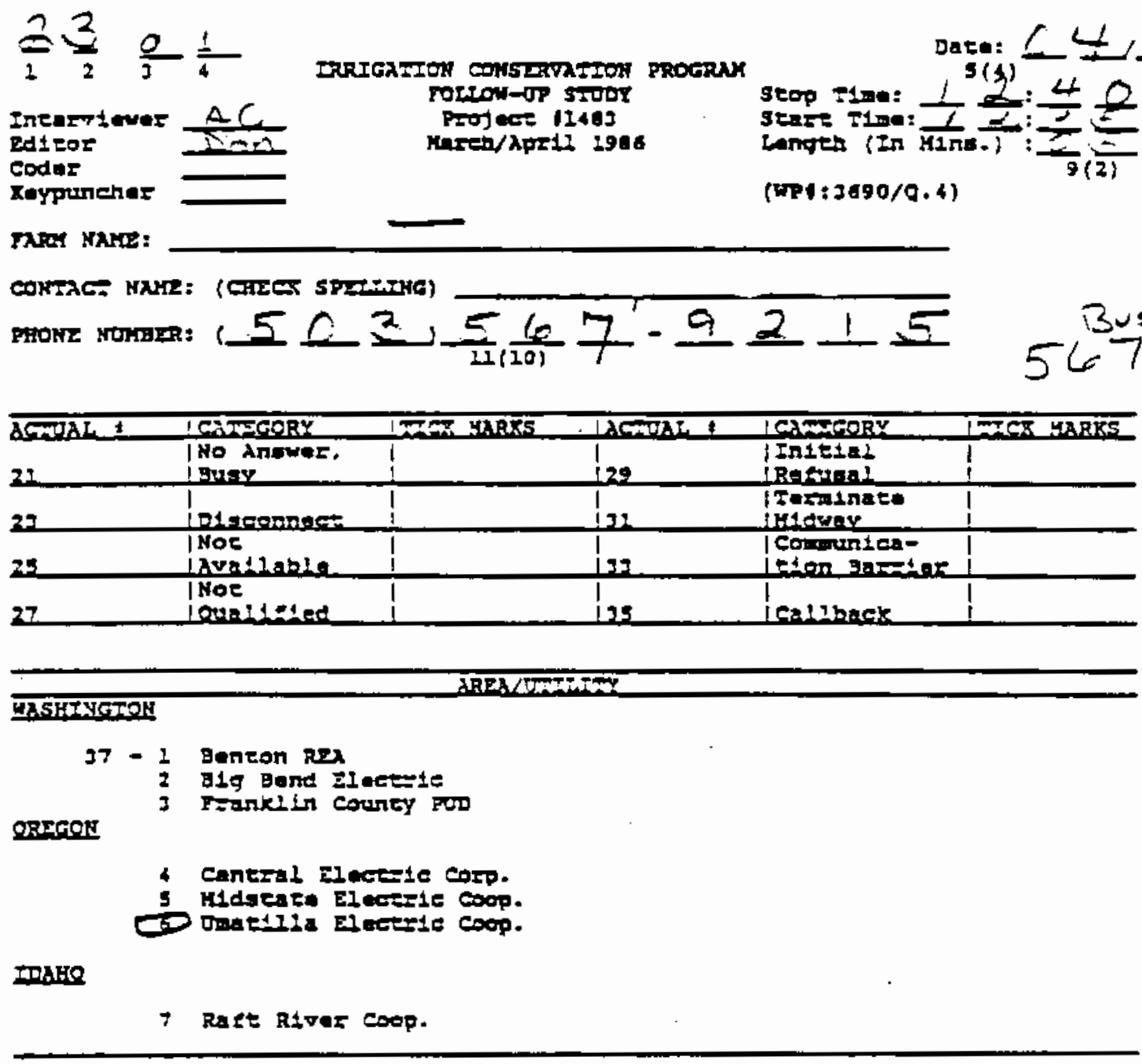

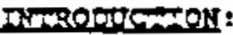

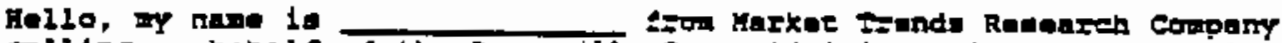

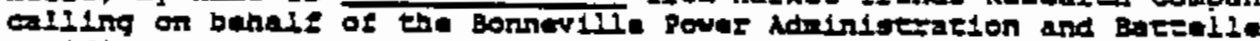

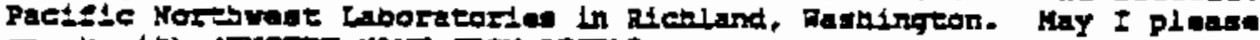

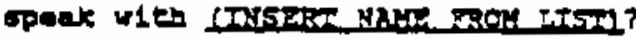

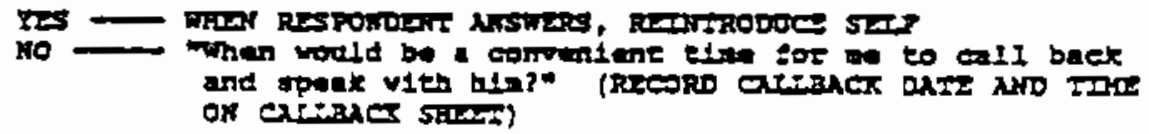

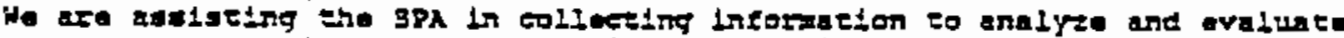

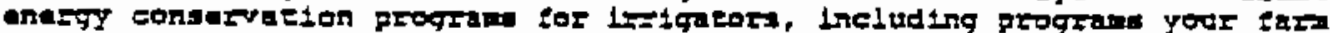
hav parfielpaed in. He understand you bava been a partelpane in the

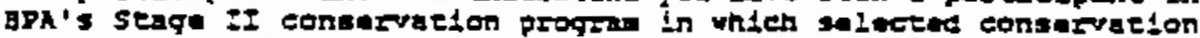

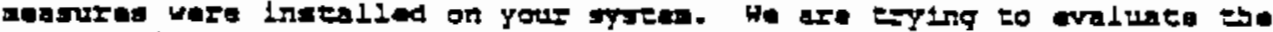
changen in energy uee that have rerulted s=on your pafticipecion in this

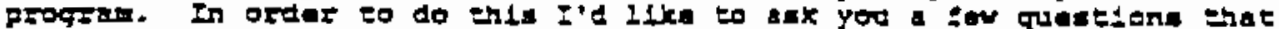

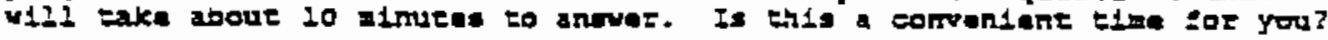

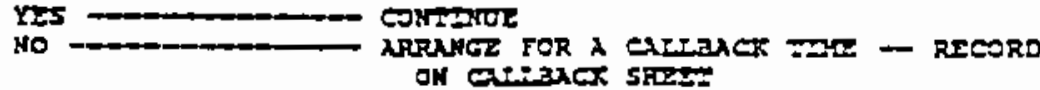

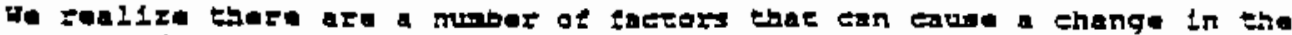

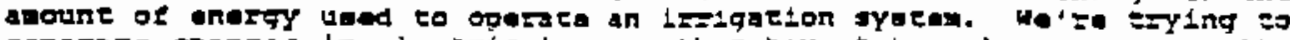

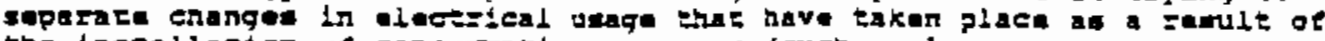

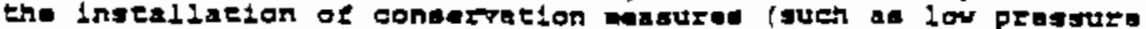

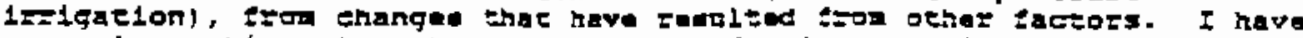
several quedions to aax you aboue your fary's operation sinea igsi.

B. 1 


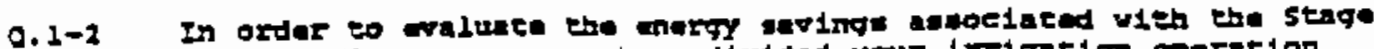
If Reerolse propran, w have divided your lisiqution operation 17to plep accounes sor mich w'd like linformation.

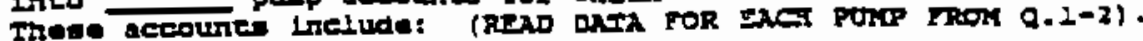
Is bis insormeton coxtuct?

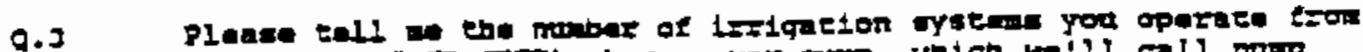

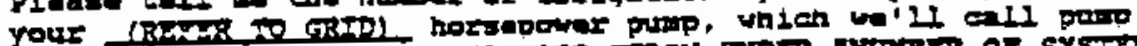

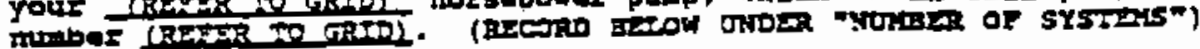

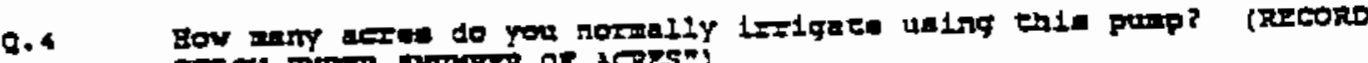

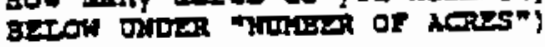

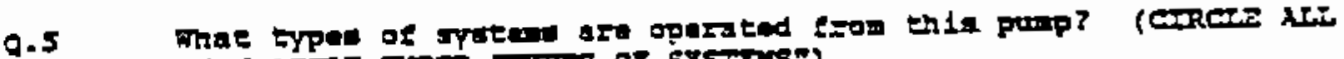

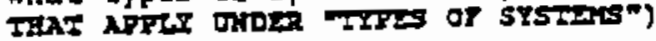

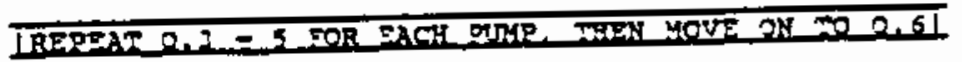

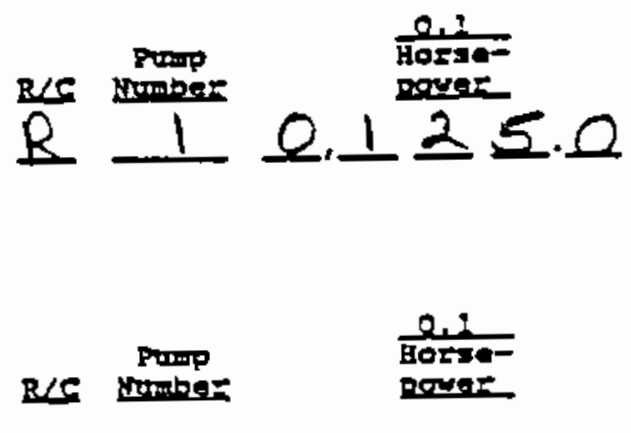

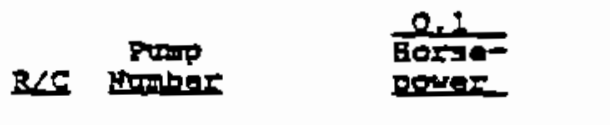
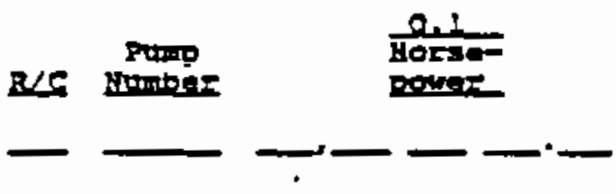

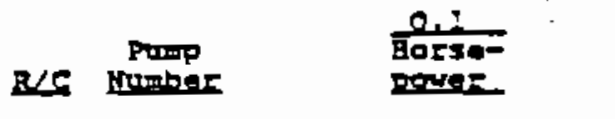

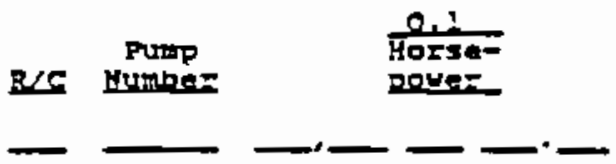

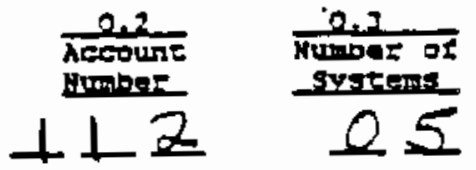

\section{2 ACeoune} Namiofe

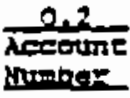

incoune

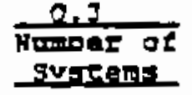

\section{2 Alombo-}

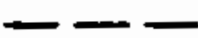

2.2 ictoun Normber

2.2 Aecourt itmoner.

25 Homer at Systeras Trumet of Syrenat.

$2+3$ romber of Systente

2.1 Itwoer of SYstemes

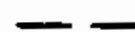

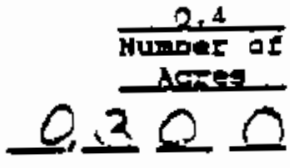

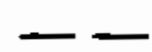

24 Mumber of Aetes

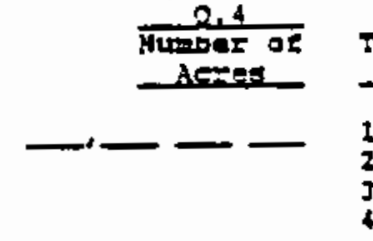

Type(s) of SYzTens

Canear Ptrot Rancmore

sideroli

other (SFeed

0.4 Number of ACFES

Q.5

xype(s) of

Systems

1 Cencer plvot 2 Bandmove

3 Sidazoli

4 othar (spote

2.4

Nomber of

Aarat

Type(3) of syrtape

1 Certen Ptrot 2 Bandione 3 S1deroli

+ othar (5PEC:

0.4 irtoper of dints

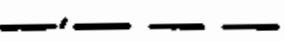

Iype (s) of

Systeme

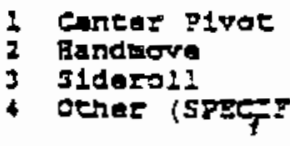

2.4

Nitiones of Acters

sypa (s) of syztems

Concer P1VDE Ganderove sideroi! ovbur (SPECI?) 


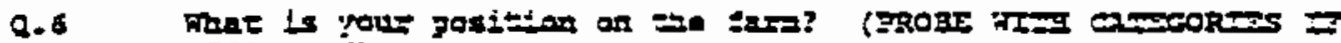
SIE $=5$ SaRY)

(58)

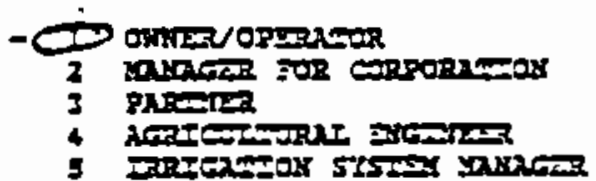

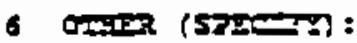

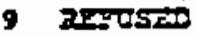

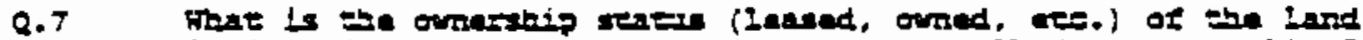

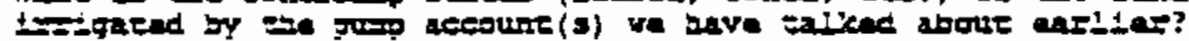
Is te $\ldots$ (REa Diss)

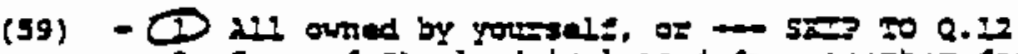

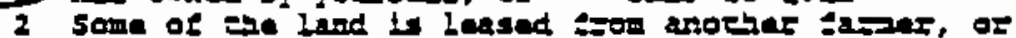

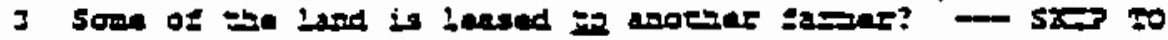
Q.20

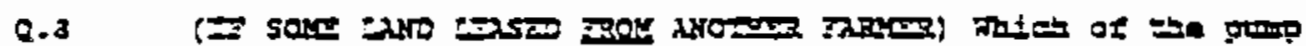
aceoures are used of

$(60)-\begin{array}{ll}1 & 5 \\ 2 & 6 \\ 3 & 7 \\ 4 & 8\end{array}$

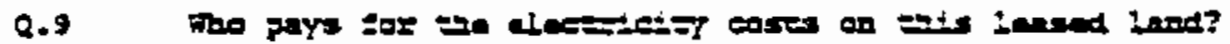

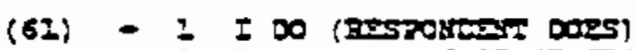

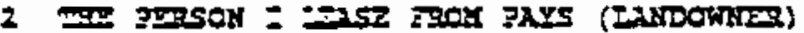

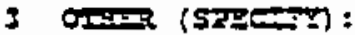

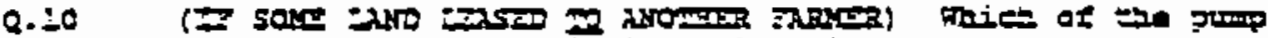

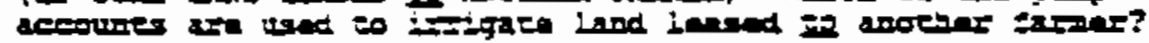

(62) -2 -

$\begin{array}{ll}1 & 9 \\ 2 & 6 \\ 3 & 7 \\ 4 & 8\end{array}$

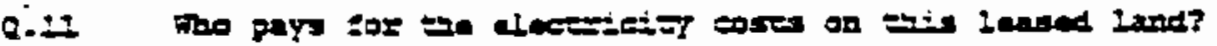

(6I) - I I 0 (30570xromiz Dass)

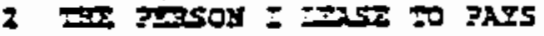

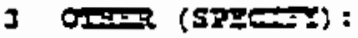

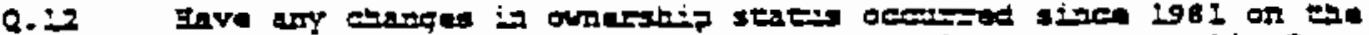

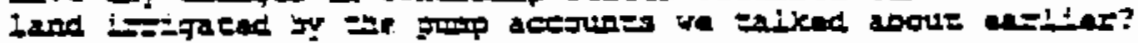

(64) - iो 5020.57 


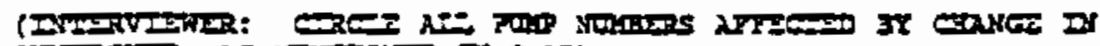

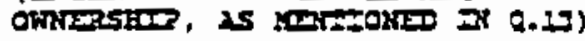

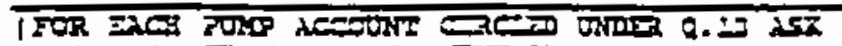

$10.4-16$,

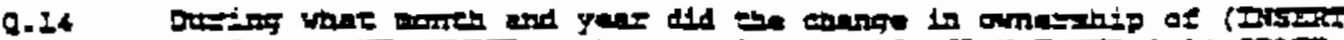

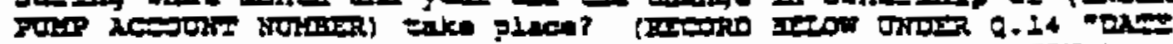

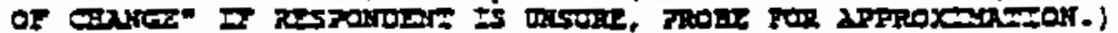

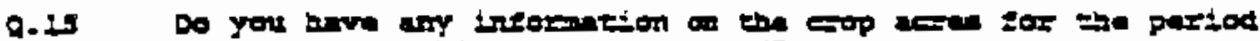

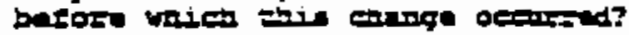

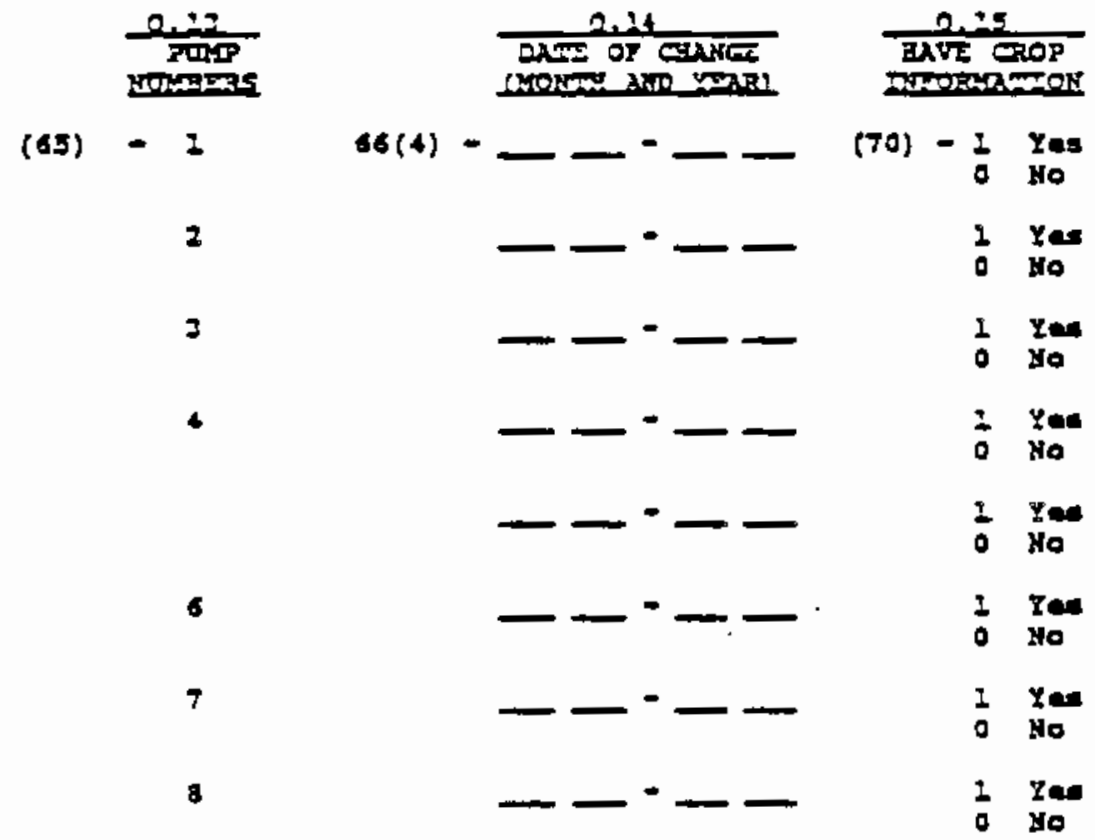

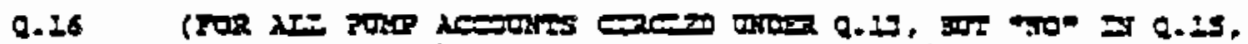

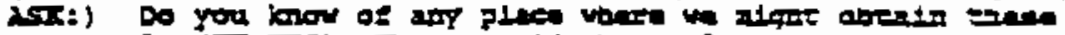

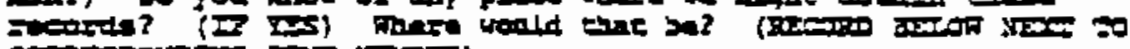

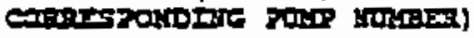

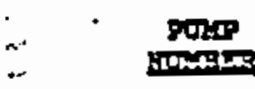

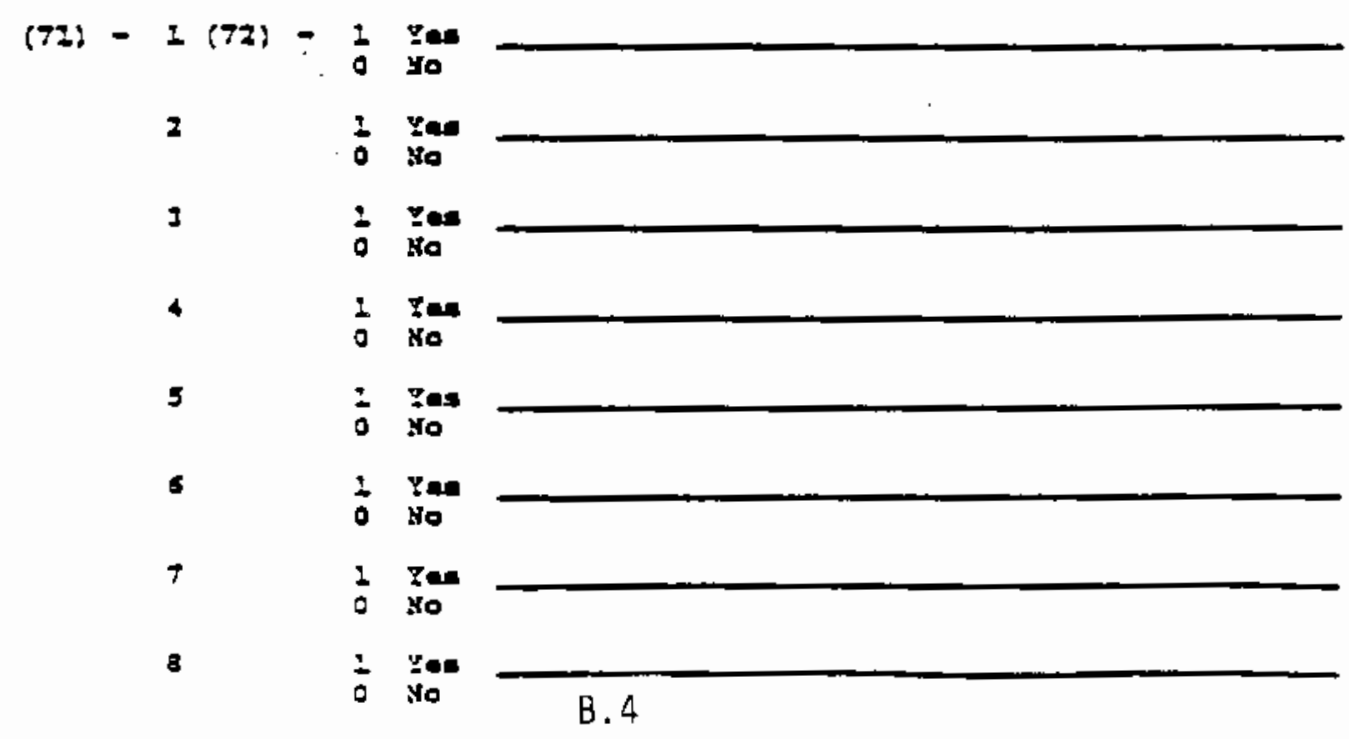




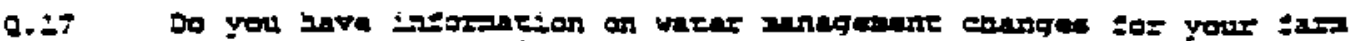

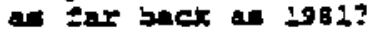

2 no

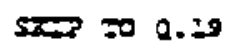

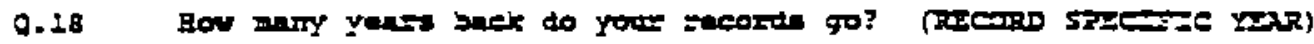

$$
\begin{aligned}
& 29 \frac{1}{74}(2) \\
& 98 \text { Dor.? 3nOT } \\
& 99 \text { atrose }
\end{aligned}
$$

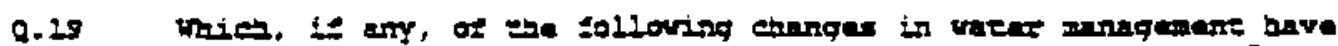

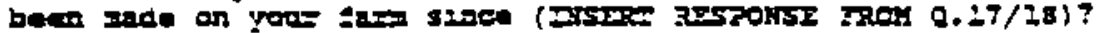

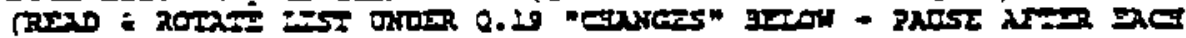

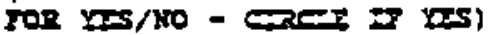

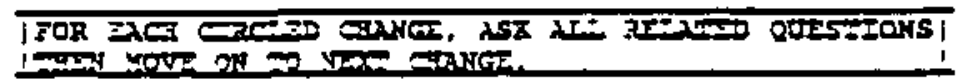

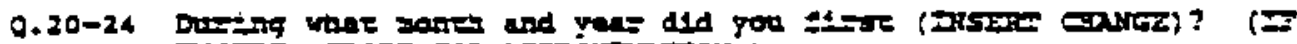

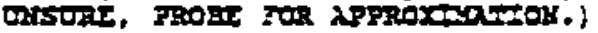

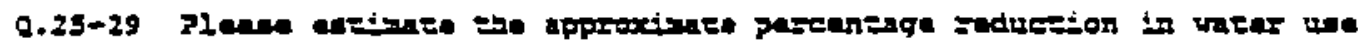

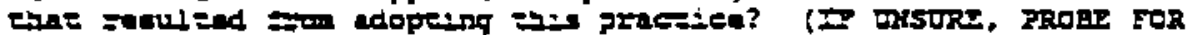

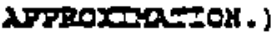

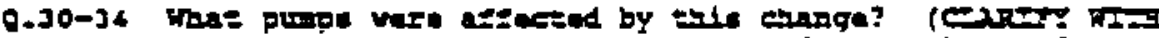

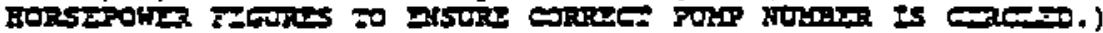

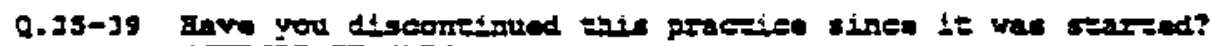
$10 \cos =1$

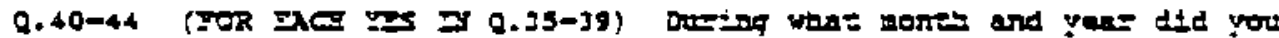

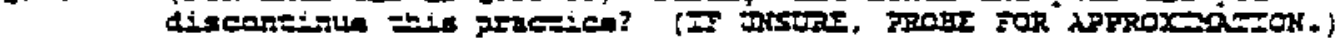
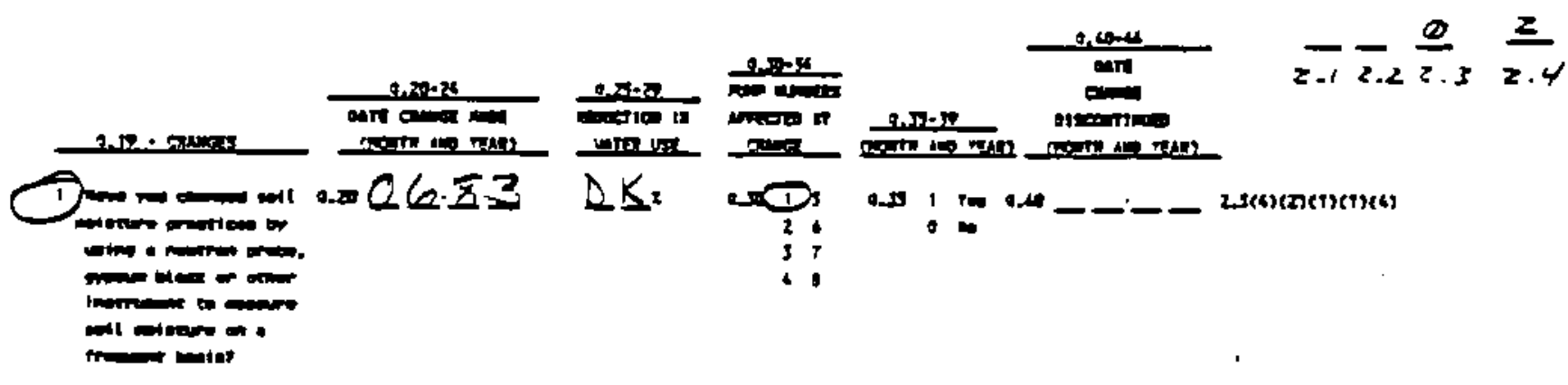

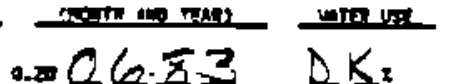$$
\longrightarrow
$$

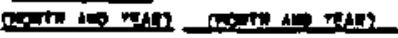

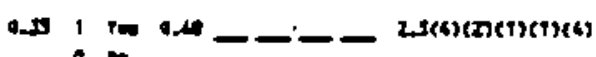

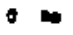

2 mon Imerim on

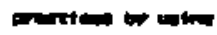
(2) - 100 inte

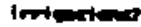
in

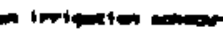
a. 0.78 DK.

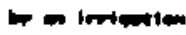

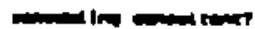

4- -

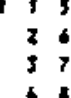

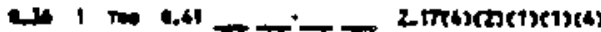
a 1.

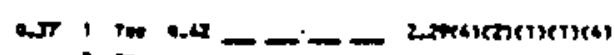

0

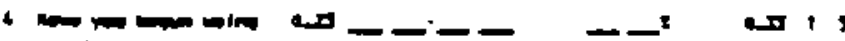
20

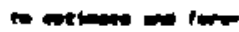
- wl matron
indertons

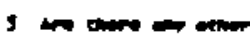

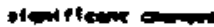 In

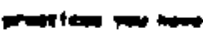
The 10

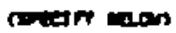

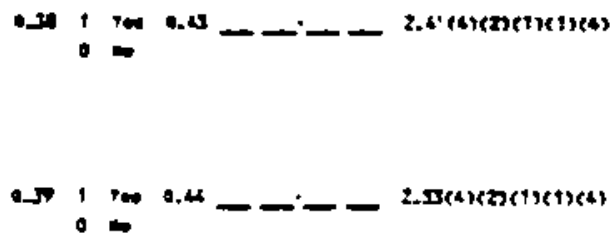




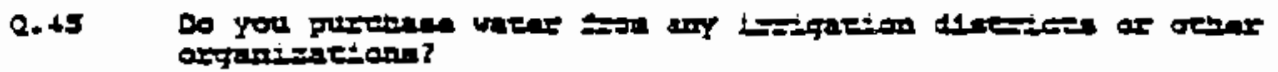

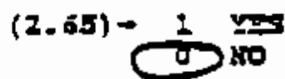

500.48

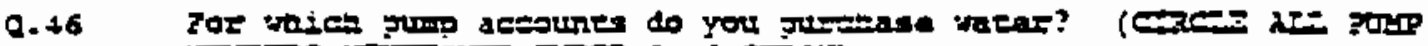

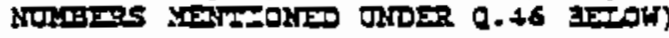

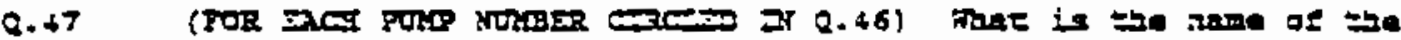

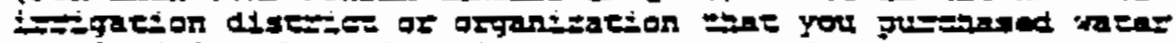

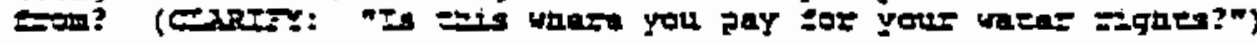

0,48

TURP

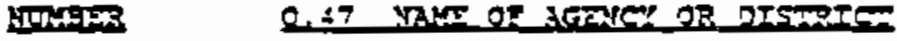

$(2.56)=1$

2

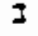

4

$\mathbf{s}$

5

7

8 


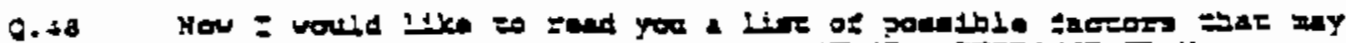

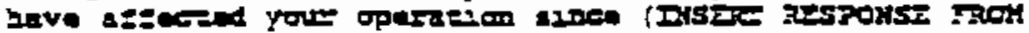

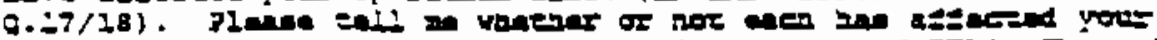

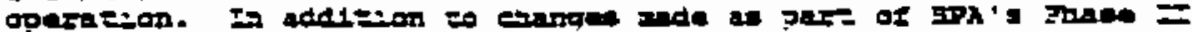

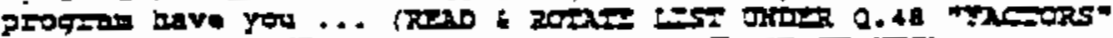

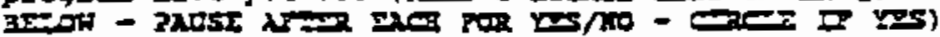

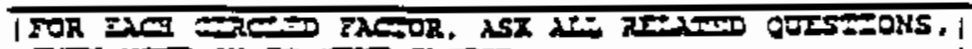

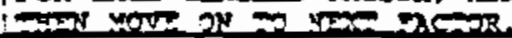

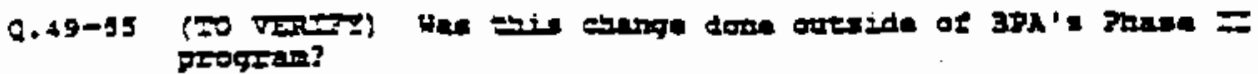

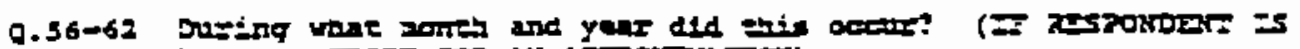

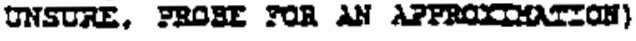

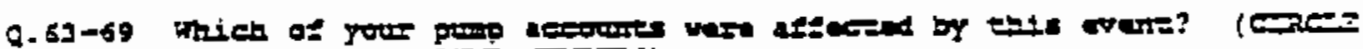

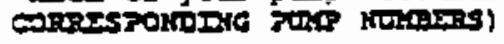

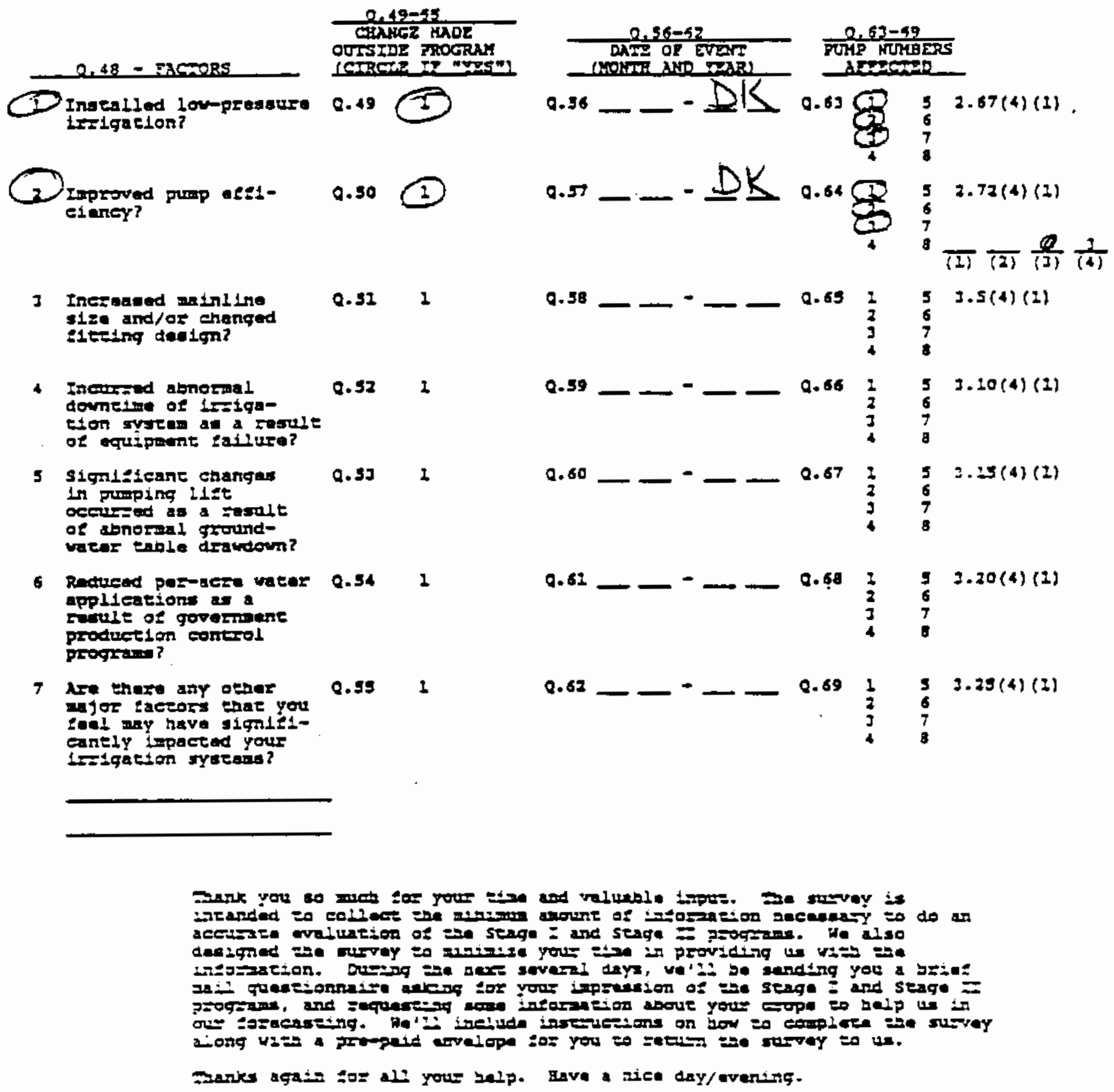

B. 7 
pleaee provide information on the crops grown on your farm

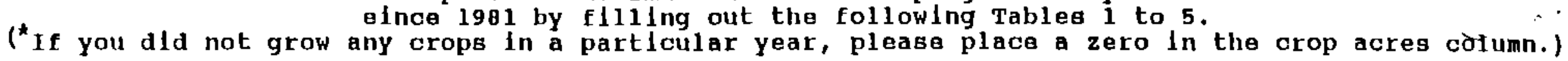

TABLE 1 - IHFORHATION ON CROPS GROWH IN $19 \underline{8} \underline{1}$

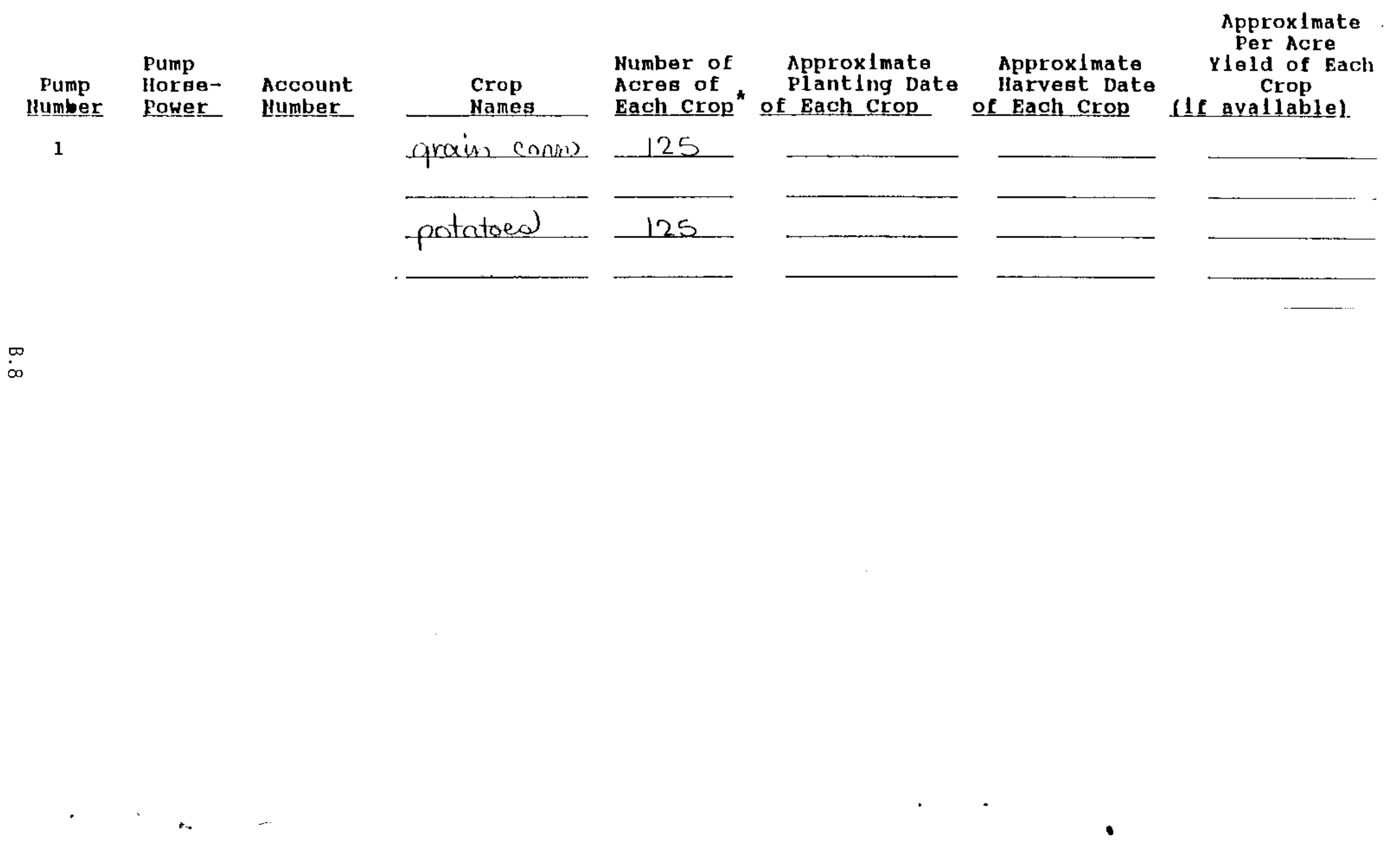


TABLE 2 - INFORMATION ON CROPS GROWN IN 1982

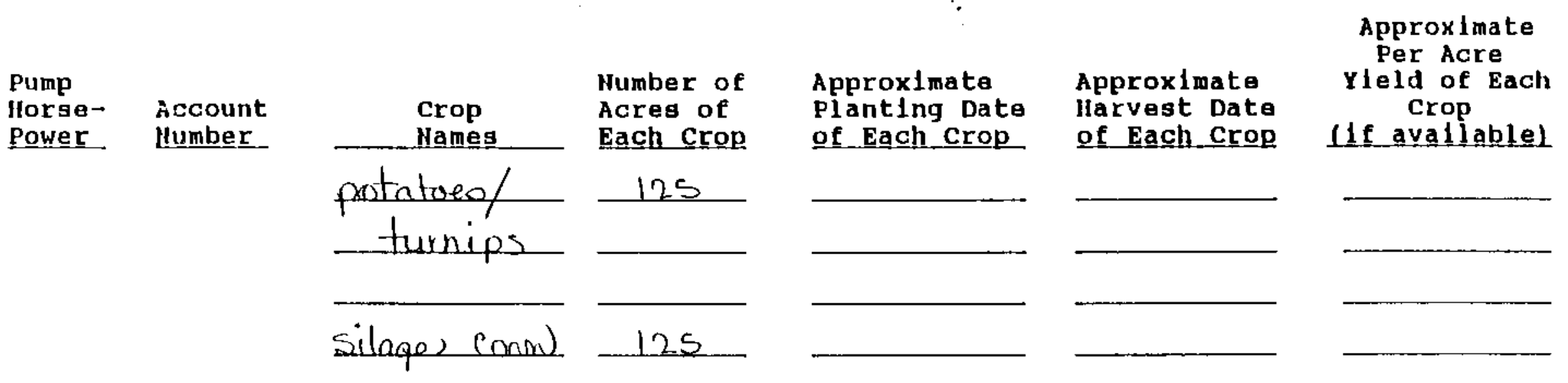


TABLE 5 - INFORHATION OH CROPS GROWN IN 1985

$\begin{array}{cll}\text { Pump } & \text { Pump } & \\ \text { liomber } & \text { Porse- } & \text { Account } \\ \text { Power } & \text { Number }\end{array}$

1

$\stackrel{\infty}{N}$

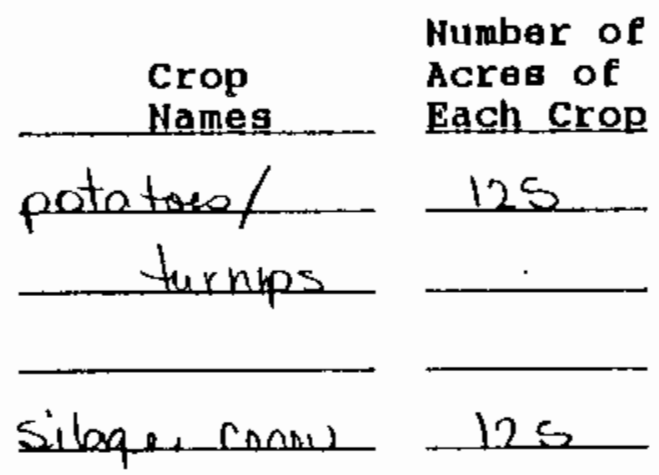

Approximate Planting Date of Each Crop.

Approximate

Harvest Date

of Each Crop
Approximate
Per Acre
Yleld of Each
crop
(If aya 1 lablel


your contribution to this study is greatly appreciated. If you have any additional comments or suggestions, please use the space below to share them with us. 


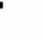




\section{DISTRIBUTION}

No. of

Copies

\section{OFFSITE}

10 Ken Keating

Bonneville Power Administration

P. 0. Box 3621

Portland, Oregon 97208

Steve Levy

Bonneville Power Administration

P. 0. Box 3621

Portland, Oregon 97208

Curt Hickman

Bonneville Power Administration

P. 0. Box 3621

Portland, Oregon 97208

Fred Gordon

Bonneville Power Administration

P. 0. Box 3621

Portland, Oregon 97208

30 DOE Technical Information Center

Mary Corrigan

Department of Energy

Forrestal Building

1000 Independence Ave., S.W.

Washington, D.C. 20585
No. of

Copies

\section{ONSITE}

DOE Richland Operations Office

J. J. Sutey

14 Pacific Northwest Laboratory

B. L. Mohler

A. J. Lyke

J. J. Tawil

B. J. Harrer (3)

B. M. Bailey

Publishing Coordination (2)

Technical Report Files (5) 


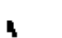

